\title{
Towards Direct Fabrication of Functional Patterns on Large-Area Substrates for Flexible Devices
}

\author{
Sean D. Cronin \\ West Virginia University
}

Follow this and additional works at: https://researchrepository.wvu.edu/etd

\section{Recommended Citation}

Cronin, Sean D., "Towards Direct Fabrication of Functional Patterns on Large-Area Substrates for Flexible Devices" (2013). Graduate Theses, Dissertations, and Problem Reports. 4957.

https://researchrepository.wvu.edu/etd/4957

This Thesis is protected by copyright and/or related rights. It has been brought to you by the The Research Repository @ WVU with permission from the rights-holder(s). You are free to use this Thesis in any way that is permitted by the copyright and related rights legislation that applies to your use. For other uses you must obtain permission from the rights-holder(s) directly, unless additional rights are indicated by a Creative Commons license in the record and/ or on the work itself. This Thesis has been accepted for inclusion in WVU Graduate Theses, Dissertations, and Problem Reports collection by an authorized administrator of The Research Repository @ WVU. For more information, please contact researchrepository@mail.wvu.edu. 
Towards Direct Fabrication of Functional Patterns on Large-Area Substrates for Flexible Devices

\title{
Sean D. Cronin
}

\author{
Thesis submitted to the \\ Benjamin M. Statler College of Engineering and Mineral Resources \\ at West Virginia University \\ in partial fulfillment of the requirements \\ for the degree of
}

Konstantinos A. Sierros, Ph.D., Chair

Edward M. Sabolsky, Ph.D.

Darran R. Cairns, Ph.D.

Department of Mechanical and Aerospace Engineering

Morgantown, West Virginia

2013

Keywords: zinc oxide, sol-gel, aqueous solution, dip-pen nanolithography Copyright 2013 Sean D. Cronin 


\section{Abstract \\ Towards Direct Fabrication of Functional Patterns on Large-Area Substrates for Flexible Devices}

\section{Sean D. Cronin}

Nowadays there is a growing interest to develop flexible devices that can be used in applications spanning from displays to energy harvesting. This is due to the potential of such devices to be integrated onto various-shaped surfaces and also to be roll-to-roll processed. However, there are still a few challenges to be tackled before their full commercialization. In particular, the direct fabrication of micro/nano-scale functional features on a large-area flexible substrate remains a critical challenge. This is because it requires both low temperature processing and precise control of the feature size.

During this study an investigation of different fabrication methods, such as hydrothermal growth and dip-pen nanolithography (DPN), is conducted in order to assess their suitability for the large-area deposition of $\mathrm{ZnO}$-based simple geometrical patterns on flexible substrates. These model micro/nano structures are characterized optically, electrically, and mechanically. In addition, the preliminary fabrication and characterization of force sensors based on flexible substrates is reported.

Experimental results from this work highlight the potential of DPN as a scalable processing technique for flexible devices. In particular, the repeatable fabrication of circular micron-sized functional features on polyester substrates is reported. It was found that both the viscosity of the starting ink material and the wettability of the starting substrate play the most critical role for the successful fabrication of such features. In addition, humidity and starting ink stability must be carefully controlled. It is believed that using DPN in a scalable manner will be the key to realize the next generation of large-area nanopatterned flexible devices. 


\section{Acknowledgements}

I would to thank the following people for their support and help in contributing to my Master's Thesis.

My research advisor and committee chair, Dr. Konstantinos Sierros, for his guidance, knowledge, and enthusiasm. Dr. Sierros has been a great mentor, without him I would not be where I am today.

Kathy Sabolsky for all her help in the laboratory and demonstrating how to operate different equipment.

Nick Morris for his help in the laboratory, taking SEM images and performing XRD. As well as our discussions about $\mathrm{ZnO}$ structures and piezoelectric devices.

Undergraduates, Jacob Cordonier and Dillon Carden for their lab work.

Finally, Katie and my parents, David and Marian, for all their loving support. 


\section{Table of Contents}

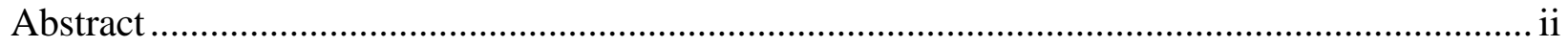

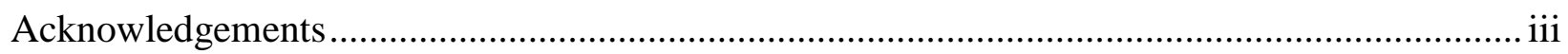

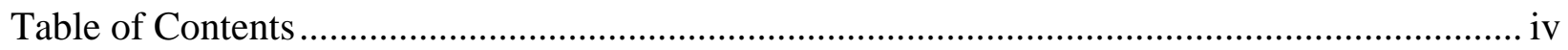

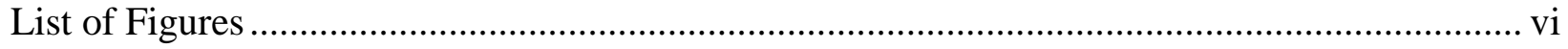

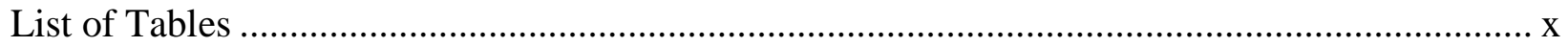

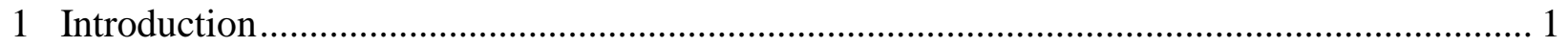

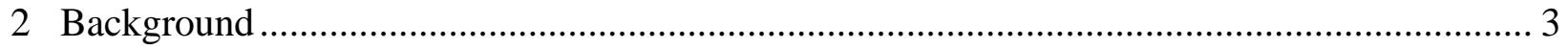

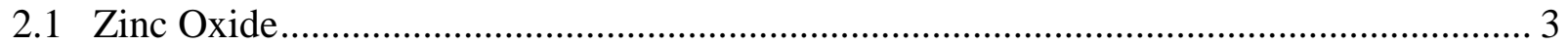

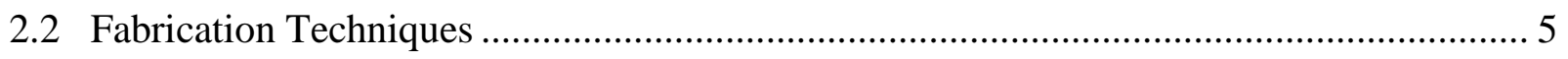

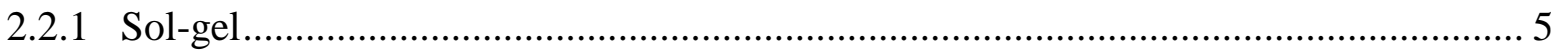

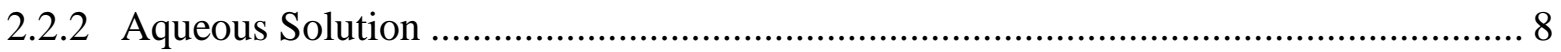

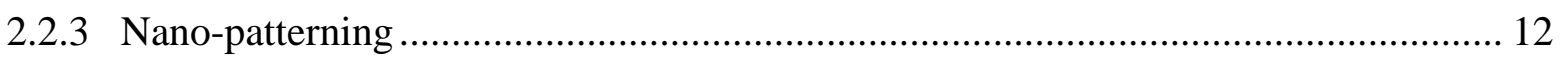

2.3 Piezoelectric Energy Harvesting and Sensing ............................................................ 15

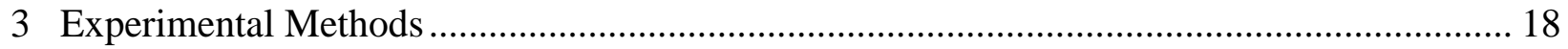

3.1 Material Fabrication ……………………………............................................... 18

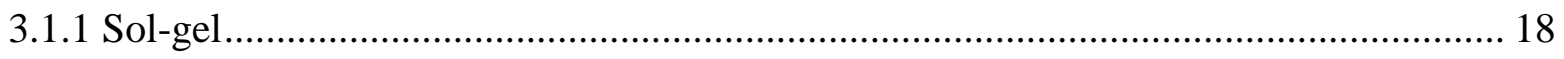

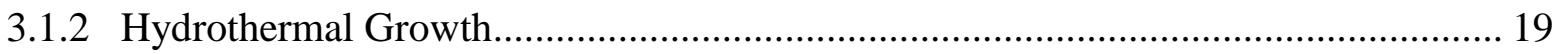

3.1.3 Dip Pen Nanolithography ……………………........................................... 20

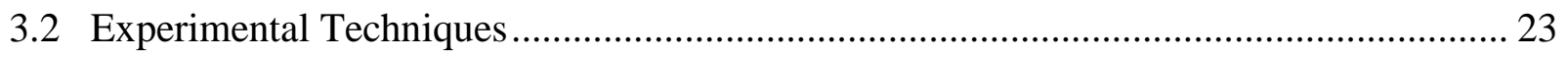

3.2.1 Optical Transmission .......................................................................................... 23

3.2.2 Stylus Profilometry …………………………..................................................... 23

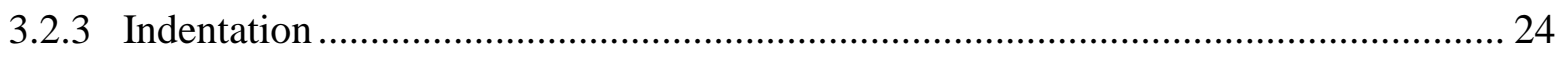

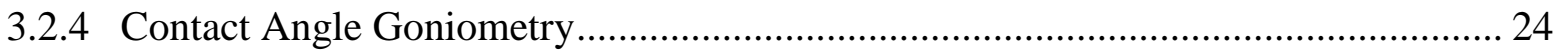

3.2.5 Atomic Force Microscopy ………………………...................................................... 25

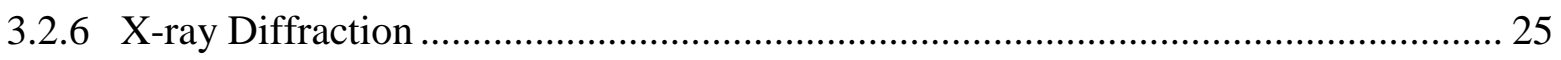

3.2.7 Linear Reciprocating Wear Tester.................................................................... 25

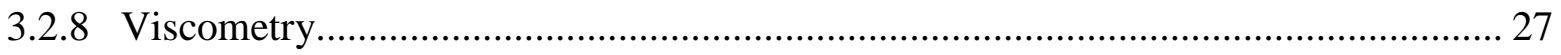

3.2.9 Optical Microscopy ………………………………….......................................... 27

3.2.10 Scanning Electron Microscopy ………………................................................. 27

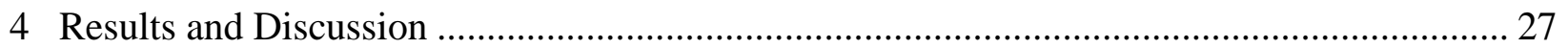




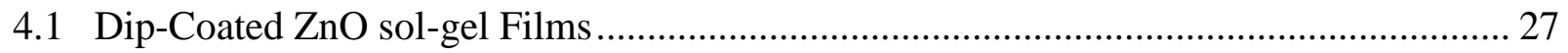

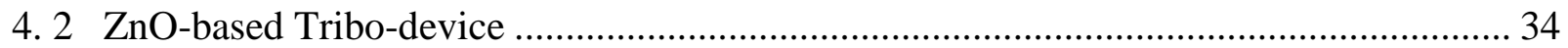

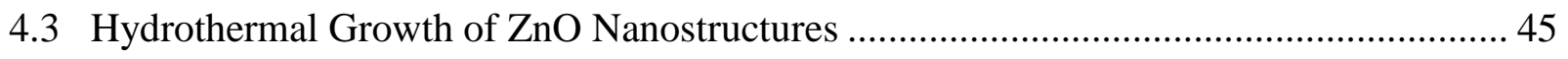

4.4 Dip-Pen Nanolithography of ZnO Patterns ......................................................... 54

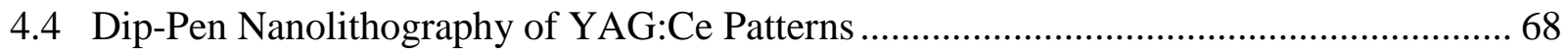

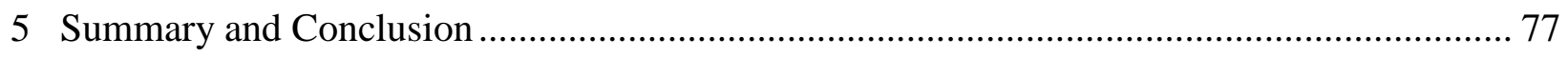

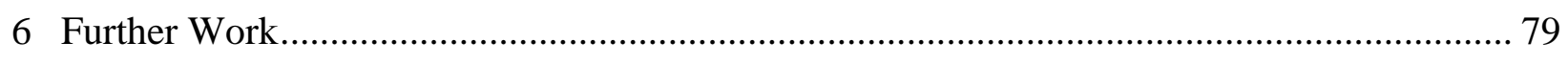

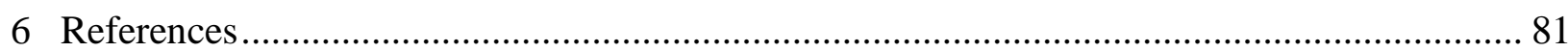




\section{List of Figures}

Figure 1: SEM images of zinc oxide films. (A) Continuous film formed by six $\mathrm{ZnO}$ layers, corresponding to a (002) orientation (B) Calcined three-layer films composed by spheroidal $\mathrm{ZnO}$ particles. (C) ZnO square slabs, corresponding to (100) orientation (D) Enlarged view of C [26] 4 Figure 2: SEM micrograph of the surface (left) and the cross section (right) of $\mathrm{ZnO}$ films heated at $450^{\circ} \mathrm{C}$ for different time: (a) $30 \mathrm{~min}$, (b) $60 \mathrm{~min}$ [49]. Scale bar is the same for all images.... 7

Figure 3: Flowchart showing the process for fabricating $\mathrm{ZnO}$ thin films.................................. 19

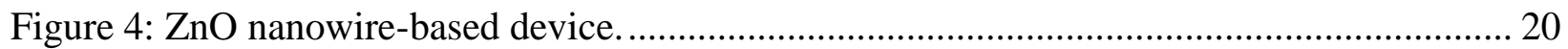

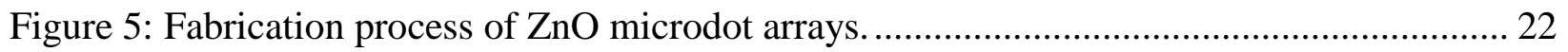

Figure 6: Multilayer stack $\mathrm{ZnO}$ microdots ready for transfer.................................................... 22

Figure 7: Schematic of custom-built reciprocating rolling-contact experimental apparatus with

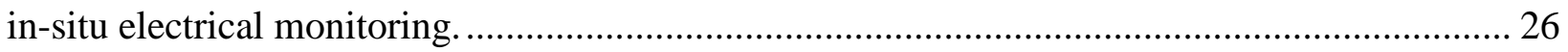

Figure 8: Optical transmittance for different film thicknesses using different solutions (a) $1 \mathrm{~mol}$

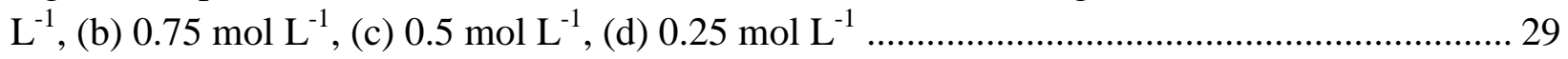

Figure 9: Optical transmittance for different solution concentrations using multiple depositions

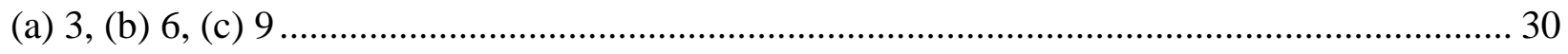

Figure 10: X-ray diffraction pattern of a $2 \theta$ scan for sol-gel deposited $\mathrm{ZnO}$ films using zinc acetate dehydrate solution. For different samples dipped 9 times.............................................. 31 Figure 11: X-ray diffraction pattern of a $2 \theta$ scan for sol-gel deposited $\mathrm{ZnO}$ films for different

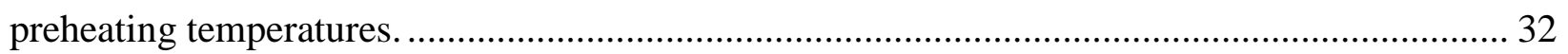

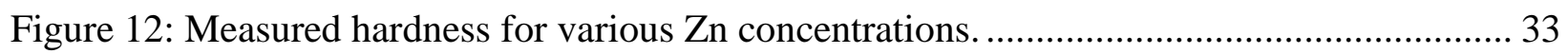
Figure 13: Load versus penetration depth for different solution concentration films (a) $0.5 \mathrm{~mol} \mathrm{~L}^{-}$

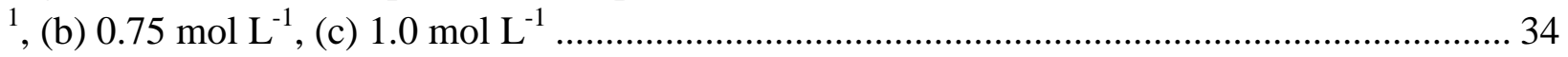

Figure 14: Contact angle values for $\mathrm{ZnO}$ versus different $\mathrm{UV}$ exposure times, inset (a) Water droplet on a non-UV exposed $\mathrm{ZnO}$ surface, inset (b) Water droplet on a 60 minute UV exposed

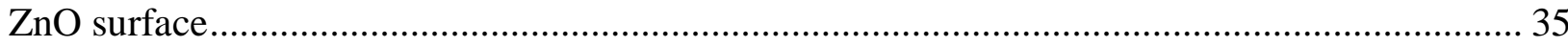

Figure 15: (a) AFM topographical and (b) friction map images of UV exposed $\mathrm{ZnO}$ surface for 60 minutes. (c) Friction signal versus applied normal load for $\mathrm{ZnO}$ single asperity sliding against a ZnO film surface before and after exposure to UV for 60 minutes. ........................................ 36 Figure 16: Load versus penetration depth indentation curves for $1 \mu \mathrm{m}$ thick $\mathrm{ZnO}$ films. A

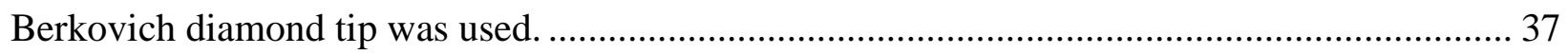
Figure 17: Weight loss of $\mathrm{ZnO}$ films versus number of reciprocating rolling-sliding cycles. The

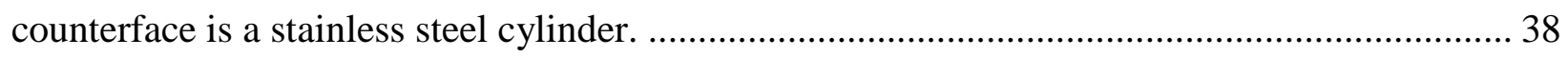
Figure 18: Weight gain of the rolling stainless-steel counterface versus number of reciprocating

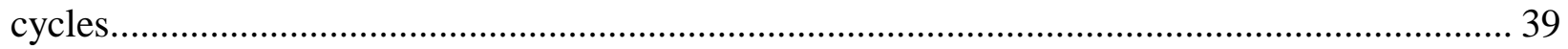

Figure 19: Optical images of non-UV exposed $\mathrm{ZnO}$ surfaces taken after various amounts of reciprocating rolling. The rolling direction is the same for all images...................................... 40 Figure 20: Optical images of 60 minutes UV exposed $\mathrm{ZnO}$ surfaces taken after various amounts of reciprocating rolling. The rolling direction is the same for all images. 41 
Figure 21: Optical images of the stainless steel cylinder surfaces. (a) Initial counterface, (b) cylinder surface after 25000 rolling cycles on a non-UV exposed $\mathrm{ZnO}$ surface, (d) cylinder surface after 25000 reciprocating cycles on a 60 minutes $\mathrm{UV}$ exposed $\mathrm{ZnO}$ film surface.......... 42 Figure 22: Image of the rolling-based configuration. The inset shows the voltage output measurement during an experiment. ................................................................................ 42 Figure 23: AC Voltage response of preliminary device design subjected to rolling for a total of 150 cycles at a frequency of $0.5 \mathrm{~Hz}$. (a) All 150 cycles, and (b) cycles from 15-20................. 43 Figure 24: AC Voltage response of preliminary device design subjected to rolling for a total of 150 cycles at a frequency of $0.25 \mathrm{~Hz}$. (a) All 150 cycles, and (b) cycles from 15-20............... 44 Figure 25: DC Voltage response of preliminary device design subjected to rolling for a total of 150 cycles at a frequency of $0.5 \mathrm{~Hz}$. (a) All 150 cycles, and (b) cycles from 15-20................. 44 Figure 26: DC Voltage response of preliminary device design subjected to rolling for a total of 150 cycles at a frequency of $0.5 \mathrm{~Hz}$. (a) All 150 cycles, and (b) cycles from 15-20................ 45 Figure 27: SEM images $\mathrm{ZnO}$ nanostructures for different growth conditions. All seed-layers were deposited on glass and dried at $100^{\circ} \mathrm{C}$ unless specified. (a) $0.025 \mathrm{~mol} \mathrm{~L}^{-1}$ solution for $24 \mathrm{hrs}$ at $95^{\circ} \mathrm{C}$ (b) $0.01 \mathrm{~mol} \mathrm{~L}^{-1}$ solution for $24 \mathrm{hrs}$ at $95^{\circ} \mathrm{C}$ (c) $0.025 \mathrm{~mol} \mathrm{~L}^{-1}$ solution for $24 \mathrm{hrs}$ at $70^{\circ} \mathrm{C}$ (d) $0.025 \mathrm{~mol} \mathrm{~L}{ }^{-1}$ solution for $24 \mathrm{hrs}$ at $95^{\circ} \mathrm{C}$, grown on $\mathrm{Au}$ (e) $0.025 \mathrm{~mol} \mathrm{~L}^{-1}$ solution for $24 \mathrm{hrs}$ at

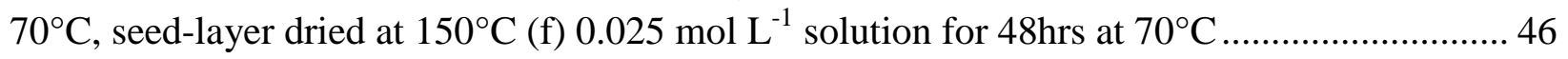

Figure 28: ZnO structures grown on PEN substrate ......................................................... 48

Figure 29: PEN-based $\mathrm{ZnO}$ nanostructure device. ............................................................... 49

Figure 30: Piezoelectric output of PEN-based $\mathrm{ZnO}$ nanostructure device. .............................. 50

Figure 31: Open circuit voltage of $\mathrm{ZnO}$ device subjected to buckling. .................................. 50

Figure 32: Open circuit voltage for PEN-based device after aging for 3 months....................... 51

Figure 33: (a) SEM image of patterned $\mathrm{ZnO}$ nanorods, (b) magnified image of highlighted region

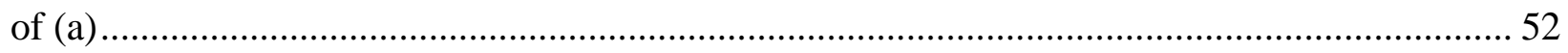

Figure 34: Open circuit voltage measured for patterned $\mathrm{ZnO}$ device during microindentation for

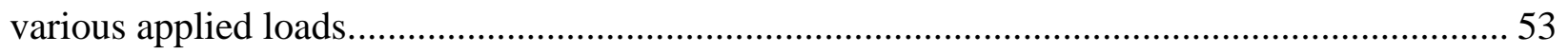

Figure 35: SEM images of $\mathrm{ZnO}$ nanorods after microindentation. ....................................... 53 Figure 36: $10 \mathrm{~s}$ dwell time for 1:1 $\mathrm{ZnO}$ to PPG solution, (a) as deposited, (b) 5 minutes after

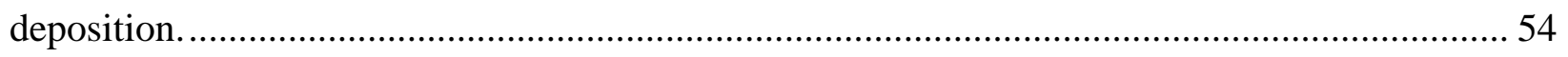

Figure 37: Viscosity of inks used for DPN as a percentage of glycerol.................................. 55 Figure 38: As deposited 2:1 $\mathrm{ZnO}$ to glycerol dots on a PVP release layer for different dwell times (a) $5 \mathrm{~s}$, (b) $10 \mathrm{~s}$, (c) $15 \mathrm{~s}$. The arrow indicates tip movement. ............................................... 56 Figure 39: As deposited 1:1 $\mathrm{ZnO}$ to glycerol dots on a PVP release layer for different dwell times (a) $5 \mathrm{~s}$, (b) $10 \mathrm{~s}$, (c) $15 \mathrm{~s}$. The arrow indicates tip movement. ............................................... 57 Figure 40: As deposited 1:2 ZnO to glycerol dots on a PVP release layer for different dwell times (a) $5 \mathrm{~s}$, (b) $10 \mathrm{~s}$, (c) $15 \mathrm{~s}$. The arrow indicates tip movement. ................................................ 57 Figure 41: As deposited radius measurements as a function of row number for 2:1 $\mathrm{ZnO}$ to

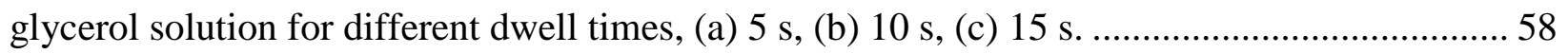


Figure 42: As deposited radius measurements as a function of row number for $1: 1 \mathrm{ZnO}$ to

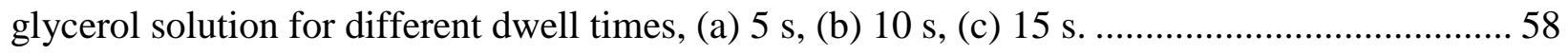
Figure 43: As deposited radius measurements as a function of row number for 1:2 $\mathrm{ZnO}$ to glycerol solution for different dwell times, (a) $5 \mathrm{~s}$, (b) $10 \mathrm{~s}$, (c) $15 \mathrm{~s}$. 59 Figure 44: Fired 2:1 $\mathrm{ZnO}$ to glycerol on PVP release layer (a) $5 \mathrm{~s}$ dwell time, (b) magnified image of highlighted area of (a), (c) $10 \mathrm{~s}$ dwell time, (d) $15 \mathrm{~s}$ dwell time. 60 Figure 45: Fired 1:1 $\mathrm{ZnO}$ to glycerol on PVP release layer for different dwell times (a) $5 \mathrm{~s}$, (b) magnified image of highlighted area of (a), (c) $10 \mathrm{~s}$, (d) magnified image of highlighted area of (c), (e) $15 \mathrm{~s}$, (f) magnified image of highlighted area of (e).

Figure 46: Fired 1:2 ZnO to glycerol on PVP release layer for different dwell times (a) $5 \mathrm{~s}$, (b) magnified image of highlighted area of (a), (c) $10 \mathrm{~s}$, (d) magnified image of highlighted area of (c). 62

Figure 47: Fired radius measurements as a function of row number for 2:1 $\mathrm{ZnO}$ to glycerol solution, (a) $5 \mathrm{~s}$ dwell time, (b) $10 \mathrm{~s}$ dwell time, (c) $15 \mathrm{~s}$ dwell time. 63 Figure 48: Fired radius measurements as a function of row number for 1:1 $\mathrm{ZnO}$ to glycerol solution, (a) $5 \mathrm{~s}$ dwell time, (b) $10 \mathrm{~s}$ dwell time, (c) $15 \mathrm{~s}$ dwell time. 63 Figure 49: Fired radius measurements as a function of row number for 1:2 $\mathrm{ZnO}$ to glycerol solution, (a) $5 \mathrm{~s}$ dwell time, (b) $10 \mathrm{~s}$ dwell time, (c) $15 \mathrm{~s}$ dwell time. 64 Figure 50: Comparison of wet and fired radii for 1:1 $\mathrm{ZnO}$ to glycerol, (a) $5 \mathrm{~s}$ dwell time, (b) $10 \mathrm{~s}$ dwell time, (c) $15 \mathrm{~s}$ dwell time. 64

Figure 51: Comparison of wet and fired radii for 1:1 $\mathrm{ZnO}$ to glycerol, (a) $5 \mathrm{~s}$ dwell time, (b) $10 \mathrm{~s}$ dwell time, (c) $15 \mathrm{~s}$ dwell time. 65

Figure 52: Comparison of wet and fired radii for 1:2 $\mathrm{ZnO}$ to glycerol, (a) $5 \mathrm{~s}$ dwell time, (b) $10 \mathrm{~s}$ dwell time. 65

Figure 53: Transferred $\mathrm{ZnO}$ dot arrays on PEN. Dwell time is $15 \mathrm{~s}$, (a) 2:1 $\mathrm{ZnO}$ to Glycerol, (b) 1:1 $\mathrm{ZnO}$ to Glycerol.

Figure 54: Comparison of fired and transferred radii for $15 \mathrm{~s}$ dwell time, (a) 2:1 $\mathrm{ZnO}$ to Glycerol (b) $1: 1 \mathrm{ZnO}$ to Glycerol. 66

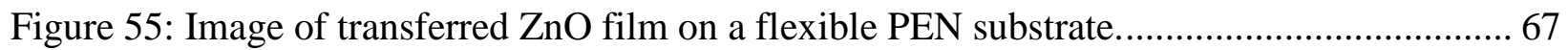

Figure 56: X-ray diffraction pattern of a $2 \theta$ scan for the transferred $\mathrm{ZnO}$ film........................ 68

Figure 57: Viscosity of inks used for DPN as a percentage of PVA. ...................................... 69 Figure 58: As deposited 3:2YAG:Ce to PVA dots on a PVP release layer for different dwell times (a) $5 \mathrm{~s}$, (b) $10 \mathrm{~s}$, (c) $15 \mathrm{~s}$. The arrow indicates tip movement......................................... 70 Figure 59: As deposited 1:1 YAG:Ce to PVA dots on a PVP release layer for different dwell times (a) $5 \mathrm{~s}$, (b) $10 \mathrm{~s}$, (c) $15 \mathrm{~s}$. The arrow indicates tip movement.......................................... 70 Figure 60: As deposited radius measurements as a function of row number for 3:2 and 1:1 YAG:Ce to PVA solution for different dwell times (a) $5 \mathrm{~s}$, (b) $10 \mathrm{~s}$, (c) $15 \mathrm{~s}$.......................... 71 Figure 61: Fired 3:2 YAG:Ce to PVA on PVP release layer for different dwell times (a) $5 \mathrm{~s}$, (b)

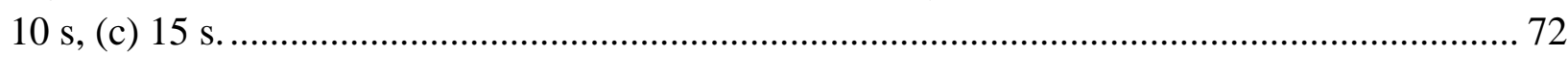


Figure 62: Fired 3:2 YAG:Ce to PVA on PVP release layer for different dwell times (a) $5 \mathrm{~s}$, (b) $10 \mathrm{~s}$, (c) $15 \mathrm{~s}$.

Figure 63: Typical SEM image of a YAG:Ce fired dot on a PVP release layer. Dwell time is $15 \mathrm{~s}$ and 1:1 YAG to PVA solution. 73

Figure 64: Fired radius measurements as a function of row number for 3:2 and 1:1 YAG:Ce to PVA solution for different dwell times, (a) $5 \mathrm{~s}$, (b) $10 \mathrm{~s}$, (c) $15 \mathrm{~s}$.

Figure 65: Comparison of wet and fired radii for 3:2 YAG:Ce to PVA for different dwell times, (a) $5 \mathrm{~s}$, (b) $10 \mathrm{~s}$, (c) $15 \mathrm{~s}$.

Figure 66: Comparison of wet and fired radii for 1:1 YAG:Ce to PVA for different dwell times, (a) $5 \mathrm{~s}$, (b) $10 \mathrm{~s}$, (c) $15 \mathrm{~s}$. 75 Figure 67: Transferred YAG:Ce dot arrays on PEN for different solutions (a) 3:2 YAG:Ce to PVA, (b) 1:1 YAG:Ce to PVA. Dwell time is $5 \mathrm{~s}$. 76

Figure 68: X-ray diffraction patterns for YAG:Ce powders fired at different temperatures. 77 


\section{List of Tables}

Table 1: Degree of preferred orientation, crystallite size and film thickness with respect to the

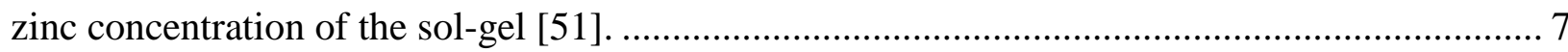

Table 2: Hydrothermal processing solutions and the structure formed [11] ............................... 9

Table 3: Comparison of the relative merits of three primary types of energy harvesting

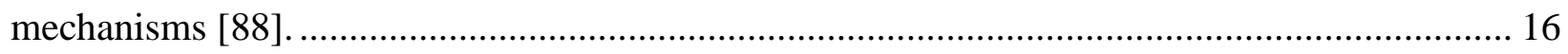

Table 4: Sol-gel deposited ZnO film thickness measurements.................................................. 28

Table 5: Growth conditions for hydrothermally grown $\mathrm{ZnO}$ structures and measured results. ... 48 


\section{Introduction}

This work aims to study different fabrication methods of simple $\mathrm{ZnO}$-based geometrical patterns onto flexible substrates. $\mathrm{ZnO}$ structures are deposited using three different techniques, sol-gel, hydrothermal, and dip-pen nanolithography (DPN). First, sol-gel processing of $\mathrm{ZnO}$ films was chosen because it is a relatively easy process and can lead to the fabrication of largearea films. Sol-gel processing requires high firing temperatures, prohibiting the use of flexible polymer substrates. As a second approach, $\mathrm{ZnO}$ nanostructures were fabricated on polymer substrates using a hydrothermal process. Then, patterns of $\mathrm{ZnO}$ nanostructures were fabricated utilizing photolithography. Finally, DPN was employed to explore nanomanufacturing of $\mathrm{ZnO}$ micro/nano geometries. This is due to its ability direct write such geometries.

$\mathrm{ZnO}$ is a relatively simple system that can be integrated into various devices such as sensors [1-2], displays [3], solar cells [4-5], and energy harvesters [6-7]. The role of $\mathrm{ZnO}$ in all these types of devices varies. For example, in solar cells it acts as a photoelectric layer whereas in energy harvesters it comprises the piezoelectric part of the device [8-9]. However, most of the work to date, and the majority of working and/or scalable device fabrication, employ $\mathrm{ZnO}$ structures that are based on rigid substrates. Therefore, fabrication methods that can reliably lead to $\mathrm{ZnO}$ small scale geometries on flexible substrates need to be further explored and enhanced.

In more specific terms, sol-gel processing has the ability to fabricate c-axis (002) oriented films [10]. The piezoelectric properties of $\mathrm{ZnO}$ is attributed to the (002) orientation allowing sol-gel processed films to be utilized in energy harvesters. Although piezoelectric $\mathrm{ZnO}$ films can be obtained via sol-gel, multiple depositions are required to obtain the desired thickness. This 
could prove to be challenging in fabricating an energy harvester because piezoelectric response may be low.

Moving toward fabricating functional $\mathrm{ZnO}$ layers on flexible substrates a hydrothermal growth process is utilized because of its low processing temperature. Additionally, various $\mathrm{ZnO}$ structures such as flowers, stars, and rods can be fabricated, allowing for optimization of the structure based on desired application [11]. ZnO nanorods fabricated through a hydrothermal process have been shown to have a high piezoelectric output, making them a good candidate for energy harvesters. Although, patterning of $\mathrm{ZnO}$ rods could prove to be difficult since these are nanostructures.

DPN has the ability to deposit complex geometries on numerous substrates. In addition, DPN has been shown to be a scalable manufacturing process, presenting the possibility to fabricate patterned functional layers via a single step. Since it is a new technology, little research has been conducted utilizing $\mathrm{ZnO}$ as an ink. Necessitating the investigation of ink properties and writing conditions. This could prove to be challenging in the progression of patterning functional layers.

In this work, sol-gel deposited films are utilized to investigate the rolling/sliding tribological properties of $\mathrm{ZnO}$ and the effects on the piezoelectric output. A preliminary piezoelectric $\mathrm{ZnO}$ nanostructure device is fabricated on a flexible substrate using hydrothermally grown. Additionally, the ability to fabricate a patterned $\mathrm{ZnO}$ nanorod device with photolithography is investigated. DPN is utilized to deposit microdots of $\mathrm{ZnO}$ on rigid substrates and the possibility of transferring them to flexible substrates. Also, YAG:Ce is used as an ink to present the versatility of DPN to deposit various patterned functional layers. 


\section{Background}

\subsection{Zinc Oxide}

Zinc oxide $(\mathrm{ZnO})$ has become a popular material for research this last decade because of its interesting properties. It is a wide band gap $(3.37 \mathrm{eV})$ semiconducting ceramic with high optical transmittance. In addition, $\mathrm{ZnO}$ films exhibit piezoelectricity [9], pyroelectricity [12], and solid lubricity [13]. In addition, it has a range of conductivity from metallic to insulating and is ferromagnetic at room-temperature $[14,15]$. The crystal structure for $\mathrm{ZnO}$ is a hexagonal wurzite which contributes to piezoelectric and pyroelectric properties. These properties allow $\mathrm{ZnO}$ to be used in a variety of applications, such as piezoelectric nanogenerators [16-21], microelectromechanical systems (MEMS) [22-23], pressure sensors [2,24], and solar cells [4-5]. In some cases $\mathrm{ZnO}$ is even being looked at as an alternative for indium tin oxide (ITO), because it is cheaper and more readily found $[4,25-26]$. $\mathrm{ZnO}$ is also deposited using a variety of methods such as spray pyrolysis[4], pulsed laser deposition (PLD) [13], chemical vapor deposition (CVD) [27], rf magnetron sputtering [9,12], aqueous solution [11,28-40], and sol-gel process $[5,25,26,41-51]$.

The versatility of $\mathrm{ZnO}$ is due to its crystal structure, which depends highly on the film processing. The main crystallographic orientations of $\mathrm{ZnO}$ are (100), (002), and (101), images of (002) and (100) oriented $\mathrm{ZnO}$ films are shown in Figure 1 [52]. To get piezoelectric properties, as well as lower electrical resistivity, $\mathrm{ZnO}$ must be c-axis (002) oriented [10]. In addition, its electrical resistivity depends on the grain size and its optical transmittance depends on the surface morphology respectively [41]. The electrical conductivity as explained by Lee et al. [25] "is directly related to the number of electrons, electrons formed by the ionization of the interstitial zinc atom and the oxygen vacancies affect the electrical conductivity of $\mathrm{ZnO}$ 
crystals." Furthermore, the hardness and elastic modulus have been shown to be dependent on annealing temperature [53]. All these properties, for solution-based processes, depend highly on how the films are heat treated, such as preheat treatment and annealing temperature, as well as the concentration of the solution used to fabricate the film.
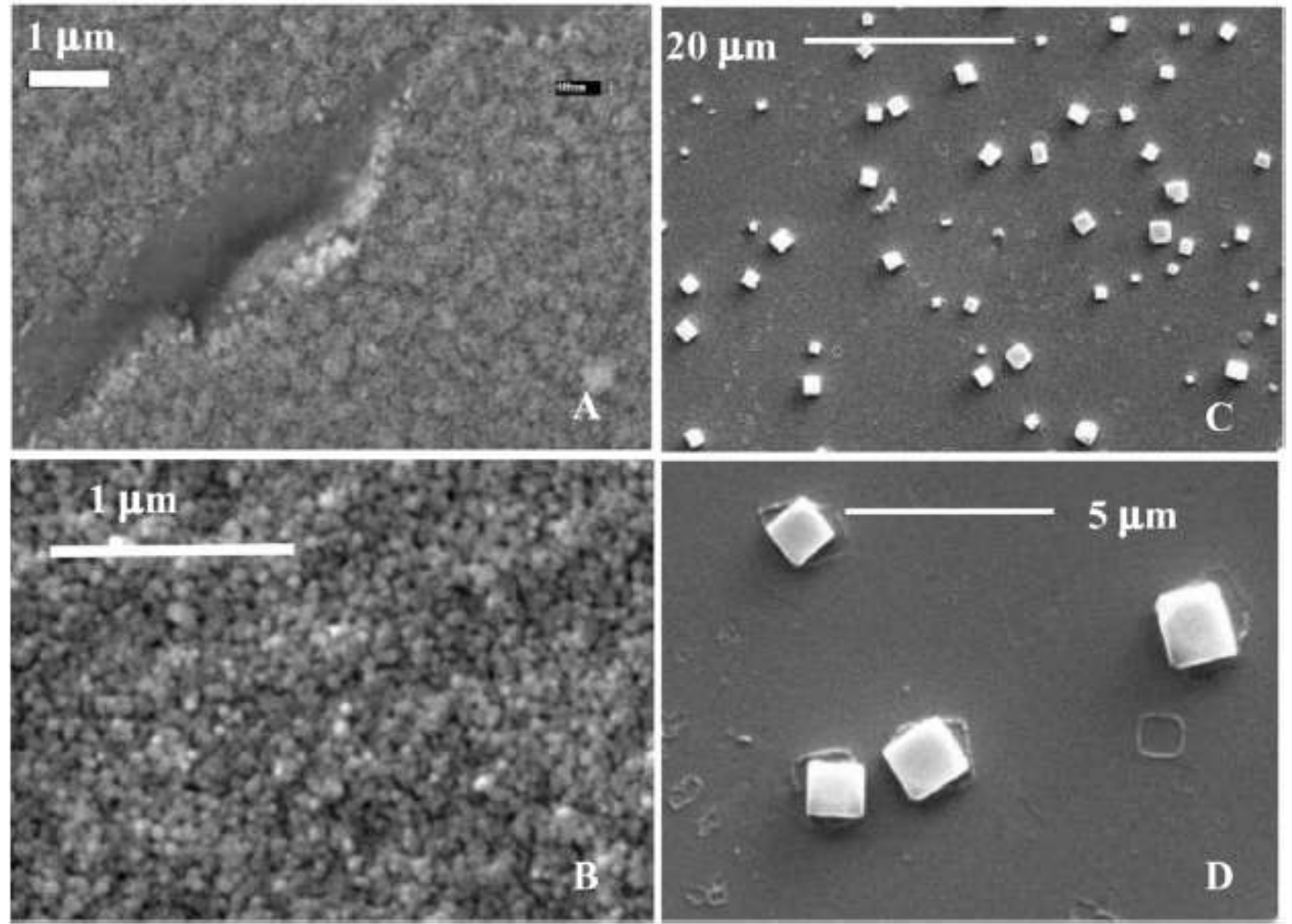

Figure 1: SEM images of zinc oxide films. (A) Continuous film formed by six ZnO layers, corresponding to a (002) orientation (B) Calcined three-layer films composed by spheroidal $\mathrm{ZnO}$ particles. (C) $\mathrm{ZnO}$ square slabs, corresponding to (100) orientation (D) Enlarged view of $C$ [26]

It is known that the wettability of $\mathrm{ZnO}$ films can be controlled by exposing the films to ultraviolet (UV) irradiation [54-57]. Feng et al. [54] evaluated the wettability of highly c-axis oriented $\mathrm{ZnO}$ nanorod films by water contact angle (CA) measurements. It was shown that the films were super-hydrophobic exhibiting a contact angle greater than $150^{\circ}$. When the films were exposed to UV irradiation for 2 hours, the resulting contact angle reached $\sim 0^{\circ}$. In addition, Sun et al. [56] investigated the wettability of both $\mathrm{ZnO}$ and $\mathrm{TiO} 2$ films deposited by CVD. The $\mathrm{ZnO}$ films were left in dark storage for several weeks and the CA was found to be $\sim 109^{\circ}$ and when 
exposed to UV, for 60 minutes, it was measured to be $\sim 5^{\circ}$. Horváth et al. [57] investigated the mechanical properties and deformation behavior of $\mathrm{ZnO}$ films exposed to $\mathrm{UV}$.

\subsection{Fabrication Techniques}

\subsubsection{Sol-gel}

Sol-gel processing of $\mathrm{ZnO}$ has become a popular subject for research because it is a low cost processing technique and, at the same time, can lead to large area coatings. During sol-gel processing a precursor and solvent are required to synthesize a solution and for $\mathrm{ZnO}$ the most common precursor met in literature is zinc acetate. There are a variety of different alcohols being utilized as solvents, such as ethanol, methanol, 2-methoxyethonal, and isopropyl alcohol. Depending on the alcohol used an additive must be added in order to induce complete dissolution [52]. To deposit the solution on to a substrate dip and/or spin coating are commonly conducted. Multiple depositions are performed to arrive at the desired thickness. After each deposition a preheat treatment is conducted to dissolve the solvent and remove the organic compounds. Once the desired thickness is reached a final post-heat treatment/annealing is performed to form a crystallized zinc oxide film.

In 1996 Kamalasanan et al. [42] explored the synthesis of thin $\mathrm{ZnO}$ films through a solgel process. It was found that highly transparent films could be synthesized and that the faster the heating rate the more translucent the film. However, x-ray diffraction (XRD) of the films did not show only the (002) peak but also (100) and (101). Ohyama et al. [43] explored the fabrication of highly (002) oriented films, and reported on the effects of preheating and postheating temperature on the (002). The $\mathrm{ZnO}$ films grain boundary decreases as the crystallinity increases leading to a decreased electrical resistivity [25]. Natsume et al. [44] found similar results but also reported that at a certain point there is a slight increase in electrical resistance due 
to the decrease in defects that produce donor levels. Furthermore, Lee et al. [25] investigated the effects of the drying temperature on the resistivity of $\mathrm{ZnO}$ films, reporting a lower resistivity for higher drying temperatures, citing the enhanced crystal structure. Moreover, $\mathrm{ZnO}$ can be doped with aluminum to lower resistance, while still maintaining its optical transparency [5,45].

It is important to understand the different processing factors that affect properties of the ZnO films. Znaidi et al. [26] investigated the physico-chemical conditions that affect the film's crystal orientation. It was reported that the preferential orientation is related to the solution concentration. Li et al. [46] reported on the influence of annealing temperature. Their films exhibited higher optical transmittance when annealed at $600^{\circ} \mathrm{C}$ as compared to lower annealing temperatures of $400^{\circ}$ and $500^{\circ} \mathrm{C}$. Kim et al. [47] studied the effect of preheating temperature, finding $275^{\circ} \mathrm{C}$ to be the optimum preheating temperature for high c-axis (002) orientation. Both parameters, preheating and post-heating temperatures were inspected by Wang et al. [48] concluding that both influence the crystal orientation, residual stress, grain size, and electrical resistivity. Further studies on the heat treatment of $\mathrm{ZnO}$ films show the evolution of the film structure for various firing times [49]. In Figure 2 the evolution from granular to columnar structure, as well as larger grain size is seen for films annealed for 60 minutes as compared with those treated for 30 minutes. Additionally, the porosity of the films can be controlled by adding polyethylene glycol to the sol [50]. 

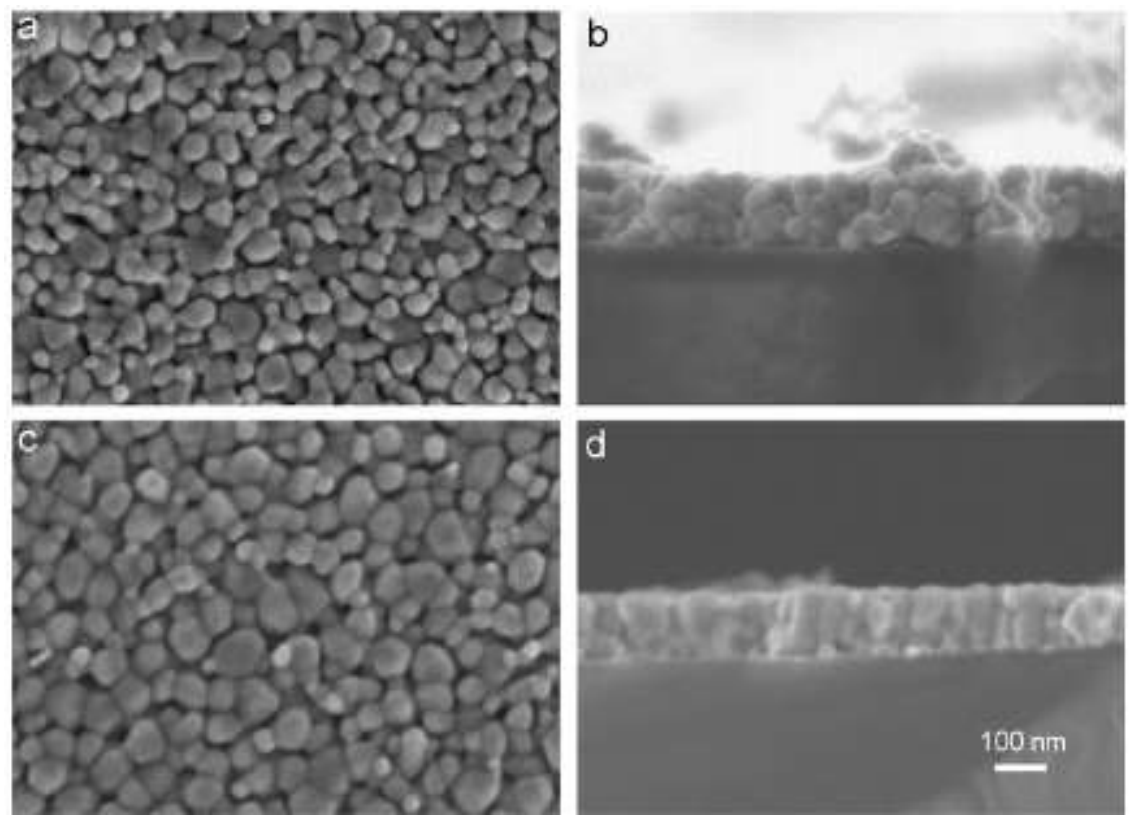

Figure 2: SEM micrograph of the surface (left) and the cross section (right) of $\mathrm{ZnO}$ films heated at $450{ }^{\circ} \mathrm{C}$ for different time: (a) $30 \mathrm{~min}$, (b) $60 \mathrm{~min}$ [49]. Scale bar is the same for all images.

A major challenge with sol-gel processing of $\mathrm{ZnO}$ films is the multiple depositions required to obtain the desired thickness. It has been found that higher zinc solution concentrations result in increased film thickness but the c-axis orientation decreases; this can be seen in Table 1 [51]. Another issue with sol-gel processing of $\mathrm{ZnO}$ is that it can only be conducted on rigid substrates because of the high processing temperatures needed. In order to move towards flexible substrate utilization, lower temperatures must be used. Furthermore, in order for sol-gel processing to be a viable technique for fabricating $\mathrm{ZnO}$ for energy harvesting devices the resulting film must exhibit c-axis orientation perpendicular to the base substrate [43].

Table 1: Degree of preferred orientation, crystallite size and film thickness with respect to the zinc concentration of the sol-gel [51].

\begin{tabular}{llllc}
\hline $\begin{array}{l}\text { Zn concentration } \\
(\mathrm{M})\end{array}$ & $\begin{array}{l}\text { Preferred } \\
\text { orientation }\end{array}$ & $\begin{array}{l}\text { Degree of }(002) \\
\text { orientation }\end{array}$ & $\begin{array}{l}\text { Crystallite } \\
\text { size }(\mathrm{nm})\end{array}$ & $\begin{array}{l}\text { Film thickness } \\
(\mathrm{nm})\end{array}$ \\
\hline 0.3 & $(002)$ & 0.96 & 288 & 84 \\
0.6 & $(002)$ & 0.62 & 385 & 185 \\
0.7 & $(002)$ & 0.50 & 315 & 188 \\
1.3 & $(101)$ & 0.22 & 348 & 437 \\
\hline
\end{tabular}




\subsubsection{Aqueous Solution}

For further development of sensors and energy harvesters it is important to fabricate a flexible device that can conform to a desired shape. To have truly flexible devices polymerbased substrates are required. Although, with the use of polymer substrates, lower processing temperatures of zinc oxide must be utilized as not to distort the polymer. Furthermore, switching from solid films to micro/nanostructures (wires, rods, and tubes) will be beneficial, since the rigidity of solid films will promote cracking and lead to the failure of the coating. Additionally, $\mathrm{ZnO}$ nanostructures can be fabricated at low temperatures compared to solid films because of the low chemical reaction temperature required. By utilizing an aqueous solution process, which uses a low processing temperature to form $\mathrm{ZnO}$ structures, fabrication of a truly flexible device is attainable.

Understanding the aqueous solution process is important in fabricating well defined, high aspect ratio nanostructures. There are different factors that affect the development of $\mathrm{ZnO}$ nanorods. Namely, they include precursors, solution concentration, solution $\mathrm{pH}$, growth time, growth temperature, and substrate/seed-layer. The precursor is a zinc source, additive, and water. Common zinc sources include: zinc nitrate $\left(\mathrm{Zn}\left(\mathrm{NO}_{3}\right)_{2}\right)$ [11, 28-33,35-39,58], zinc chloride[11,40],zinc acetate [11], and zinc sulfate [11,34]. The common additives used are hexamethylenetetramine (HMT,HMTA) [11,28-33,35,37,39,58], ethylenediamine (en) [11], ammonium hydroxide [36,38]. Govender et al. [11] performed a comprehensive study on the effects of different zinc sources and additives, showing that different solutions generate different formations, see Table 2 . 
Table 2: Hydrothermal processing solutions and the structure formed [11].

\begin{tabular}{|c|c|c|c|c|c|c|}
\hline \multicolumn{2}{|c|}{ Zinc Source } & $\begin{array}{c}\text { Zinc } \\
\text { nitrate }\end{array}$ & $\begin{array}{c}\text { Zinc } \\
\text { acetate }\end{array}$ & $\begin{array}{c}\text { Zinc } \\
\text { formate }\end{array}$ & $\begin{array}{c}\text { Zinc } \\
\text { chloride }\end{array}$ & Zinc sulfate \\
\hline \multirow{4}{*}{ Additive } & en & $\begin{array}{c}\text { No } \\
\text { reaction }\end{array}$ & Stars & Stars & Stars & $\begin{array}{c}\text { Flower-and } \\
\text { platelike particles }\end{array}$ \\
\cline { 2 - 7 } & TEA & Nodules & No reaction & No reaction & No reaction & No reaction \\
\cline { 2 - 7 } & HMTA & Needles & Rods & Rods & Rods & $\begin{array}{c}\text { No film/platelike } \\
\text { ppts }\end{array}$ \\
\hline
\end{tabular}

Vayssieres [28-30] and his collaborators established the foundation for the studies of $\mathrm{ZnO}$ micro/nanostructures, using an equimolar aqueous solution of zinc nitrate and HTMA. The length of the structures depends on the growth time. It should be mentioned that an aqueous solution of zinc nitrate and HMTA leads to a growth rate of $\sim 1 \mu \mathrm{m} / \mathrm{hr}$ at $95^{\circ} \mathrm{C}$ [28]. To form tubular arrays rather than rods, the substrate is left in the nutrient solution for 2 days. After the first day microrods are formed, then on the second day variations in the morphology occur resulting in microtubes [29]. Additionally, the width of the rods depends on the solution concentrations - the higher the concentration the larger the width. For example, a $0.1 \mathrm{~mol} \mathrm{~L}^{-1}$ solution produces $1-2 \mu \mathrm{m}$ width rods and a $0.01 \mathrm{~mol} \mathrm{~L}^{-1}$ solution produces $100-200 \mathrm{~nm}$ width rods [30]. Vayssieres' claim of a linear relation of the solution concentration to rod width is disputed by a few researchers. Both Guo et al. [31] and Muhamad et al. [32] showed non-linear relations of solution concentration to rod width. In addition, Xu et al. [33] showed that with increasing solution concentration the density increases. The density is defined as the number of rods per area.

Yamabi et al. [34] investigated the effects of $\mathrm{pH}$ on the growth of nanorods by using zinc sulfate and a variety of complexing agents, as well as utilizing sodium hydroxide ( $\mathrm{NaOH})$ to control the $\mathrm{pH}$. It was found that for all complexing agents a $\mathrm{pH}$ value of 9.0-13.0 will produce 
wurtzite $\mathrm{ZnO}$ structures. While using the more traditional solution of zinc nitrate and HTMA the diameter of the nanorods decreases exponentially with $\mathrm{pH}$ level [35].

The growth time allows the nanorods to develop, meaning the length of the rods and the density. Li et al. [35] found that growing times of up to $10 \mathrm{hrs}$ nanorods were formed and after $10 \mathrm{hrs}$ nanotubes, with diameters of $40-60 \mathrm{~nm}$, started to form on top of the nanorods. After 20 hrs the nanotubes had become longer and were "spaghetti" like, entangled with one another. In the early stages of growth the rods predominantly grow laterally and beyond 6hrs the lateral growth yields [31,33]. The diameter and length of the desired structures depends on the growth time.

The growth temperature has a significant influence on the aspect ratio of the nanorods [31]. The aspect ratio is defined as the diameter to length of the structure ratio. It has been reported that the length of rods increases with increasing temperature from $40^{\circ}$ to $95^{\circ} \mathrm{C}$ [31]. Additionally, the shape of the nanorods becomes pyramidal-shaped for temperatures above $80^{\circ} \mathrm{C}$ and a hexagonal prism shape for temperatures of $60^{\circ}$ and $70^{\circ} \mathrm{C}$ [33]. This agrees with Tak et al. [36] finding that for $90^{\circ} \mathrm{C}$ the nanorods had broader tips and a more faceted shape than that of rods grown at $60^{\circ} \mathrm{C}$. Moreover, Ahsanulhaq et al. [37] found that increasing the growth temperature from $70^{\circ} \mathrm{C}$ to $110^{\circ} \mathrm{C}$ nanopencils are formed instead of nanorods. While, Li et al. [35] found that the diameters of their nanorods increased from 100-300 nm to 500-800 nm when decreasing the temperature from $98^{\circ} \mathrm{C}$ to $92^{\circ} \mathrm{C}$. In addition, they found that this temperature change caused the $\mathrm{pH}$ value to increase. $\mathrm{Xu}$ et. al [33] concluded that the optimum growth temperature for zinc nitrate and HTMA solution is $70^{\circ} \mathrm{C}$, as compared to temperatures of $60^{\circ} \mathrm{C}$ and $95^{\circ} \mathrm{C}$. 
Various substrates were used in each study, and some studies investigated the affects of substrates. It is required that the substrate be smooth for aligned growth [33]. Additionally, the type and crystallinity of substrates has almost no influence on the orientation and growth [28]. Comparing the growth on a rigid substrate and a flexible substrate it has been concluded that the substrate has little influence on the growth [33]. Although the substrate may not affect the growth, enhanced growth could be obtained by depositing a seed-layer.

The seed-layer effects how well nucleation sites are formed for the nanorods. Different types of seed-layers may be used to promote better growth; additionally it can act as an electrode for a flexible device [58]. It is seen that substrates with seed-layers have superior aligned rods, which may be due to the matching lattice structure [35]. Different seed-layers have different affects on the growth of $\mathrm{ZnO}$ structures. Song et al. [38] compared two different $\mathrm{ZnO}$ seedlayers with $\mathrm{Al}$-doped $\mathrm{ZnO}$ film and $\mathrm{Ga}$-doped $\mathrm{ZnO}$ film. It was found that the seed-layers promoted different growth rates, in addition to the average diameter and density. Chen et al. [40] investigated the effects of a bare substrate with a sol-gel deposited $\mathrm{ZnO}$ layer fired at various temperatures; additionally three types of substrates were utilized. Finding that firing the seed-layer at $200^{\circ} \mathrm{C}$ produced poorly aligned rods as compared to above $200^{\circ} \mathrm{C}$ and promoted growth. Furthermore, with the higher temperature fired seed-layers had larger diameter nanorods. While a silicon substrate without a seed-layer showed multiped $\mathrm{ZnO}$ rods. She et al. [41] compared the growth of $\mathrm{ZnO}$ on ITO-coated glass and ITO-coated glass with an Au seedlayer; it was found that the Au coated specimen had denser arrays of nanotubes. Govender et al. [11] examined the influence of a $\mathrm{ZnO}$ and $\mathrm{Au}$ seed-layer on fluorine doped tin oxide $(\mathrm{TO}(\mathrm{F}))$ glass. Their findings showed that there were differences in the diameters but not in the lengths of the rods. 


\subsubsection{Nano-patterning}

In further developing the fabrication of $\mathrm{ZnO}$ structures, it is important to look for successful manufacturing processes. To use $\mathrm{ZnO}$ as an active layer in nanogenerators or sensing device, it is vital to be able to control the size of the features and the geometry. In addition to being able to be fabricated on various substrates: rigid and/or flexible. There are many different nanopatterning techniques that are used to fabricate micro/nanosized patterns. A few common techniques used are photolithography, electron beam (e-beam) lithography, inkjet printing, and dip-pen nanolithography (DPN).

Photolithography is the most common technique used in the fabrication of semiconductors and integrated circuits [59]. In this method, a light sensitive polymeric material, "photoresist", is coated on a substrate, and then a photomask, with the desired pattern, is placed on the coated substrate and exposed to UV light. The exposed areas, subjected to UV, react to the UV, inducing chemical etching, removing the photoresist to leave a pattern. Photolithography has been used in the fabrication of patterned $\mathrm{ZnO}$ nanowires in selective areas by prohibiting the growth of the nanowires on polymer materials for macroelectronincs [60]. Additionally, it has been used to remove a seed-layer by depositing a photoresist and removing the desired pattern, then depositing the seed-layer and stripping away the rest of the photoresist leaving the desired pattern [61]. A major problem with this is that growth may still occur in the non-seed-layer areas. Although, photolithography is a possible technique, the equipment cost is expensive and there are limitations on the possible materials used [62].

E-beam lithography is similar to photolithography, except instead of exposing the material to light, a beam of electrons is used. E-beam lithography is a more precise technique than photolithography, being able to fabricate features as small as $5 \mathrm{~nm}$ [63]. Although, this 
technique is relatively slow as compared to photolithography [59]. Additionally, like photolithography, it is an expensive processing technique [64]. Kim et al. [65] utilized e-beam lithography to fabricate prepatterned holes, exposing a seed-layer, for growth of $\mathrm{ZnO}$ microrods, a hole size of $3 \mu \mathrm{m}$ produced microrods with a diameter of $3 \pm 0.21 \mu \mathrm{m}$. E-beam lithography can be used to fabricate highly uniform $\mathrm{ZnO}$ nanowire arrays with controllable pattern and size on crystalline substrates [66].

Ink-jet printing is a material-conserving type of direct writing technique, in which liquid material (ink) is deposited on a substrate via sequences of droplets [67]. Ink-jet printing can be broken up into two categories: continuous and drop-on-demand (DOD). Continuous ink-jet printing is when a continuous stream of ink droplets, selectively charged, flow through an electric field. This causes the charged droplets to be deflected into a gutter and allows the uncharged droplets to be deposited [68]. While, ink droplets are only ejected when used in imaging on the substrate for DOD ink-printing [69]. Both methods yield fluid droplets with diameters ranging from $10-150 \mu \mathrm{m}$. The printability of an ink is the reciprocal $(\mathrm{Z})$ of the Ohnesorge number as defined by Fromm [70]. Additionally, Reis and Derby [71] proposed that printable inks are in the range of $10>Z>1$. $Z$ values greater than 10 , the formation of satellite drops occur; while, $\mathrm{Z}$ values below 1, the ink is too viscous and will not eject.

DPN is a direct writing technique that involves dipping an atomic force microscope (AFM) tip in ink, writing material, and transferring the ink onto the substrate [72]. DPN is a technique that was developed by Mirkin and co-workers, in 1999, for transfer of 1octadecnethiol (ODT) on to gold surfaces $[73,74]$. A great advantage of DPN is that it is a single step process with a low risk of cross-contamination, which is likely to occur in a multi-step process [72]. Furthermore, DPN is able to fabricate sub-100 nm features, as small as $10 \mathrm{~nm}$, and 
is limited by the diameter of the DPN tip [75,76]. DPN is able to precisely deposit multiple inks in parallel or successively [76,77]. Finally, DPN is a scalable technique, which was proven by Salita et al. [78] by fabricating a 55,000 tip array with a spacing of $90 \mu \mathrm{m}$ by $20 \mu \mathrm{m}$, which was used to deposit approximately 88 million gold dots with a diameter of $100 \pm 20 \mathrm{~nm}$.

As mentioned before, DPN was originally developed for studying self-assembled monolayers (SAM), where ODT and 16-mercaptohexadecanoic acid (MHA) were deposited on Au surfaces [72,74]. Since then, various types of inks have been used for DPN. Su et al. [79] reported on the deposition on sol-based inks. Three model systems were used to demonstrate the deposition of sol-based inks: $\mathrm{Al}_{2} \mathrm{O}_{3}, \mathrm{SiO}_{2}$, and $\mathrm{SnO}_{2}$. Successful deposition of patterned solidstate materials was achieved with sub-200nm features. Fu et al. [80] demonstrated the deposition of barium hexaferrite $(\mathrm{BaFe})$ using DPN and a sol-gel based ink, as resolution to lithography and etching process of hard magnetic materials. Magnetic structures were fabricated on the scale of hundreds of nanometers down to $90 \mathrm{~nm}$. Gundiah et al. [81] reported on the deposition of $\mathrm{Fe}_{2} \mathrm{O}_{3}$ under ambient conditions with a writing speed of $\sim 1 \mu \mathrm{m} / \mathrm{s}$. The linewidths ranged from 140-200 $\mathrm{nm}$ and were $10 \mu \mathrm{m}$ in length. Also, high aspect ratio lines could be obtained, meaning a scanned area of $9000 \mathrm{~nm}$ by $230 \mathrm{~nm}$ produced a $9010 \mathrm{~nm}$ by $226 \mathrm{~nm}$ line. Bismuth ferrite $\left(\mathrm{BiFeO}_{3}\right)$ nanodots have been fabricated on $\mathrm{Nb}$-doped $\mathrm{SrTiO}_{3}$ substrate using a sol-based ink. Deposition times ranged from 0.1 to 10 s producing nanodots to have size increments of 30 to $180 \mathrm{~nm}$ [82]. Similarly, nanodots $\mathrm{PbTiO}_{3}$ (PTO) was deposited on $\mathrm{Nb}$-doped $\mathrm{SrTiO}_{3}$, which exhibited size increments of 37 to $200 \mathrm{~nm}$ for deposition times between 0.1- and 10s [83]. Son et al. [84] fabricated $\mathrm{ZnO}$ nanowires on a stepped sapphire to produce $30 \mathrm{~nm}$ diameter semicircular nanowires. 


\subsection{Piezoelectric Energy Harvesting and Sensing}

Over the past few years, piezoelectric energy harvesting and sensing devices have gained significant attention. A limiting factor in nanosystems is its power system, which have limited lifetime because of their size [85]. Furthermore, a key to developing fully self-powered systems is energy harvesting [86]. The recent advances in the ability for high piezoelectric response films open the possibility for a wide variety of applications [87]. Flexible nanogenerators can serve as pressure sensors for fluids and gases or as a heart-pulse monitor [1]. Piezoelectric films play a significant role in advancing sensing systems.

There are a few different types of energy harvesters/sensors, each with their own advantages and disadvantages. Roundy et. al. [88] explains there are three basic methods to harvest energy for wireless sensors from vibrations: piezoelectric, electro-magnetic, and electrostatic. When a piezoelectric material is mechanically strained, charge separation occurs within the material, which produces a voltage [88]. The electro-magnetic effect occurs when power produced by a magnet oscillating through a coil initiates a current in the coil. Electrostatic energy harvesting contains two conductors separated by a dielectric. As these conductors move relative to each other, they produce energy stored in a capacitor [88]. A table of the advantages and disadvantages of each mechanism is shown below. 
Table 3: Comparison of the relative merits of three primary types of energy harvesting mechanisms [88].

\begin{tabular}{lll}
\hline Mechanism & Advantages & Disadvantages \\
\hline Piezoelectric & $\begin{array}{l}\text { No voltage } \\
\text { source needed } \\
\text { Output voltage is } 3-8 \mathrm{~V} \\
\text { Easier to integrate } \\
\text { in microsystems }\end{array}$ & $\begin{array}{l}\text { More difficult to } \\
\text { integrate in microsystems }\end{array}$ \\
Electrostatic & $\begin{array}{l}\text { Separate voltage } \\
\text { source needed } \\
\text { Practical difficulties } \\
\text { Electro-magnetic }\end{array}$ & No voltage source needed voltage is \\
& & $\begin{array}{l}\text { Output } \\
0.1-0.2 \mathrm{~V}\end{array}$ \\
\hline
\end{tabular}

Common active layers for piezoelectric devices are barium titanate $\left(\mathrm{BaTiO}_{3}\right)$ [89], gallium nitride (GaN) [90], lead zirconate titanate (PZT) [91,92], poly(vinylidene fluoride) (PVDF) [93], and $\mathrm{ZnO}$ [17-21]. $\mathrm{ZnO}$ has a wide range of properties, as mentioned earlier, but it is also biologically safe, giving it an advantage over other piezoelectric materials [94]. Piezoelectric power generation can be in the form of either alternating current (AC) or direct current (DC), depending on the set-up, which is based on the direction of the force being applied to the material [95]. AC power is generated when a force applied normally to vertical nanowires (NWs), while DC power is produced by a force exerted normally to the axis of a NW [95].

Gao et al. [16] investigated the piezoelectric response of $\mathrm{ZnO}$ NWs on a polymer substrate using an atomic force microscope (AFM). The highest output voltage of a single NW was measured to be $45 \mathrm{mV}$. Xu et al. [17] demonstrated the ability of vertically aligned $\mathrm{ZnO}$ NWs as a nanogenerator to power a $\mathrm{pH}$ or UV sensor. Wang et al. [18] fabricated a thermal energy harvester based on $\mathrm{ZnO}$ NWs supported by a polymer matrix producing a maximum output of $\sim 10 \mathrm{mV}$. The devices could also be used for harvesting energy from mechanical, light, pressure, or fluids. Biomechanical energy, such as finger movement, can be harvested with a single $\mathrm{ZnO} \mathrm{NW}$ laterally on a polymer [19]. Additionally, placing four single NW devices in 
series produces an AC voltage of $\sim 0.1-0.15 \mathrm{~V}$. More recently, Lee et al. [20] developed a wearable nanogenerator with a $\mathrm{ZnO} \mathrm{NW}$ array supported by PVDF, which produced a $0.1 \mathrm{~V}$ from the bending of an elbow. Choi et al. [21] fabricated a $\mathrm{ZnO}$ based energy scavenger that can harvest energy from mechanical and solar energy simultaneously. The highest reported output voltage to date for a nanogenerator is $209 \mathrm{~V}$ [92].

Furthermore, piezoelectric active layers are used for a wide range of sensory applications, from biomedical to mechanical sensing. Kuoni et al. [24] fabricated a fluid flow pressure sensor utilizing a $\mathrm{ZnO}$ active layer on polyimide (PI). The sensor was able to accurately measure stroke volumes in the range of $\mathrm{nL}$ and sub-nL. Chang et al. [25] used lateral $\mathrm{ZnO} \mathrm{NWs}$ on $\mathrm{Ga} / \mathrm{Glass}$ and $\mathrm{Ga} / \mathrm{Si}_{3} \mathrm{~N}_{4} / \mathrm{SiO}_{2} / \mathrm{Si}$ for a vacuum pressure sensor. Findings included that as the chamber pressure increased, the resistances increased logarithmically. Erol et al. [96] fabricated a relative humidity sensor based on $\mathrm{ZnO}$ using a sol-gel process, showing high sensitive to changes in humidity. Wang et al. [97] built a field effect transistor from a single $\mathrm{ZnO}$ NW with two Ohmic contacts, which was applied as a force sensor with the capability of measuring forces in the nanonewton range. Tseng and Naidu [98] investigated the use of a piezoelectric transducer for detecting damage in structures, showing great promise in monitoring and less expensive alternative to current techniques.

An ever developing technology today is tactile (touch) sensing. Which, Lee and Nicholls [99] explain is the key to furthering the development of mechatronic devices and measuring instruments. Murat Koc and Akca [100] designed a tactile sensor to mimic the tactile sensing of a gecko, spider, and other insects. To increase the spatial resolution and flexibility, they used poly(dimethylsiloxane) (PDMS) pillars and a PVDF film. Finite analysis calculated a spatial resolution of $60 \mu \mathrm{m}$, a human hand has a spatial resolution of $40 \mu \mathrm{m}$. Krishna and Rajanna [101] 
fabricated a tactile sensor with PZT deposited on varying amounts of base electrode arrays. Showing improved spatial resolution with larger arrays of electrodes.

\section{Experimental Methods}

\subsection{Material Fabrication}

\subsubsection{Sol-gel}

$\mathrm{ZnO}$ films were fabricated using the sol-gel process. A flow chart of the film preparation is shown in Figure 3. Zinc acetate dihydrate $\left(\mathrm{Zn}\left(\mathrm{CH}_{3} \mathrm{OO}\right)_{2} \cdot 2 \mathrm{H}_{2} \mathrm{O}\right)$ was dissolved in a solution of isopropanol (IPA) and monoethanolamine (MEA) at room temperature. The molar ratio of MEA to zinc acetate was held at a 1:1 ratio and the concentration of zinc acetate was equal to $0.25-$ $1.0 \mathrm{~mol} \mathrm{~L} \mathrm{~L}^{-1}$. The mixture was then stirred at $60^{\circ} \mathrm{C}$ for 2 hours to yield a clear homogenous solution. The solution was then syringe-filtered using a Fisherbrand $0.45 \mu \mathrm{m}$ polytetrafluoroethylene filter. Gel films were deposited on the substrate by dip coating of sodalime glass microscope slides of area equal to $75 \times 25 \mathrm{~mm}$. The withdrawal rate was $50 \mathrm{~mm} / \mathrm{min}$. In order to get the desired film thicknesses of $1 \mu \mathrm{m}$, a number of dips were performed. After each dip the films were pre-heated at a temperature of $250^{\circ} \mathrm{C}$ to $275^{\circ} \mathrm{C}$ for 10 minutes, and they were post-heated at $500^{\circ} \mathrm{C}$ for 1 hour. The heat treatments were conducted by placing the samples in an electric furnace at the respective temperatures. 


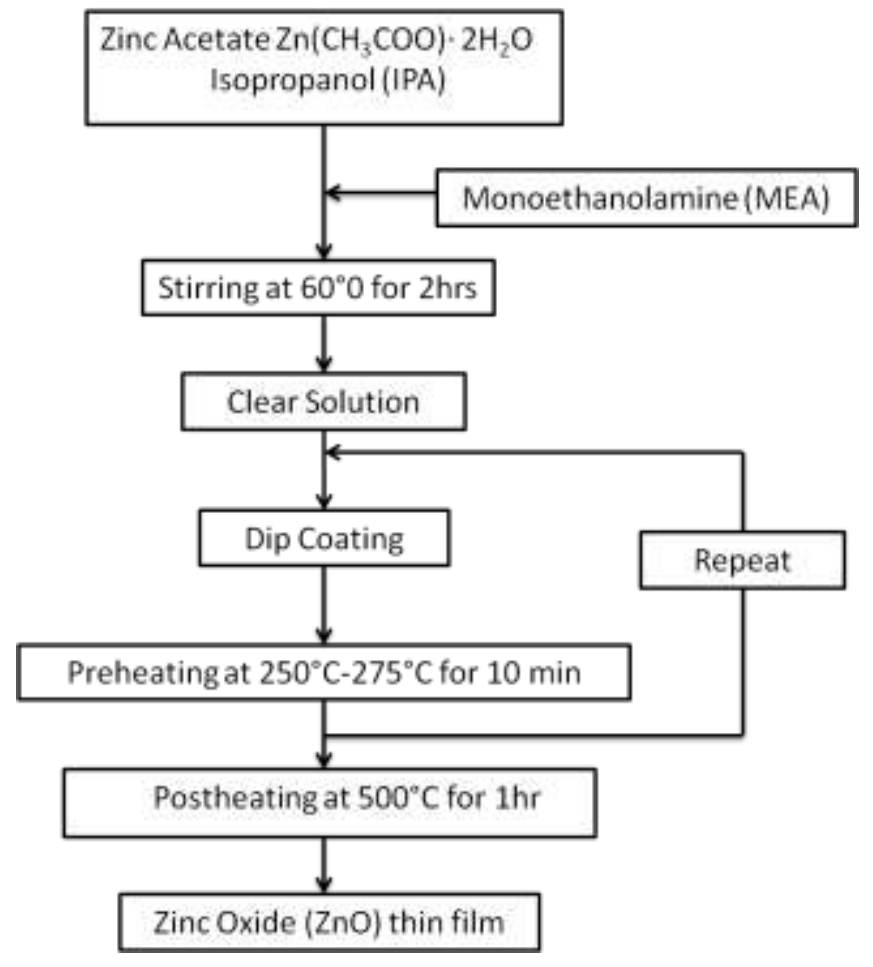

Figure 3: Flowchart showing the process for fabricating $\mathrm{ZnO}$ thin films.

\subsubsection{Hydrothermal Growth}

$\mathrm{ZnO}$ structures were grown through a hydrothermal process on various substrates. First, the substrates are cleaned by placing in acetone, IPA, and finally distilled water, then dried using a hot plate set to $100^{\circ} \mathrm{C}$. A $\mathrm{ZnO}$-seed-layer was deposited by spin coating the zinc acetate dihydrate solution $\left(0.75 \mathrm{~mol} \mathrm{~L}^{-1}\right)$ mentioned before. The solution was spun at $1000 \mathrm{RPM}$ for 60 s. Next, the seed solution coated substrate was dried on a hot plate at $100^{\circ} \mathrm{C}-150^{\circ} \mathrm{C}$ for 10 minutes, depending on the substrate. Then, a nutrient solution of zinc nitrate hexahydrate $\left(\mathrm{Zn}\left(\mathrm{NO}_{3}\right)_{2} * 6 \mathrm{H}_{2} \mathrm{O}\right)$, hexamethylenetetramine (HTMA; $\left.\mathrm{C}_{6} \mathrm{H}_{12} \mathrm{~N}_{4}\right)$, and distilled water were mixed together in a $235 \mathrm{~mL}$ mason jar (Ball, Daleville, IN) with a screw lid. The molar ratio of zinc nitrate and HTMA was held at 1:1. The molar concentration of the solution was varied from 0.01 to $0.025 \mathrm{~mol} \mathrm{~L}^{-1}$. The substrates were placed upside-down on top of the nutrient solution; all substrates used could float on top of the surface of the nutrient solution. The mason jar was 
then placed in an oven at $70^{\circ} \mathrm{C}-95^{\circ} \mathrm{C}$ for 24 to 48 hours. After the growth process the sample was thoroughly washed in distilled water and dried on a hot plate at $100^{\circ} \mathrm{C}-120^{\circ} \mathrm{C}$ for 5 minutes.

Preliminary devices were fabricated by growing $\mathrm{ZnO}$ nanostructures on gold or chromium coated substrates, which acted as the bottom electrode. A small section of the coated substrate was covered with scotch tape to prevent growth; this section is where the voltmeter will be connected. Once the growth process, as explained above, is complete, poly(methyl methacrylate) (PMMA) is spin coated onto the surface of the NWs. The PMMA is then oxygen plasma etched until the tips of the ZnO NWs are exposed. Finally, a chromium coated piece of polyethylene naphthalate $(\mathrm{PEN})$ is placed on top to complete the device, which can be seen in Figure 4.

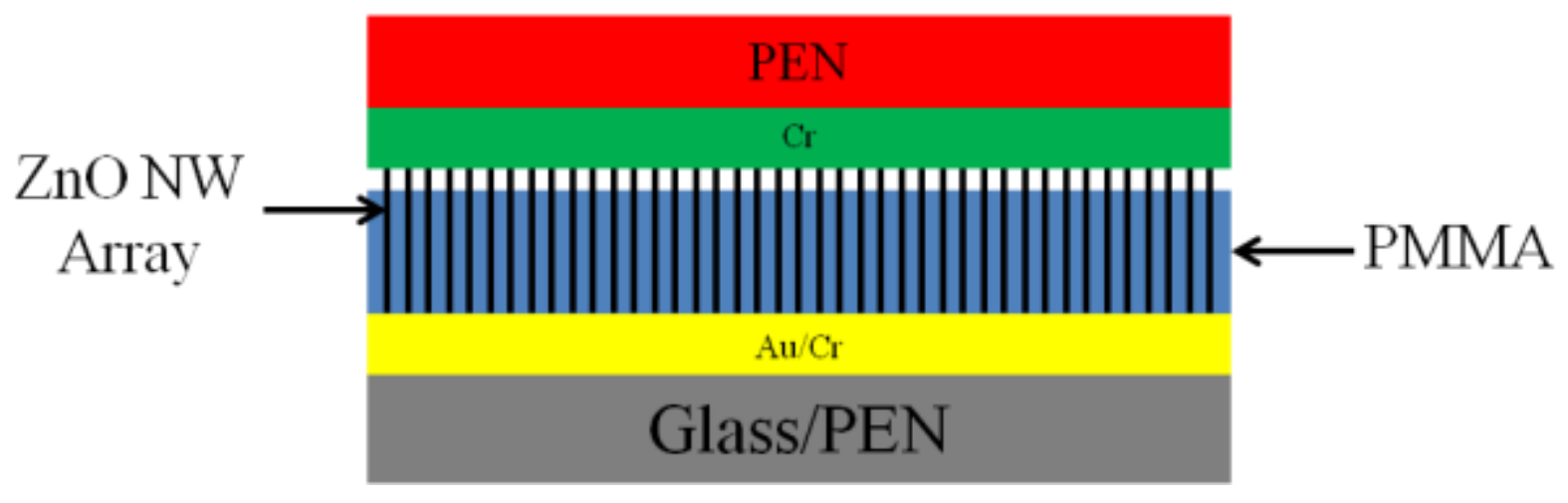

Figure 4: ZnO nanowire-based device.

\subsubsection{Dip Pen Nanolithography}

The fabrication process of $\mathrm{ZnO}$ microdots on a rigid substrate to a flexible substrate is illustrated in Figure 5. First, an aqueous solution of 3\% wt. polyvinylpyrrolidone (PVP, Molecular Weight=8,000) was fabricated by slowly adding PVP to deionized water, while continuously stirring with a magnetic stir bar. To ensure that the PVP fully dissolved, the 
solution was left overnight under continuous stirring at room temperature. Then, the 3\% PVP aqueous solution was deposited by dip coating onto soda-lime glass microscope slides with an area equal to $75 \times 25 \mathrm{~mm}$. The withdrawal rate was $200 \mathrm{~mm} / \mathrm{min}$. The glass slides were then fired at $300^{\circ} \mathrm{C}$ for $1 \mathrm{hr}$, with a heating rate of $3^{\circ} \mathrm{C} / \mathrm{min}$. Once cooled, the glass slides were cut into 3 equal sized squares of $25 \times 25 \mathrm{~mm}$.

The patterns of $\mathrm{ZnO}$ microdots were prepared on the release layer by dip-pen nanolithography. $\mathrm{ZnO}$ inks were prepared from the same solution as mentioned in the sol-gel section $\left(0.75 \mathrm{~mol} \mathrm{~L}^{-1}\right)$ and glycerol $(99.5 \%)$ was added as a thickening agent. The sol-gel and glycerol mixture was sonicated for 15 minutes to ensure complete mixing. Various amounts of glycerol were added to the sol to find the optimum writing ink. DPN experiments were performed under ambient conditions by employing an NLP 2000 system (Nanoink Inc., Chicago, IL). The system was equipped with Type M pens using the A-frame cantilever side with a spring constant $\mathrm{k}=35 \mathrm{~N} / \mathrm{m}$. The tip on each cantilever has a nominal radius of $15 \mathrm{~nm}$. A micropipette was used to fill the 12 ink reservoirs of the inkwell chip with $\sim 0.1 \mu \mathrm{L}$ for each reservoir. To control the size of the microdots, dwell times of $5 \mathrm{~s}, 10 \mathrm{~s}$, and $15 \mathrm{~s}$ were used. The dots were then heated to $500^{\circ} \mathrm{C}$ at a rate of $1^{\circ} \mathrm{C} / \mathrm{min}$ and held for $1 \mathrm{hr}$. Finally, the prepared $\mathrm{ZnO}$ microdots are transferred onto a polymer substrate using a similar technique to Kozuka et al. [102,103]. The fired $\mathrm{ZnO}$ microdots on the release layer were prepared in a multi-stack, which can be seen in Figure 6. The multi-stack was then placed in a hot press (PHI, City of Industry, CA), with the temperature set to $170^{\circ} \mathrm{C}$, the softening point of PEN. Heating the polymer substrate to its softening point allows the surface of the polymer to act as an adhesive [103]. Then, the multilayer stack was then placed in the hot press and a pressure of $8 \mathrm{MPa}$ was applied for 15 minutes. Once the 15 minutes were up the multi-stack was taken out of the hot press and cooled 
at room-temperature before disassembling the multi-stack. Finally, the polymer substrate was removed from the rigid substrate.

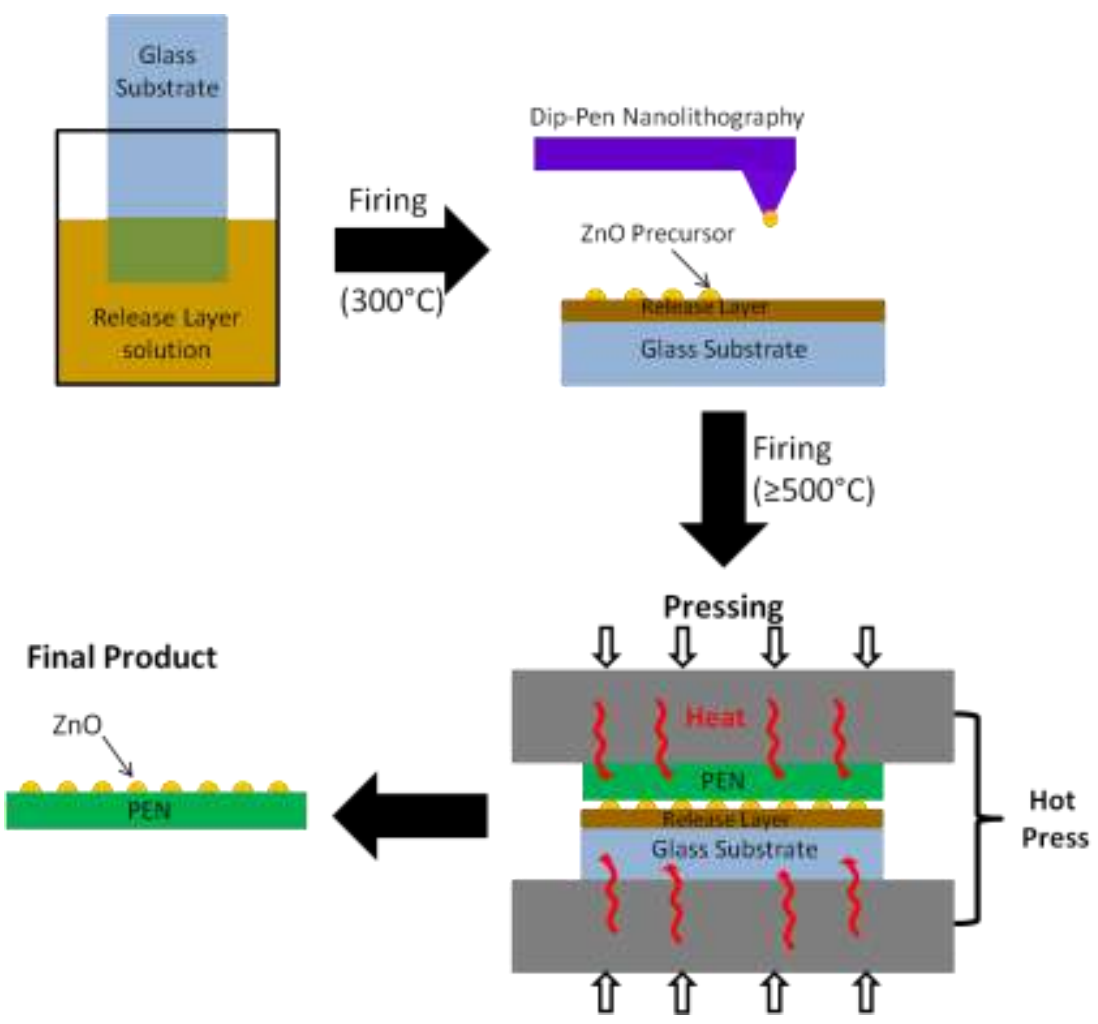

Figure 5: Fabrication process of $\mathrm{ZnO}$ microdot arrays.

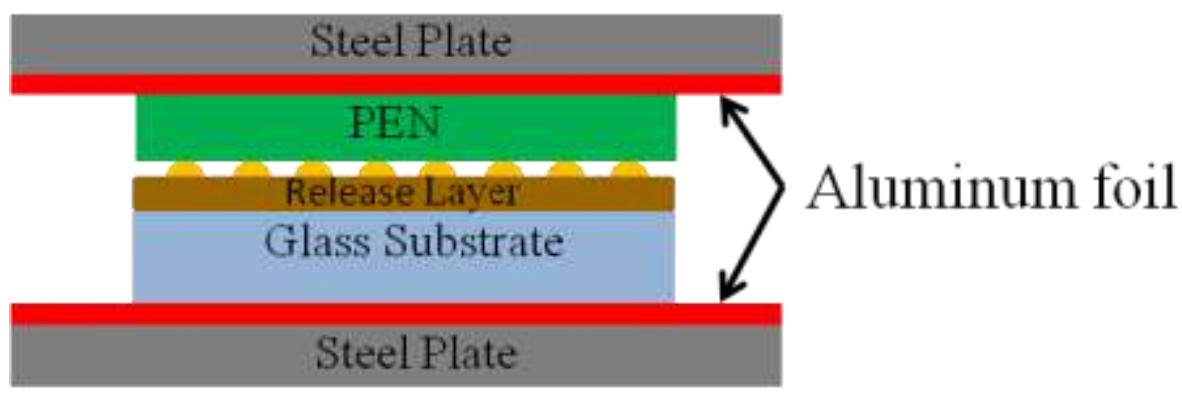

Figure 6: Multilayer stack $\mathrm{ZnO}$ microdots ready for transfer.

In addition to using $\mathrm{ZnO}$, a more complex chemistry of cerium doped yttrium aluminum garnet (YAG:Ce) was attempted. A phosphor was chosen as a model system since such materials usually consist of relatively complex chemistries, where the materials synthesis 
requires high temperature and/or pressure. In order to synthesize the YAG:Ce sols, a similar process to the one reported previously by Garskaite et al. [103] was followed. The same process was then followed with a few exceptions. An aqueous solution of $3 \%$ polyvinyl alcohol (PVA, Celvol 513) was added to the YAG:Ce sol as a wetting and thickening agent. Weight ratio of YAG:Ce sol to PVA solution was 3:2, 1:1, 2:3, and 1:2 to find the optimum solution for writing. Once the solutions were fabricated, the same process for the $\mathrm{ZnO}$ microdots was followed, expect writing occurred under ambient temperature and $90 \%$ relative humidity.

\subsection{Experimental Techniques}

\subsubsection{Optical Transmission}

The optical transmission of the films fabricated was measured using an Ocean Optics Jaz Spectrometer (JAZ-COMBO) with a Tungsten Halogen light source over a wavelength range of 200 to $850 \mathrm{~nm}$. Only the visible light spectrum will be focused on for the films.

\subsubsection{Stylus Profilometry}

A Veeco Dektak 150 stylus profilometer (Bruker AXS, Tucson, AZ) was used to measure the film thickness. The Dektak 150 stylus used had a $12.5 \mu \mathrm{m}$ radius tip with a nominal applied normal force of $0.05 \mathrm{mN}$. The film thickness was measured by by etching away a small area of the film with a $6 \%$ aqueous solution of hydrochloric $(\mathrm{HCl})$ acid for 5 minutes to 15 minutes, depending on film thickness. The films were then rinsed in deionized water for 5 minutes to stop the etching process. The films where then dried at room temperature. Once dry multiple scans were run across the etched area of the samples 


\subsubsection{Indentation}

Mechanical properties, elastic modulus and hardness, of the sol-gel films were measured using indentation. Nanoindentation was performed using a Nano-Indentation Tester $\left(\mathrm{NHT}^{2}\right)$ by CSM Instruments and experiments were conducted using a Berkovich diamond tip and a $10 \mu \mathrm{m}$ radius spherical diamond tip. The force used to indent was dependent on the film thickness, as it is suggested that the maximum penetration depth is no more than $10 \%$ of the film thickness. Additionally, experiments were conducted using the ASTM standard of 30 seconds for loading/unloading.

Microindentation was performed with a Leco M-400-G by Newage Testing Instruments with a load range of $10 \mathrm{~g}$ to $1 \mathrm{~kg}$. The instrument was equipped with a Vickers diamond tip. A thin $5 \mathrm{~mm}$ by $5 \mathrm{~mm}$ stainless steel plate was placed on top of the device as to apply a pressure over a larger area of the nanorods. The microindenter was utilized for applying a known force to the preliminary $\mathrm{ZnO}$ nanorod devices to correlate the output voltage with the pressure applied. The microindenter utilizes a loading/unloading rate of 5 seconds.

\subsubsection{Contact Angle Goniometry}

The hydrophobicity of sol-gel deposited films was analyzed before and after UV irradiation. This hydrophobicity was quantified using a lab-built sessile drop contact angle goniometer [105]. Five droplets approximately $2-\mu \mathrm{L}$ of deionized water were placed over a macroscopic area of the films approximately 1-2 mm apart using an automatic microsyringe

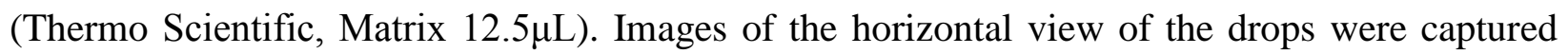
using a digital microscope and analyzed using the image analysis program ImageJ with the "Drop Shape Analysis" plugin, the low-bond axisymmetric drop shape analysis (L-BADSA) method. 


\subsubsection{Atomic Force Microscopy}

Atomic force microscopy (AFM) provided high resolution surface and friction mapping for the $\mathrm{ZnO}$ films before and after UV. AFM was performed using a Molecular Imaging PicoScan 3000 system in contact mode with silicon tips (CSC37B, MikroMasch) on cantilevers with force constant $\mathrm{k}=0.3 \mathrm{~N} / \mathrm{m}$ and radius of curvature less than $10 \mathrm{~nm}$.

\subsubsection{X-ray Diffraction}

A films' crystal structure was investigated using X-ray Diffraction (XRD). XRD was performed using a Bruker D8 Discover with $\mathrm{Cu} \mathrm{K} \alpha$ radiation and a $2 \theta$ scan from $30^{\circ}$ to $60^{\circ}$.

\subsubsection{Linear Reciprocating Wear Tester}

Macro-tribological experiments were performed using a custom-built reciprocating wear tester, a modified form of a previously mentioned device [106]. Samples were placed on a custom-built holder to avoid clamping complications. The counter-surface used was a stainless steel cylinder, with dimensions of $15.9 \mathrm{~mm}$ in diameter and $25 \mathrm{~mm}$ in length. The cylinder performed a mixed rolling-sliding motion in a reciprocating fashion along the sample's surface. The reciprocating length was equal to $35 \mathrm{~mm}$. Stainless steel was used because of its moderate coefficient of friction and its structural rigidity. A constant, relatively moderate, load $F$ equal to $2.5 \mathrm{~N}$ was applied normally to the reciprocating direction. The samples were tested in increments of reciprocating cycles until the coating was totally removed. The rolling frequency was set equal to $0.5 \mathrm{~Hz}$ for all tests. In addition, tests were performed on samples both exposed and non-exposed to UV light. The electrical output of the piezoelectric devices was monitored in-situ as shown in Figure 7 below. 


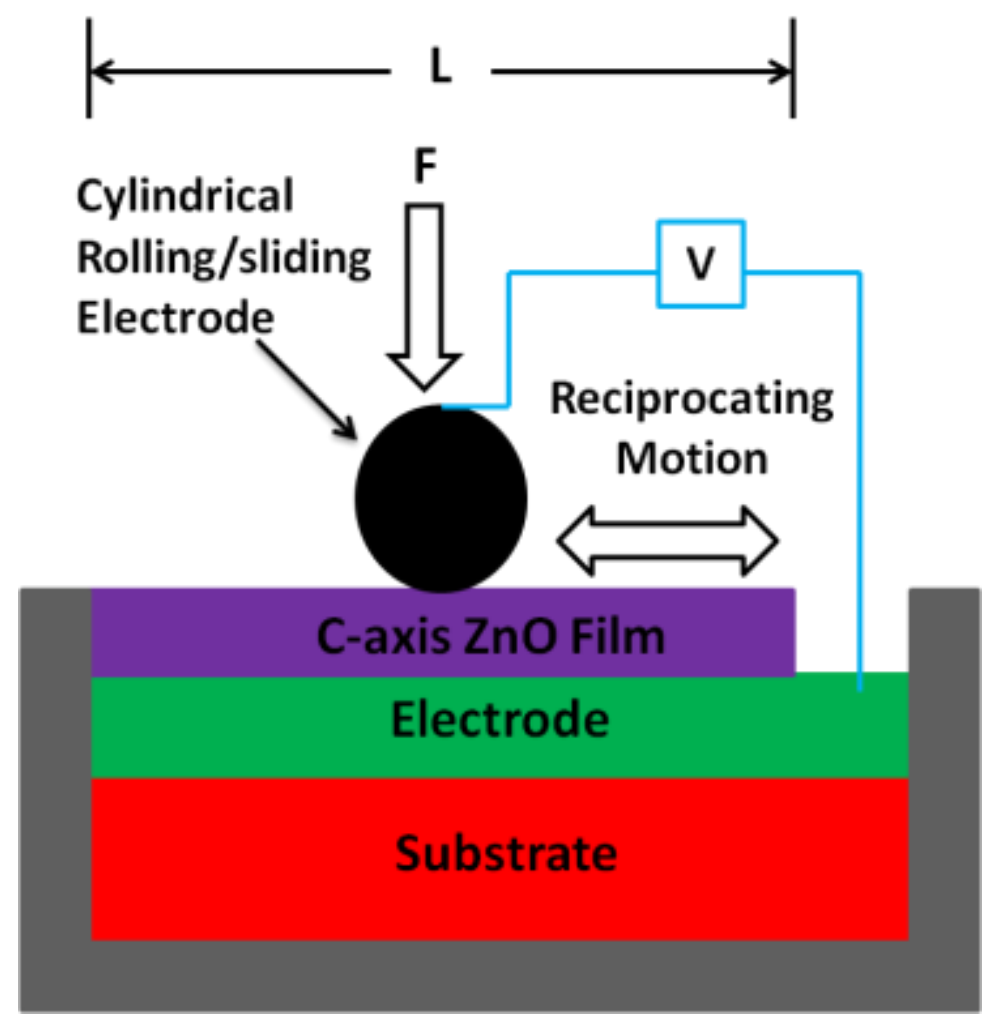

Figure 7: Schematic of custom-built reciprocating rolling-contact experimental apparatus with in-situ electrical monitoring.

In order to quantify the wear rate of the films, as well as transfer, weight measurements were conducted before and after each test for both the top and bottom surfaces using a high sensitivity digital balance (DV215CD, Ohaus, 0.01 $\pm 0.02 \mathrm{mg}$ ). After testing and before weighing, the samples were washed in acetone, IPA, and finally distilled water, then dried using a hot plate set to $120^{\circ} \mathrm{C}$.

For the preliminary nanogenerating devices created electrical contacts were place on the electrode and cylindrical electrode for in situ voltage monitoring. The voltage generated by the sample was recorded using an Agilent 349708 data acquisition/switch unit. 


\subsubsection{Viscometry}

A Brookerfield DV - II+ Pro viscometer equipped with a CPE - 40 spindle, with a radius of $2.4 \mathrm{~cm}$, was used to measure the viscosity of the inks utilized for DPN. Measurements were taken at rotational rates of 20 to 200 RPMs.

\subsubsection{Optical Microscopy}

Optical images where taken with two different optical microscopes: a Leica optical microscope equipped with a frame grabber (Guppy, Allied Visions Technology) and the optical microscope equipped on the NLP 2000 system. The Leica optical microscope was used to take optical images of both the worn sol-gel processed $\mathrm{ZnO}$ films and counterface surfaces used for tribological studies. The NLP 2000 system optical microscope was used to take images of the wet, fired, and transferred microdots. Furthermore, the images of the microdots were analyzed using ImageJ to measure the radius of dots.

\subsubsection{Scanning Electron Microscopy}

A JEOL (JSM-7600F) Scanning Electron Microscope (SEM) was used to take images of the $\mathrm{ZnO}$ nanostructures to analyze diameter and density. Additionally, the SEM was utilized to take high magnification images of $\mathrm{ZnO}$ and $\mathrm{YAG}$ dots after transfer.

\section{Results and Discussion}

\subsection{Dip-Coated ZnO sol-gel Films}

Table 4 displays the measured film thicknesses for the samples fabricated. It is observed that with higher concentrations of $\mathrm{Zn}$, the thicker the films are with each dip. Additionally, lower concentrations have more uniform thicknesses per dip. 
Table 4: Sol-gel deposited $\mathrm{ZnO}$ film thickness measurements

\begin{tabular}{|c|c|c|c|c|c|c|c|c|c|c|c|c|}
\hline $\begin{array}{c}\text { Solution } \\
\begin{array}{c}\text { Concentration } \\
\left(\mathrm{mol} \mathrm{L}^{-1}\right)\end{array}\end{array}$ & \multicolumn{3}{|c|}{0.25} & \multicolumn{3}{c|}{0.5} & \multicolumn{3}{c|}{0.75} & \multicolumn{3}{c|}{1.0} \\
\hline $\begin{array}{c}\text { Number } \\
\text { of Dips }\end{array}$ & 3 & 6 & 9 & 3 & 6 & 9 & 3 & 6 & 9 & 3 & 6 & 9 \\
\hline $\begin{array}{c}\text { Thickness } \\
(\mathrm{nm})\end{array}$ & $\sim 21$ & $\sim 40$ & $\sim 60$ & $\sim 120$ & $\sim 240$ & $\sim 360$ & $\sim 140$ & $\sim 270$ & $\sim 400$ & $\sim 215$ & $\sim 500$ & $\sim 600$ \\
\hline $\begin{array}{c}\text { Thickness per } \\
\text { Dip (nm) }\end{array}$ & $\sim 7$ & $\sim 6.6$ & $\sim 6.6$ & $\sim 40$ & $\sim 40$ & $\sim 40$ & $\sim 45$ & $\sim 45$ & $\sim 45$ & $\sim 72$ & $\sim 80$ & $\sim 66$ \\
\hline
\end{tabular}

The optical transmission measurements of $\mathrm{ZnO}$ films with different solution concentrations and thicknesses can be seen in Figures 8 and 9. All the measurements were taken with respect to the substrate; a background graph of a clean substrate is included in each graph. The films were pre-heated at a temperature of $275^{\circ} \mathrm{C}$ and post-heated at a temperature of $500^{\circ} \mathrm{C}$. It can be seen that the optical transmission is dependent on the thickness of the film, showing the thicker the film the lower the optical transmission. In addition, higher concentrations of $\mathrm{Zn}$ the exhibited decreases in optical transmission, but this can be attributed to the larger thicknesses since the higher $\mathrm{Zn}$ concentration solution form thicker films. 

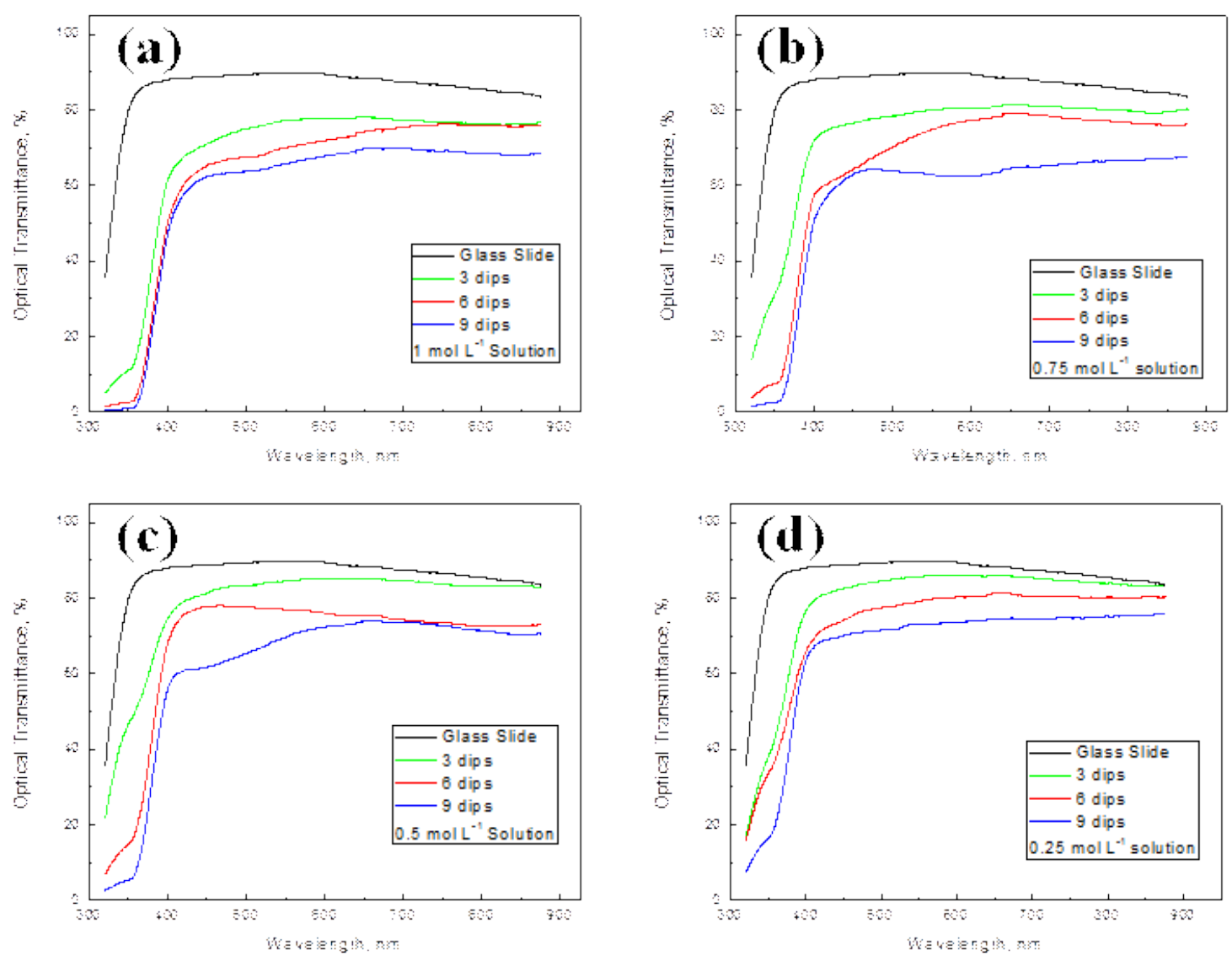

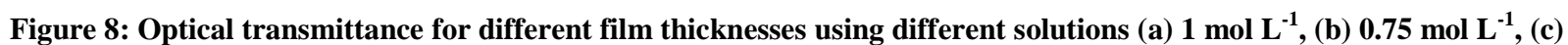
$0.5 \mathrm{~mol} \mathrm{~L}^{-1}$, (d) $0.25 \mathrm{~mol} \mathrm{~L}^{-1}$ 

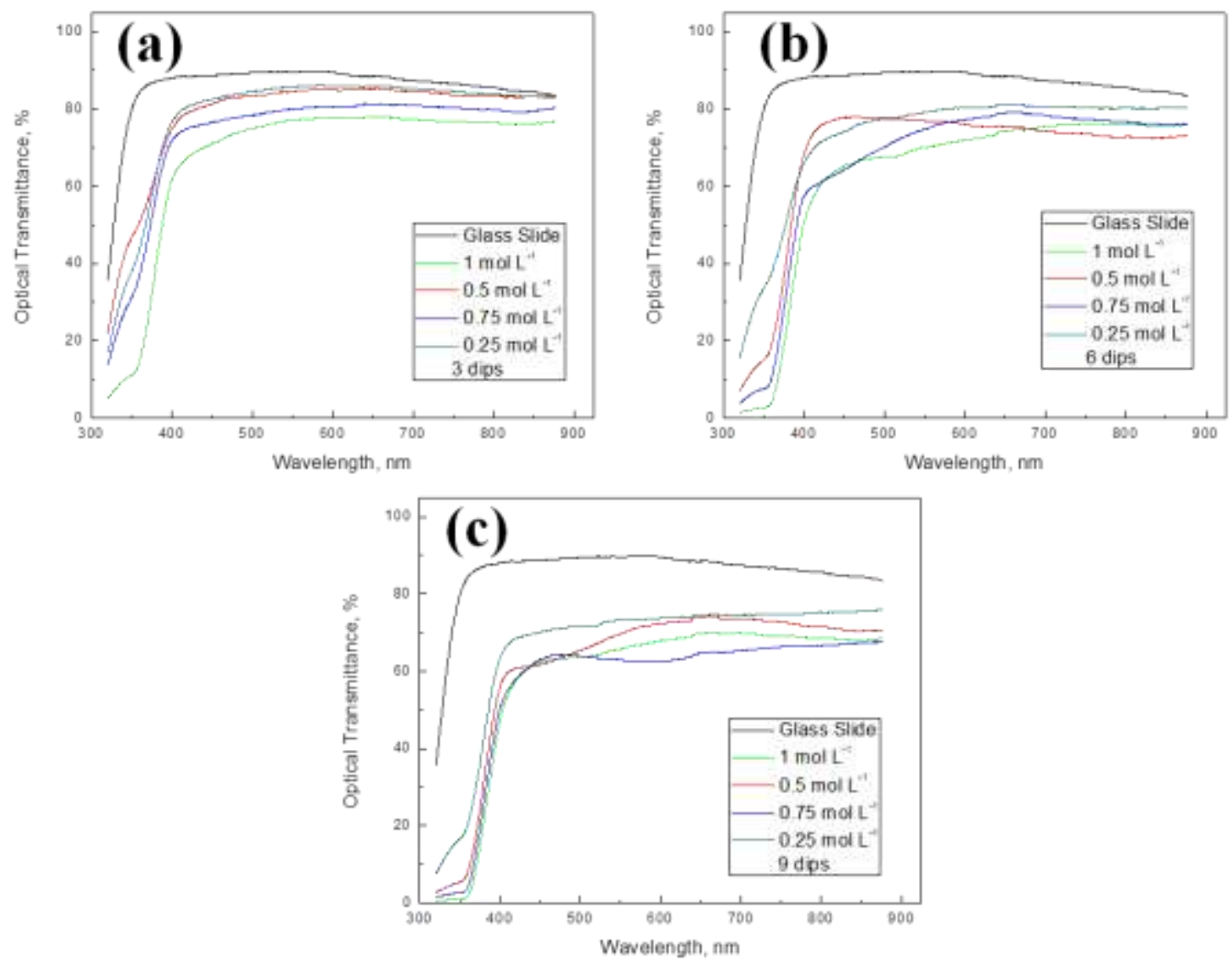

Figure 9: Optical transmittance for different solution concentrations using multiple depositions (a) 3, (b) 6, (c) 9

Figure 10 shows comparison XRD spectrums for sol-gel deposited $\mathrm{ZnO}$ films with varying solution concentrations of $\mathrm{Zn}$. All films were dipped 9 times, preheated at $275^{\circ} \mathrm{C}$ and post-heated at $500^{\circ} \mathrm{C}$. It is observed that all films exhibit a c-axis (002) orientation, which is known to indicate piezoelectric film properties [14]. It is noticed that the $0.75 \mathrm{~mol} \mathrm{~L}^{-1}$ solution demonstrated the strongest c-axis (002) orientation. 


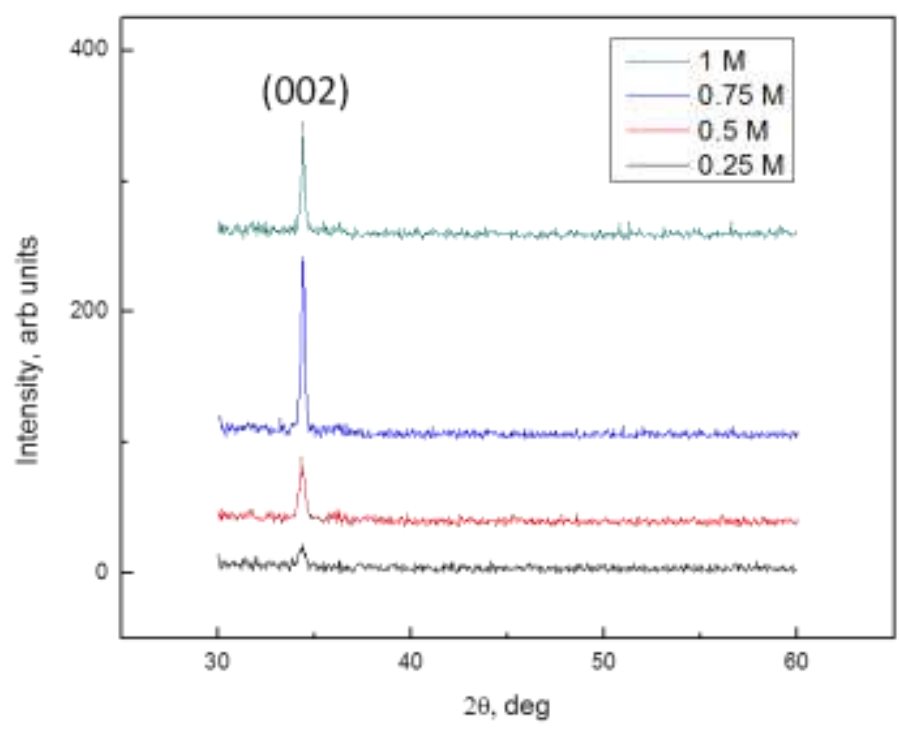

Figure 10: X-ray diffraction pattern of a $2 \theta$ scan for sol-gel deposited $\mathrm{ZnO}$ films using zinc acetate dehydrate solution. For different samples dipped 9 times.

Additionally, the effect of preheating temperature on the films was investigated utilizing XRD. Spectrums of films preheated at $250^{\circ} \mathrm{C}$ and $275^{\circ} \mathrm{C}$ are shown in Figure 11. Both films were post-heated at $500^{\circ} \mathrm{C}$ for $1 \mathrm{hr}$ and the solution concentration was held at $1.0 \mathrm{~mol} \mathrm{~L}^{-1}$. The preheating temperature of $275^{\circ} \mathrm{C}$ exhibits a stronger c-axis orientation. In addition, it is observed that the film preheated at $250^{\circ} \mathrm{C}$ demonstrates small diffraction peaks that correspond to (100) and (101). 


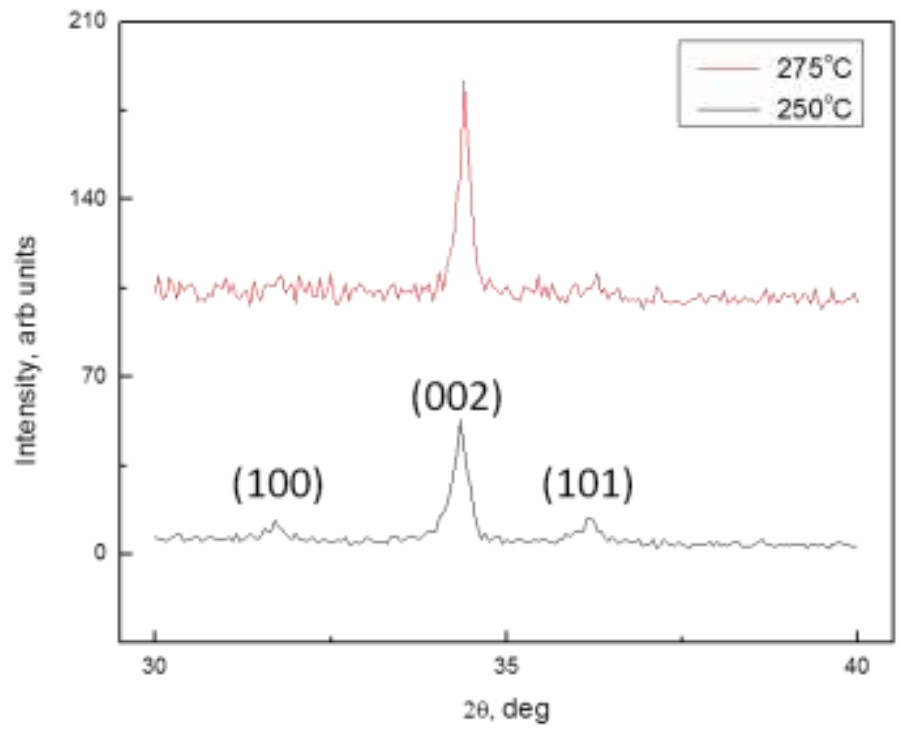

Figure 11: X-ray diffraction pattern of a $2 \theta$ scan for sol-gel deposited $\mathrm{ZnO}$ films for different preheating temperatures. Furthermore, nanoindentation experiments were performed in order to assess the mechanical properties of the sol-gel derived $\mathrm{ZnO}$ films by measuring their hardness and elastic modulus. To ensure that there was no substrate effect, the maximum penetration depth was limited to less than $10 \%$ of the film thickness. For this reason, a spherical indenter was utilized as the samples were too thin for a Berkovich tip. A maximum load of $1 \mathrm{mN}$ was found to be sufficient for obtaining reliable measurements and penetrating less than $10 \%$ of the film thickness. All indents were performed with a linear loading/unloading rate of $30 \mathrm{~s}$ and a $10 \mathrm{~s}$ pause. A matrix of indents was performed across various sections of the samples. Only the 9 dip samples were utilized for indentation measurements, as the other samples were too thin to indent without obatining substrate affects. Furthermore, the $0.25 \mathrm{~mol} \mathrm{~L}^{-1}$ was too thin to acquire proper data. The elastic modulus for the $0.5,0.75$, and $1.0 \mathrm{~mol} \mathrm{~L}^{-1}$ was measured to be $71.686 \pm 2.040$ $\mathrm{GPa}, 71.456 \pm 2.194 \mathrm{GPa}$, and 70.223 \pm 3.263 respectively. Additionally, the measured hardness is shown in Figure 12. It is observed that there is litte deviation between solution concentrations 
for hardness and elastic modulus measurements, showing the $\mathrm{Zn}$ concentration has little effect on the elastic modulus. Representive indentation curves are shown in Figure 13.

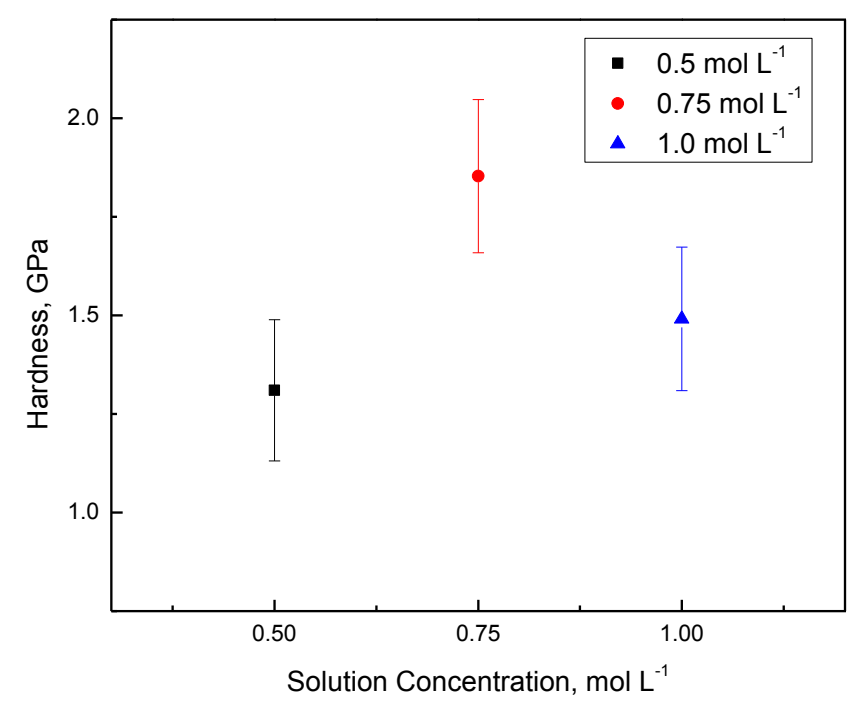

Figure 12: Measured hardness for various $\mathrm{Zn}$ concentrations. 

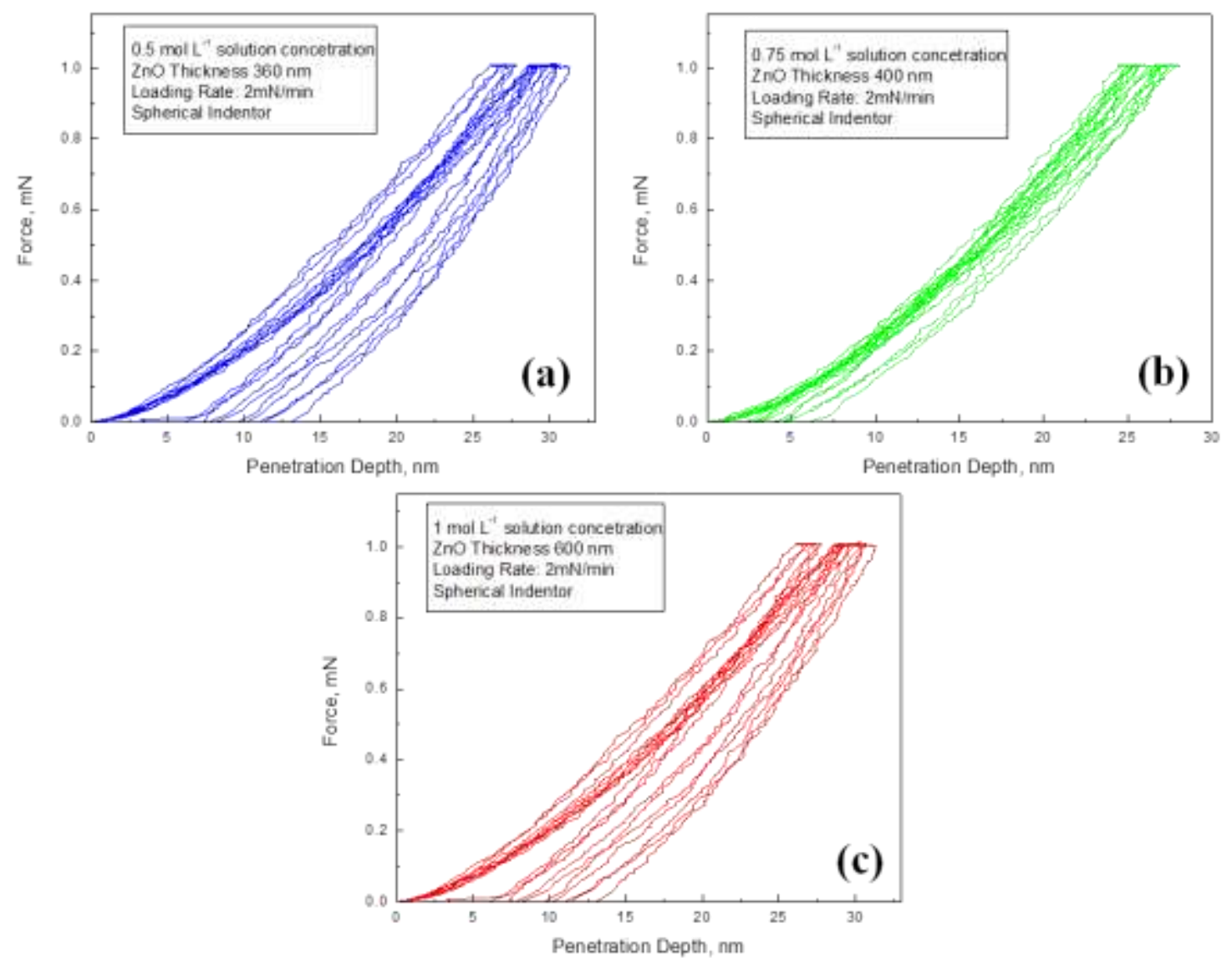

Figure 13: Load versus penetration depth for different solution concentration films (a) $0.5 \mathrm{~mol} \mathrm{~L}^{-1}$, (b) $0.75 \mathrm{~mol} \mathrm{~L}^{-1}$, (c) 1.0 mol L $\mathbf{L}^{-1}$

\section{2 ZnO-based Tribo-device}

$\mathrm{A} \mathrm{ZnO}$ based piezoelectric device was fabricated by following the sol-gel procedure to deposit a $1 \mu \mathrm{m}$ thick film onto a gold-coated glass slide. A $1.0 \mathrm{~mol} \mathrm{~L}^{-1}$ solution was used with a preheating temperature of $250^{\circ} \mathrm{C}$ and post-heating temperature of $500^{\circ} \mathrm{C}$, for the preliminary device. In Figure 14, a graph of the contact angle measurements at different UV exposure times is shown for the $1 \mu \mathrm{m}$ thick film. It is observed that as the exposure time increases, the $\mathrm{ZnO}$ films become more hydrophilic, and thus exhibit increased adhesion. This is an indirect method to control the frictional response of the $\mathrm{ZnO}$ surfaces. It can be expected that an increasing 
coefficient of friction with increasing exposure time is due to the increased adhesion component, which defines friction as a physical phenomenon. In this case, higher interatomic forces may be observed between the tribological pair. Such forces may also be expected to lead to increased frictional heating and thus friction-induced energy losses of the tribological system.

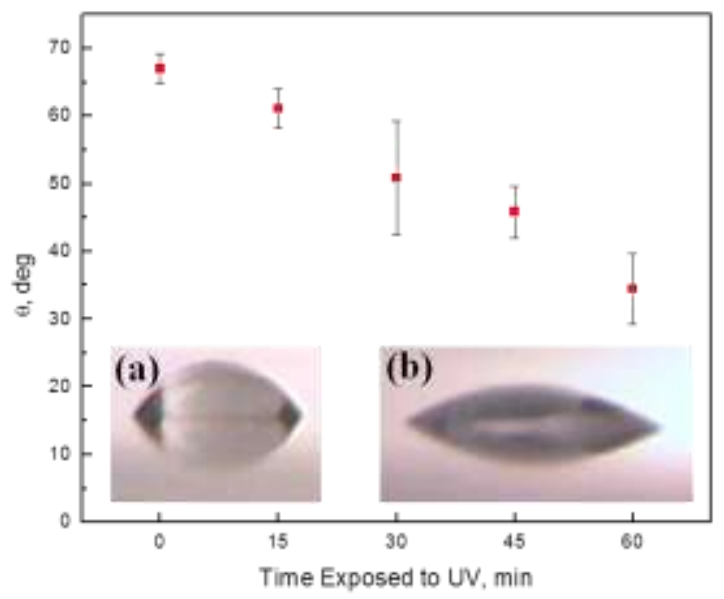

Figure 14: Contact angle values for $\mathrm{ZnO}$ versus different UV exposure times, inset (a) Water droplet on a non-UV exposed ZnO surface, inset (b) Water droplet on a 60 minute $\mathrm{UV}$ exposed $\mathrm{ZnO}$ surface

Atomic force microscopy Si 'single asperity' measurements, Figure 15, were performed on non-UV and 60 minute UV-exposed surfaces to obtain additional information about the $\mathrm{ZnO}$ frictional behavior. As shown in Figure 15b, a friction map of the UV exposed surface indicates higher friction on and around the high surface asperity peaks, whereas the valley regions are observed to exhibit lower frictional behavior. This result may be attributed to the elasto-plastic junctions formed between the Si counter-face nanoasperities and the $\mathrm{ZnO}$ surface asperity peaks. Asperity interlocking may also contribute to the increased frictional response of such areas. 

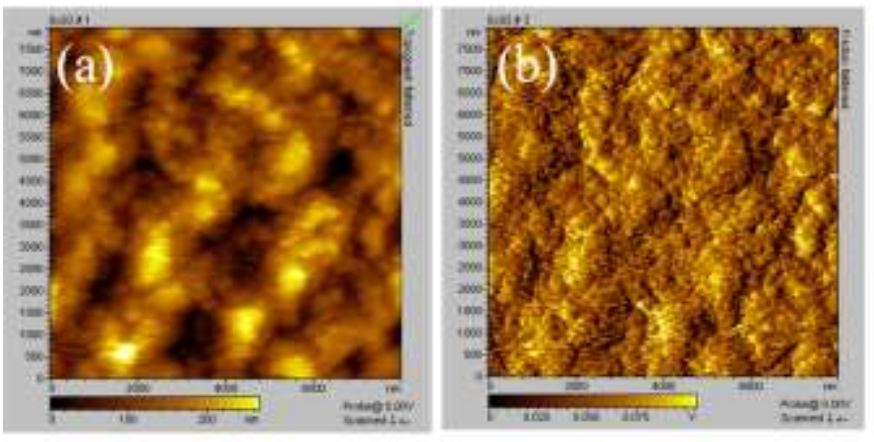

(c)

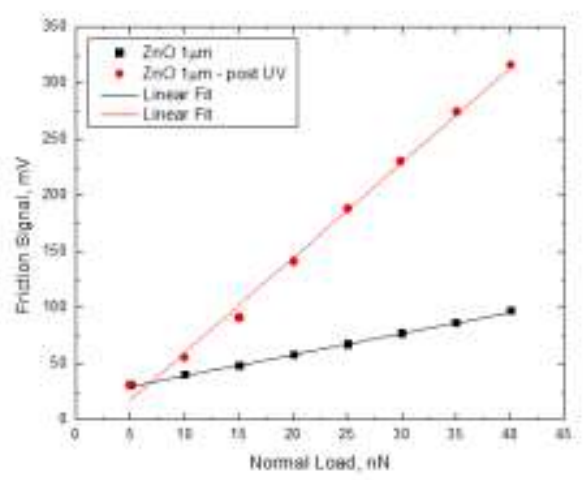

Figure 15: (a) AFM topographical and (b) friction map images of UV exposed ZnO surface for 60 minutes. (c) Friction signal versus applied normal load for $\mathrm{ZnO}$ single asperity sliding against a $\mathrm{ZnO}$ film surface before and after exposure to UV for 60 minutes.

Figure 15c depicts the $\mathrm{ZnO}$ film frictional response before and after UV exposure. The measured relative friction coefficient, when $\mathrm{ZnO}$ slides on $\mathrm{ZnO}$, is observed to increase from 0.097 to 0.421 upon exposure of the surface to UV irradiation for 60 minutes. This result denotes a significant increase and confirms our previous postulations resulted from the contact angle measurements.

Furthermore, nanoindentation experiments were performed in order to assess the mechanical properties of the sol-gel derived $\mathrm{ZnO}$ film by measuring their hardness and their elastic modulus. As stated before, to ensure that there was no substrate effect, the maximum penetration depth was limited to less than $10 \%$ of the film thickness. In this experiment a Berkovich tip is utilized. Additionally, a maximum load of $0.5 \mathrm{mN}$ was determined to be sufficient for obtaining reliable data and not exceeding the maximum penetration depth allowed. Matrices of indents were performed on several areas of the film surface. Also, all indents were performed with a standard linear loading/unloading time of 30 seconds and a 10 second pause. The $\mathrm{ZnO}$ films' hardness and elastic modulus were measured to be $3.86 \pm 0.47 \mathrm{GPa}$ and $81.31 \pm$ 
9.97 GPa respectively. Representative indentation curves for the $\mathrm{ZnO}$ films are shown in Figure 16. Although, these results are not representative of earlier findings, they are comparable to a previous study of mechanical properties of sol-gel deposited $\mathrm{ZnO}$ films [55]. The variation in prior result may be due to the uses of a Berkovich instead of a spherical indenter.

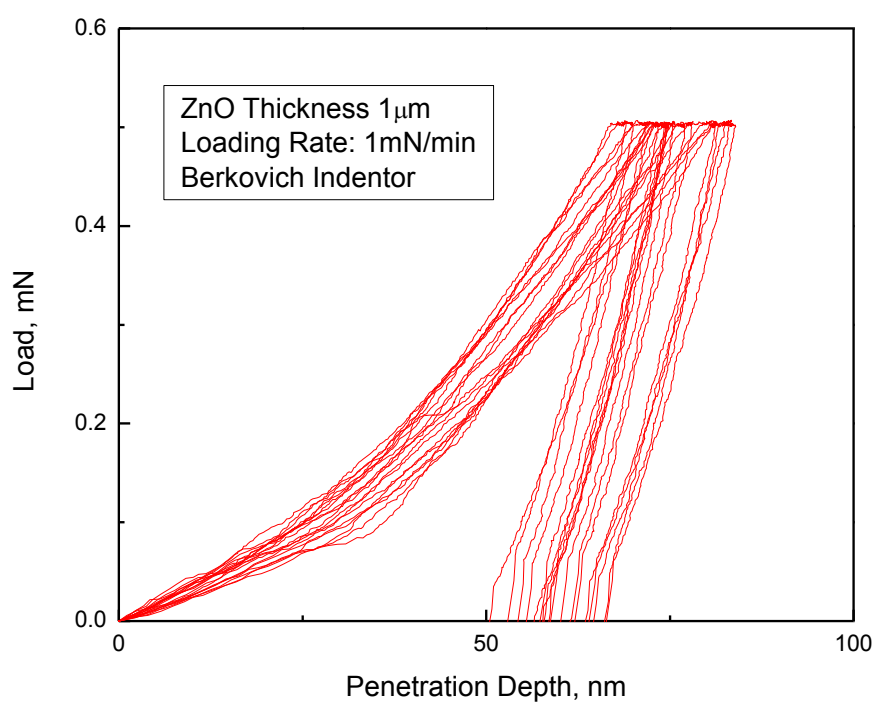

Figure 16: Load versus penetration depth indentation curves for $1 \mu \mathrm{m}$ thick ZnO films. A Berkovich diamond tip was used.

In addition, rolling-sliding experimental-based analysis was performed in order to further our investigations regarding the reliability, wear resistance, and functionality of the $\mathrm{ZnO}$ films as the main component in rotational-based harvesters and/or sensors. Based on the dimensions and the mechanical properties of the film and cylinder material pair and the applied normal loading, the Hertzian contact pressure of the cylinder on flat was calculated to be equal to $16 \mathrm{MPa}$.

Weight measurements were performed before and after testing in order to determine the wear behavior of the film during repeated reciprocating rolling/sliding motion. Both $\mathrm{ZnO}$ 
samples and stainless steel cylindrical counterfaces were measured before and after testing. The $\mathrm{ZnO}$ surfaces were cleaned after each test and before the weight measurements.

Figure 17 shows the variation of weight loss with the number of reciprocating cycles for a non-UV exposed sample and a 60 minute UV- exposed sample. Relatively low weight loss is observed for both samples below 7000 reciprocating cycles. Above 7000 cycles a significantly increased wear of the UV exposed $\mathrm{ZnO}$ surface is noted. This may be attributed to the increased adhesion, due to the UV irradiation, coupled with possible surface fatigue, especially above 20000 reciprocating cycles. The non-UV exposed sample is observed to exhibit slightly increased wear above 7000 cycles. However, the observed wear is not as pronounced as in the UV-exposed counterpart.

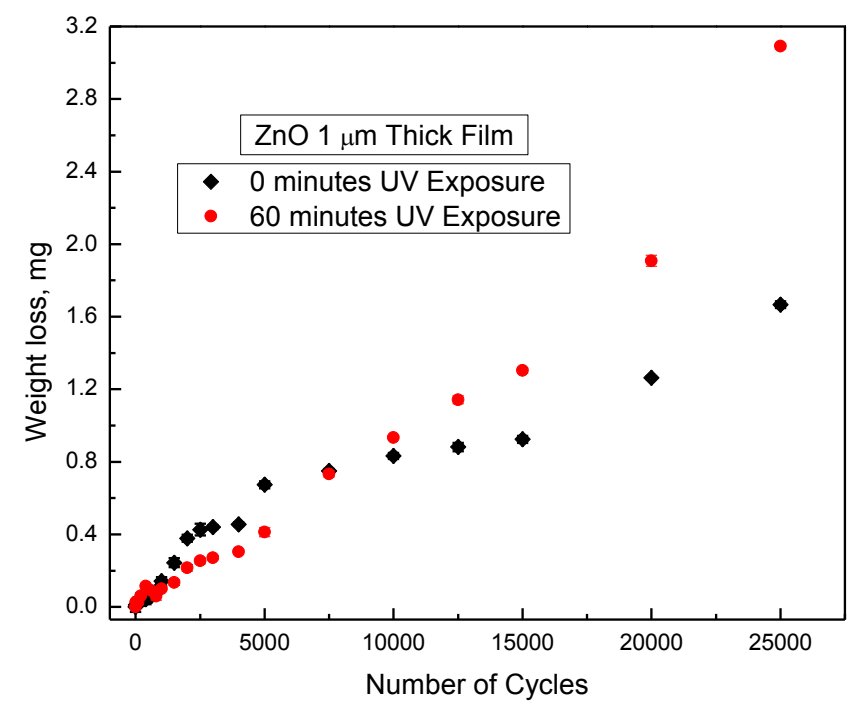

Figure 17: Weight loss of $\mathrm{ZnO}$ films versus number of reciprocating rolling-sliding cycles. The counterface is a stainless steel cylinder. 
Also, it is important to monitor the weight of the counterface before and after each experiment in order to assess potential material transfer from the $\mathrm{ZnO}$ film to the rolling/sliding cylinder. The weight gain of the counterface as opposed to number of reciprocating cycles is shown in Figure 18. Significant material transfer from the film to the steel cylinder is observed in the case when the $\mathrm{ZnO}$ surface is exposed to UV light. This is consistent with our previous observations indicating increased $\mathrm{ZnO}$ surface adhesion upon exposure to $\mathrm{UV}$ irradiation. On the other hand, the hydrophobic and more lubricious nature of the non UV-exposed $\mathrm{ZnO}$ surface leads to relatively limited material transfer to the rolling-sliding counterbody.

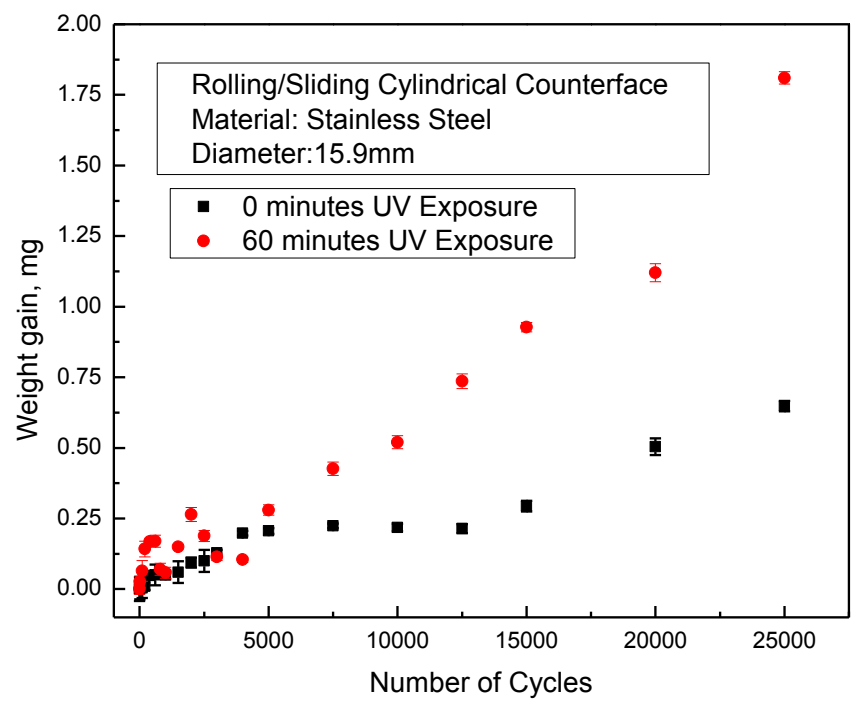

Figure 18: Weight gain of the rolling stainless-steel counterface versus number of reciprocating cycles.

In order to analyze potential wear mechanisms after testing, the $\mathrm{ZnO}$ surfaces were observed using optical microscopy. Also, images of the counterfaces were taken in order to observe potential debris build-up. Figure 19 shows images of the non-UV exposed surfaces after various amounts of cycles. In addition, Figure 20 shows respective images of the 60 minute UV exposed film surfaces after a number of reciprocating cycles. In both cases, mixed rolling- 
sliding tribological mechanisms are observed. Micro-crack formation and delamination is observed above 200 cycles in both cases. However, as the number of cycles increases, such phenomena are observed to become more pronounced. The latter indicates the significant role that the surface fatigue plays in rolling-sliding tribological applications. The generated $\mathrm{ZnO}$ debris may also play a significant role, especially in the UV exposed surface case, as a third body that induces abrasive wear. Such debris is generated due to the formation of adhesive junctions and their subsequent rupture. The cyclic stress interactions may also be responsible for the abrasion mechanisms observed. Three main mechanisms are observed at relatively high numbers of reciprocating cycles: micro-cutting, micro-ploughing and micro-cracking.
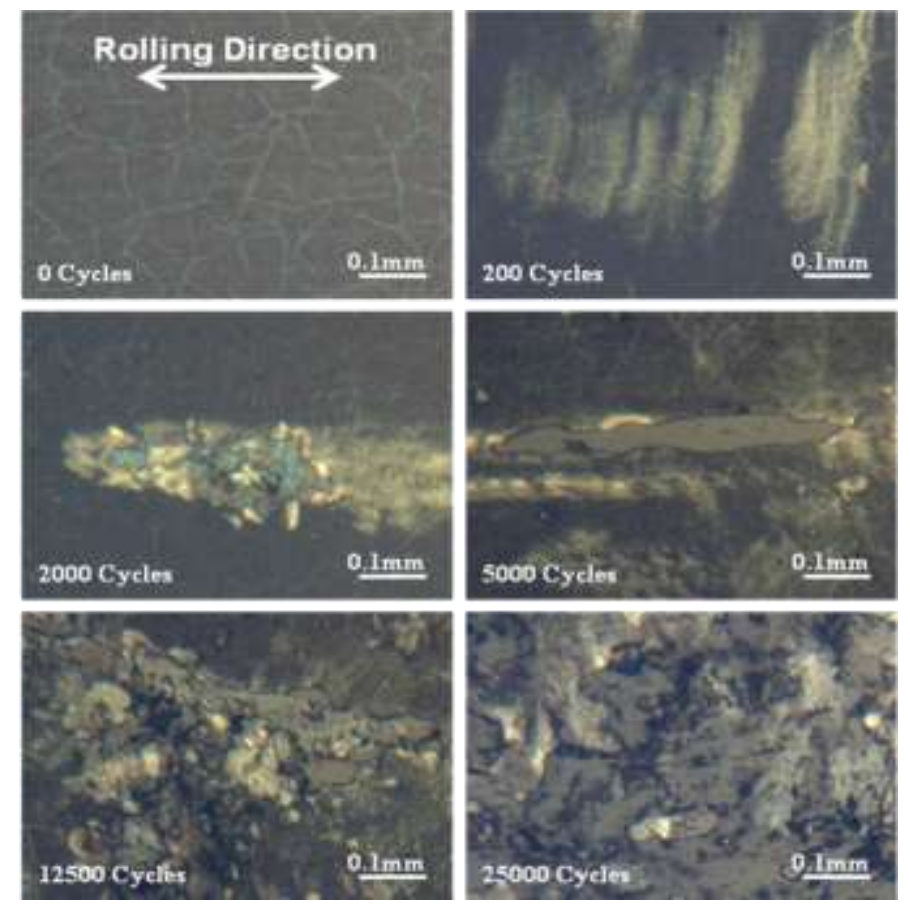

Figure 19: Optical images of non-UV exposed $\mathrm{ZnO}$ surfaces taken after various amounts of reciprocating rolling. The rolling direction is the same for all images. 

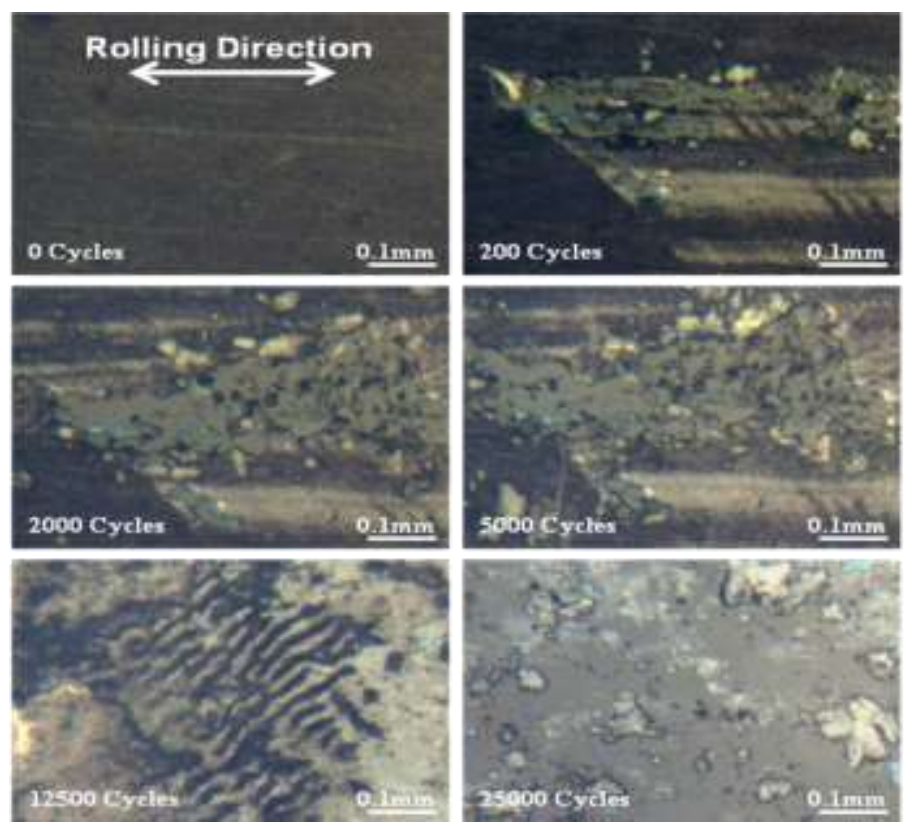

Figure 20: Optical images of 60 minutes UV exposed ZnO surfaces taken after various amounts of reciprocating rolling. The rolling direction is the same for all images.

The $\mathrm{ZnO}$ material transfer to the cylindrical counter-surface is shown in Figure 21. In both cases, the cylinder surface is observed to have accumulated debris. This phenomenon is more pronounced in the UV-exposed surface case, where the whole surface area appears to be covered by debris particles. Such particles are closely-packed to form a continuous layer. 

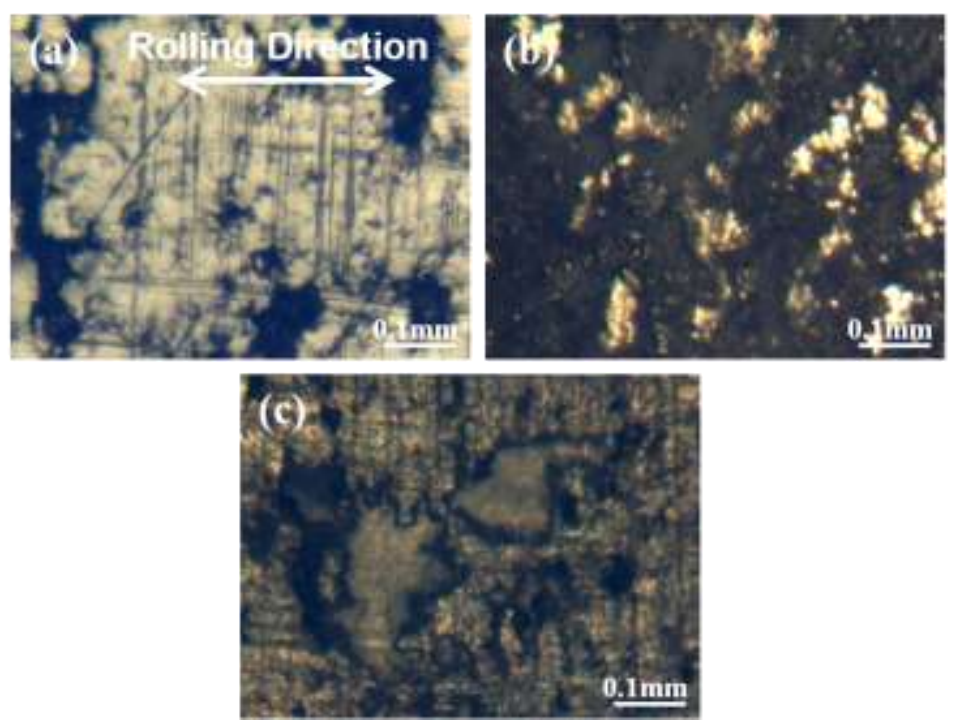

Figure 21: Optical images of the stainless steel cylinder surfaces. (a) Initial counterface, (b) cylinder surface after 25000 rolling cycles on a non-UV exposed ZnO surface, (d) cylinder surface after 25000 reciprocating cycles on a 60 minutes UV exposed $\mathrm{ZnO}$ film surface

Furthermore, the rolling-sliding based piezoelectric output of a preliminary device design was investigated using the apparatus depicted in Figure 22. Such apparatus allows for the in-situ monitoring of the tribological pair with the counterface cylinder being the top, moving, electrode.

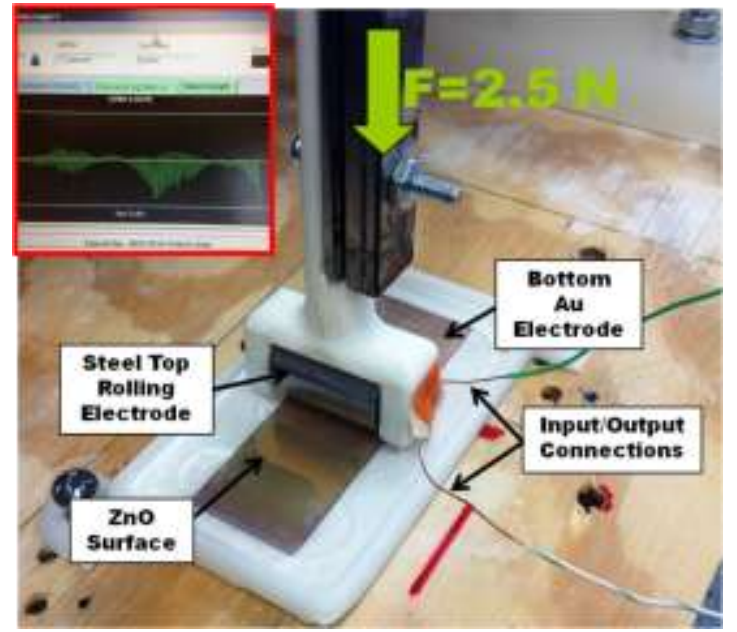

Figure 22: Image of the rolling-based configuration. The inset shows the voltage output measurement during an experiment. 
Figure 23, 24, 25, and 26 show preliminary results of the device response versus the number of reciprocating cycles. The energy harvesting/sensing device exhibits a maximum voltage output of $24 \mathrm{mV}$, under mixed sliding/rolling conditions for a rolling frequency equal to $0.5 \mathrm{~Hz}$ for both AC and DC voltage. Significant hysteresis is observed especially in the higher frequency case for AC voltage measurements. This may be attributed to the contact conditions established in the tribological interface. Although such interaction is complicated, it can also be used in a positive manner. In particular, the proposed design can be used as a tribological contact sensor for condition monitoring applications. When a lower rolling frequency is used, less hysteresis is observed in general. The piezoelectric crystals have more time to charge-discharge in this case. Also, the generation of less frictional heating may lead to the reduced hysteresis response. However, in both cases the preliminary devices were able to perform reliably for up to 7500 cycles.
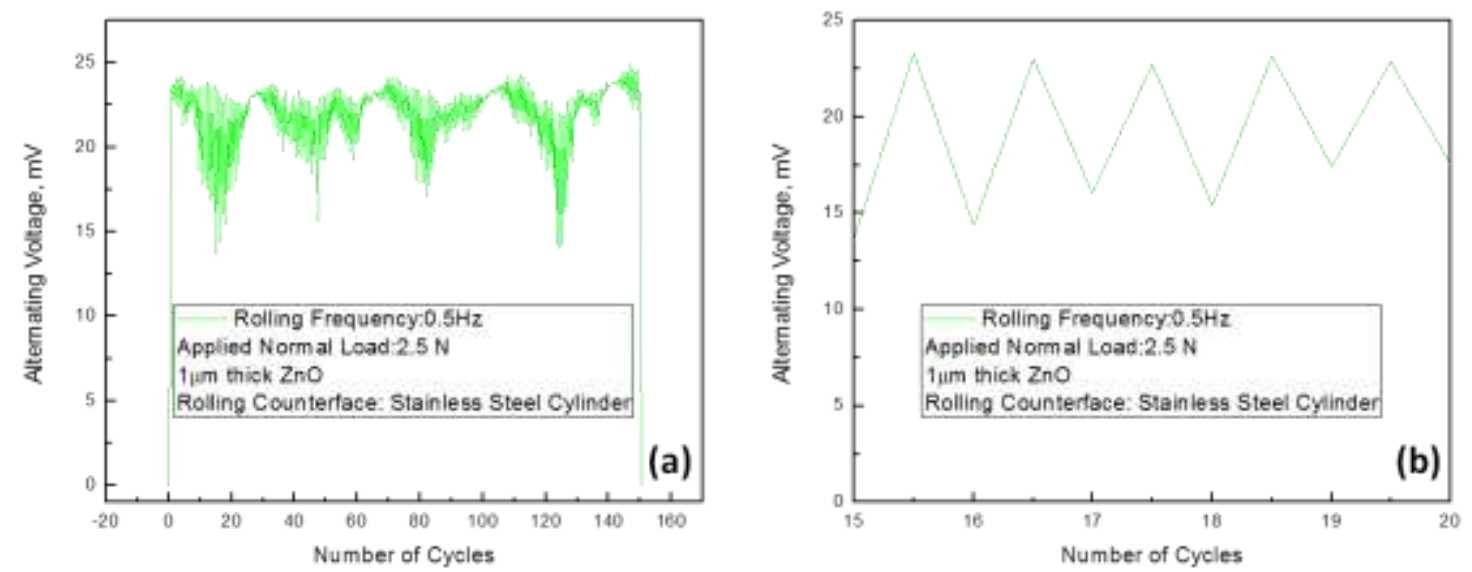

Figure 23: AC Voltage response of preliminary device design subjected to rolling for a total of 150 cycles at a frequency of 0.5 Hz. (a) All 150 cycles, and (b) cycles from 15-20 

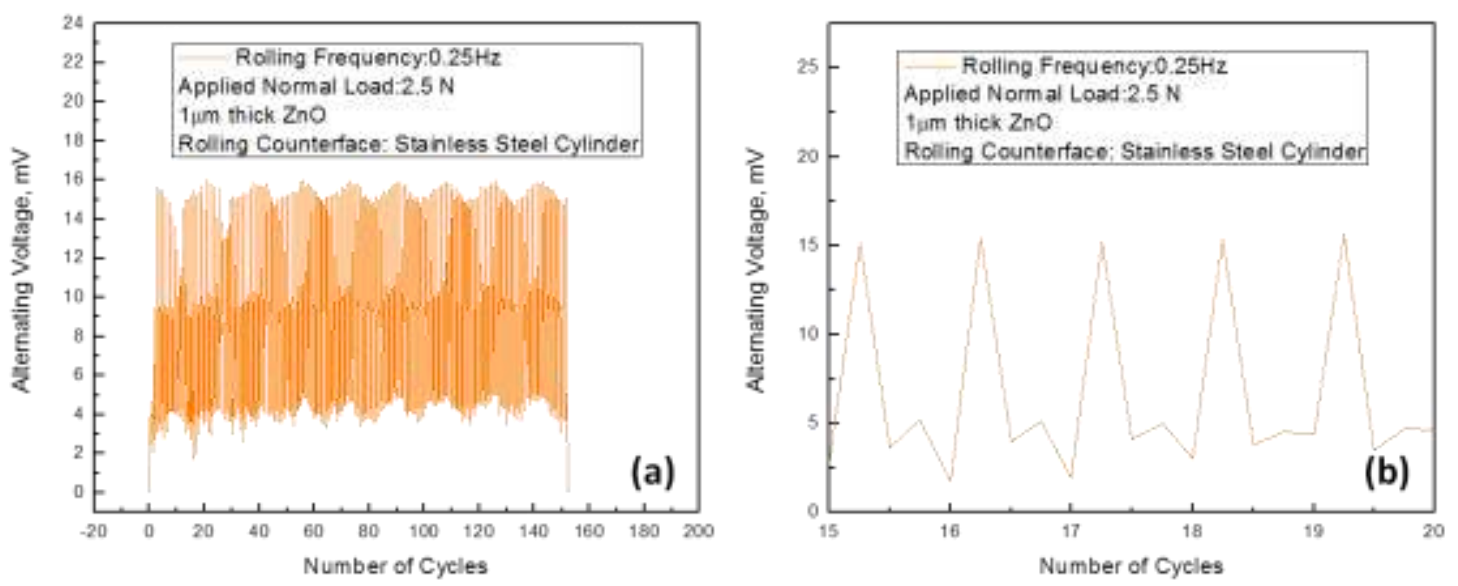

Figure 24: AC Voltage response of preliminary device design subjected to rolling for a total of 150 cycles at a frequency of $0.25 \mathrm{~Hz}$. (a) All 150 cycles, and (b) cycles from 15-20
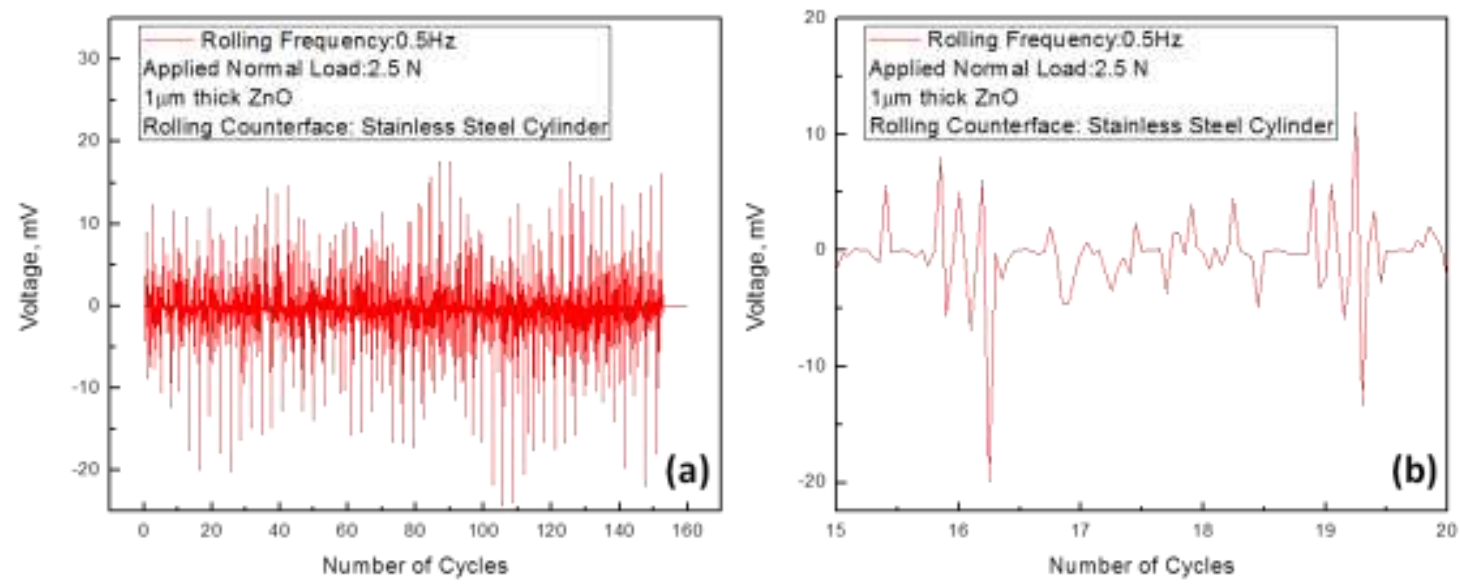

Figure 25: DC Voltage response of preliminary device design subjected to rolling for a total of 150 cycles at a frequency of 0.5 Hz. (a) All 150 cycles, and (b) cycles from 15-20 

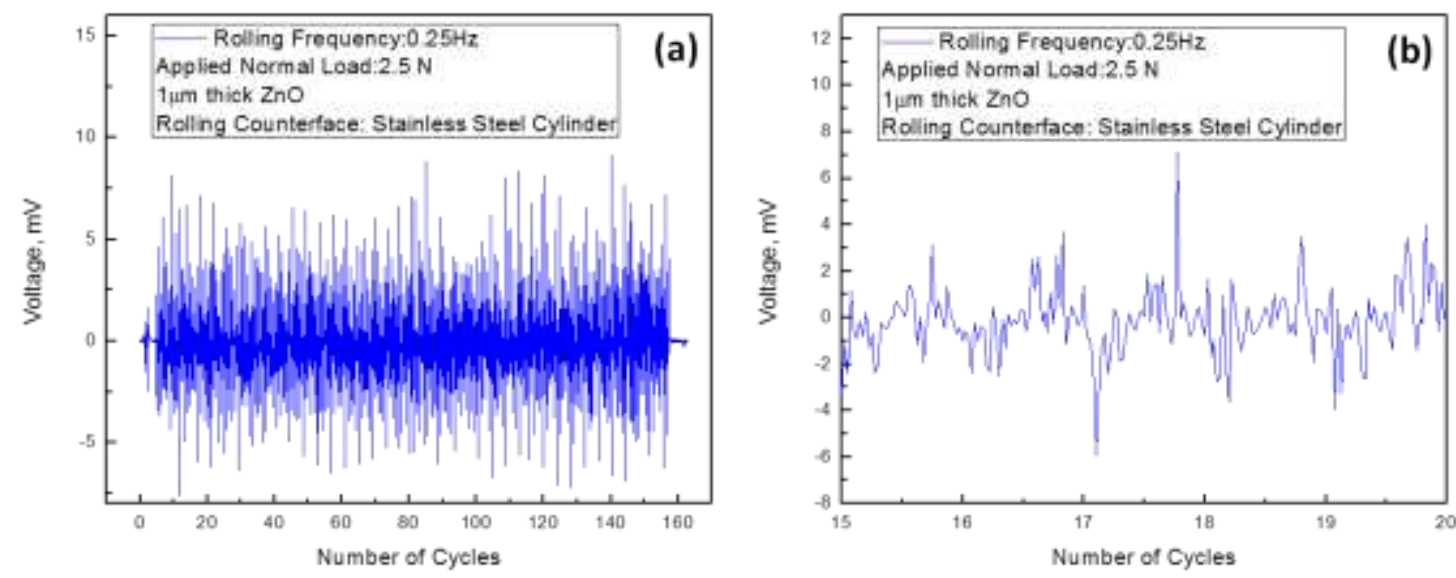

Figure 26: DC Voltage response of preliminary device design subjected to rolling for a total of 150 cycles at a frequency of 0.5 Hz. (a) All 150 cycles, and (b) cycles from 15-20

\subsection{Hydrothermal Growth of $\mathrm{ZnO}$ Nanostructures}

In this section, $\mathrm{ZnO}$ nanostructures are grown through a hydrothermal process. Comparisons of different aspects of the growth are investigated, as well as piezoelectric response. Figure 27 shows SEM images for $\mathrm{ZnO}$ nanostructures for different growth conditions. The baseline growth conditions were a $0.025 \mathrm{~mol} \mathrm{~L}^{-1}$ solution, $95^{\circ} \mathrm{C}$ temperature for $24 \mathrm{hrs}$ on a glass substrate with a seed-layer dried at $100^{\circ} \mathrm{C}$, Figure 27 (a). Image analysis was utilized to quantify average diameter and density of the structures; the results are displayed in Table 5. 

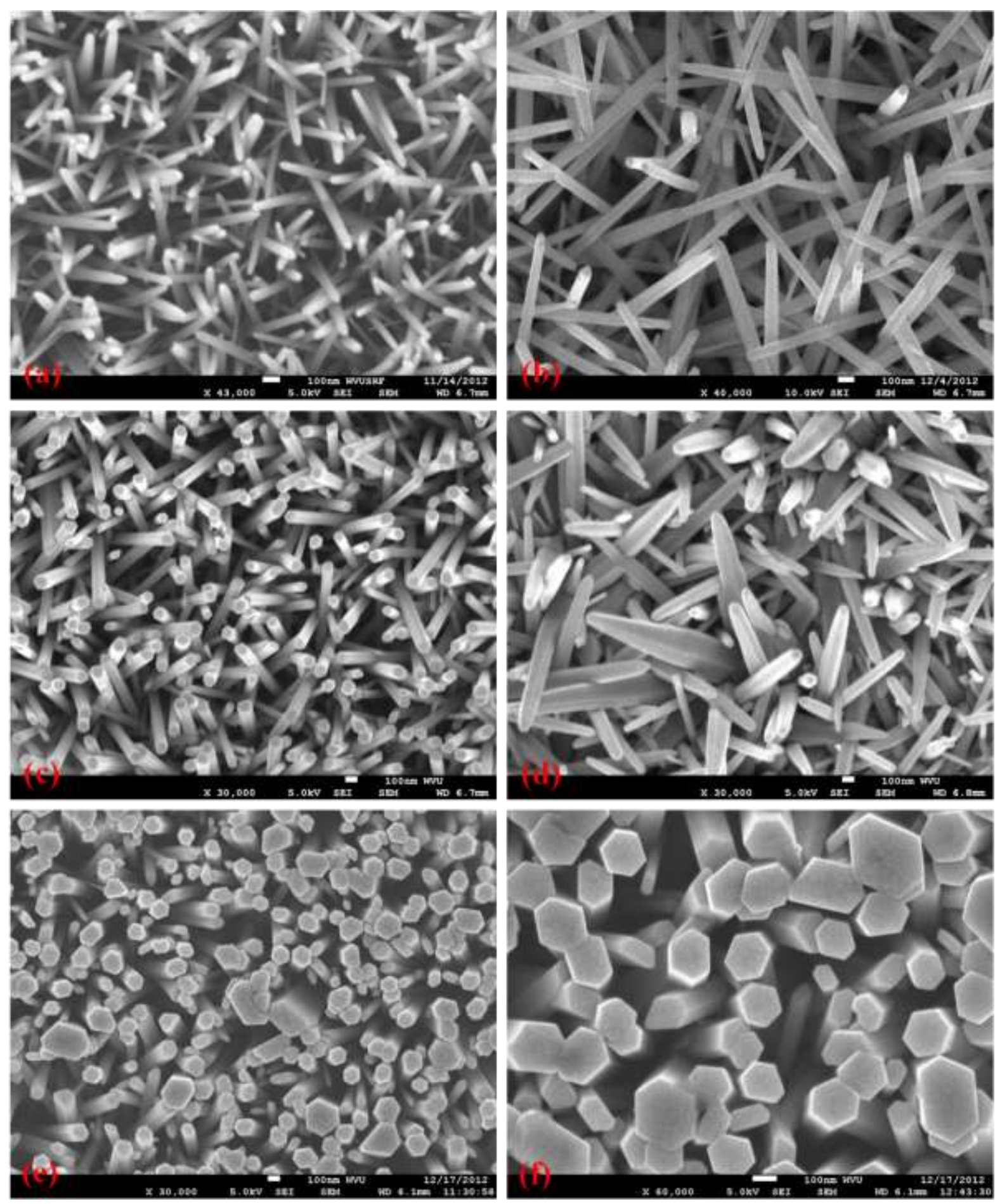

Figure 27: SEM images ZnO nanostructures for different growth conditions. All seed-layers were deposited on glass and dried at $100^{\circ} \mathrm{C}$ unless specified. (a) $0.025 \mathrm{~mol} \mathrm{~L}^{-1}$ solution for $24 \mathrm{hrs}$ at $95^{\circ} \mathrm{C}$ (b) $0.01 \mathrm{~mol} \mathrm{~L}^{-1}$ solution for $24 \mathrm{hrs} \mathrm{at} 95^{\circ} \mathrm{C}$ (c) $0.025 \mathrm{~mol} \mathrm{~L}^{-1}$ solution for $24 \mathrm{hrs}$ at $70^{\circ} \mathrm{C}$ (d) $0.025 \mathrm{~mol} \mathrm{~L}^{-1}$ solution for $24 \mathrm{hrs}$ at $95^{\circ} \mathrm{C}$, grown on $\mathrm{Au}(\mathrm{e}) 0.025 \mathrm{~mol} \mathrm{~L}^{-1}$ solution for $24 \mathrm{hrs}$ at $70^{\circ} \mathrm{C}$, seed-layer dried at $150^{\circ} \mathrm{C}$ (f) $0.025 \mathrm{~mol} \mathrm{~L}^{-1}$ solution for $48 \mathrm{hrs} \mathrm{at} 70^{\circ} \mathrm{C}$ 
Upon comparison of Figure 27 (a) and 27 (b) the $\mathrm{ZnO}$ structures look very similar and from image analysis the average radii are almost identical. Although, the $0.025 \mathrm{~mol} \mathrm{~L}^{-1}$ solution is over twice as dense compared to $0.01 \mathrm{~mol} \mathrm{~L}^{-1}$. The increased amounts of $\mathrm{Zn}$ produce more nucleation sites at the surface of the substrate generating a higher density [33]. Decreasing the temperature from $95^{\circ} \mathrm{C}$ to $70^{\circ} \mathrm{C}$, the structures move from a pyramidal shape to hexagonal prism shape, this can be seen by the increase in average radius. It is noticed that the density has decrease a little with the lower temperature. The diffusion length and mobility of the $\mathrm{Zn}$ ions becomes increasingly limited at the substrate, lowering the density [33]. Moreover, at higher temperatures the HTMA decomposes at a faster rate, resulting in wider based structures.

In Figure 27 (d) gold was sputtered onto a glass substrate and then a seed-layer was spincoated onto the gold surface. It is seen that larger structures have developed compared to Figure 27 (a), which is attributed to the lower density. The larger structures can be attributed to the better crystal lattice matching of the gold surface than just a seed-layer on glass. Figure 27 (c) and (e) displays the difference in the drying temperature of the seed-layer, which were dried at $100^{\circ} \mathrm{C}$ and $150^{\circ} \mathrm{C}$. On inspection, the $150^{\circ} \mathrm{C}$ seed-layer sample possesses larger diameter structures and better vertical orientation. The higher drying temperature increases the grain size of the seed-layer, improving the crystallinity [107]. Additionally, the larger grain size allows for larger nucleation sites to develop increasing the diameter of the rods. The density shown to be lower but this can be attributed to the larger diameter features. By extending the growth time from $24 \mathrm{hrs}$ to $48 \mathrm{hrs}$ the diameter of the rods is almost doubled, showing continued lateral growth after 24 hrs, seen in Figure 27 (f). In addition, it can be seen that some of the structures have started to merge together. 
Table 5: Growth conditions for hydrothermally grown $\mathrm{ZnO}$ structures and measured results.

\begin{tabular}{|c|c|c|c|c|c|c|c|}
\hline $\begin{array}{c}\text { Solution } \\
\text { Concetration } \\
\left(\mathrm{mol} \mathrm{L}^{-1}\right)\end{array}$ & $\begin{array}{c}\text { Growth } \\
\text { Time } \\
(\mathrm{hr})\end{array}$ & $\begin{array}{c}\text { Growth } \\
\text { Temperature } \\
\left({ }^{\circ} \mathrm{C}\right)\end{array}$ & Substrate & $\begin{array}{c}\text { Seed-layer } \\
\text { Drying } \\
\text { Temperature } \\
\left({ }^{\circ} \mathrm{C}\right)\end{array}$ & $\begin{array}{c}\text { Average } \\
\text { Radius } \\
(\mathrm{nm})\end{array}$ & $\begin{array}{c}\text { Density } \\
(\text { per 100 } \\
\left.\mu \mathrm{m}^{2}\right)\end{array}$ & Figure \\
\hline 0.025 & 24 & 95 & Glass & 100 & 25 & 2400 & $25(\mathrm{a})$ \\
\hline 0.01 & 24 & 95 & Glass & 100 & 24 & 1100 & $25(\mathrm{~b})$ \\
\hline 0.025 & 24 & 70 & Glass & 100 & 54 & 1800 & $25(\mathrm{c})$ \\
\hline 0.025 & 24 & 95 & $\begin{array}{c}\text { Au on } \\
\text { Glass }\end{array}$ & 100 & 36 & 750 & $25(\mathrm{~d})$ \\
\hline 0.025 & 24 & 70 & Glass & 150 & 86 & 1600 & $25(\mathrm{e})$ \\
\hline 0.025 & 48 & 70 & Glass & 100 & 98 & 1400 & $25(\mathrm{f})$ \\
\hline 0.025 & 24 & 70 & PEN & 100 & 45 & 1000 & 26 \\
\hline
\end{tabular}

The low processing temperatures of hydrothermal growth allows for the use of flexible substrates. Even though it has been noticed that drying the seed-layer at $150^{\circ} \mathrm{C}$ produces highly oriented nanorods, this temperature will generate residual stresses in most polymers. In this case, a drying temperature of $100^{\circ} \mathrm{C}$ is used for the seed-layer deposited on a PEN substrate. Then the sample was placed in a $0.025 \mathrm{~mol} \mathrm{~L}^{-1}$ solution at $70^{\circ} \mathrm{C}$ for $24 \mathrm{hrs}$. Images of the grown $\mathrm{ZnO}$ structures can be seen in Figure 28. It is observed that there are large $\mathrm{ZnO}$ structures, about $1 \mu \mathrm{m}$ in diameter, along with the nanorods.
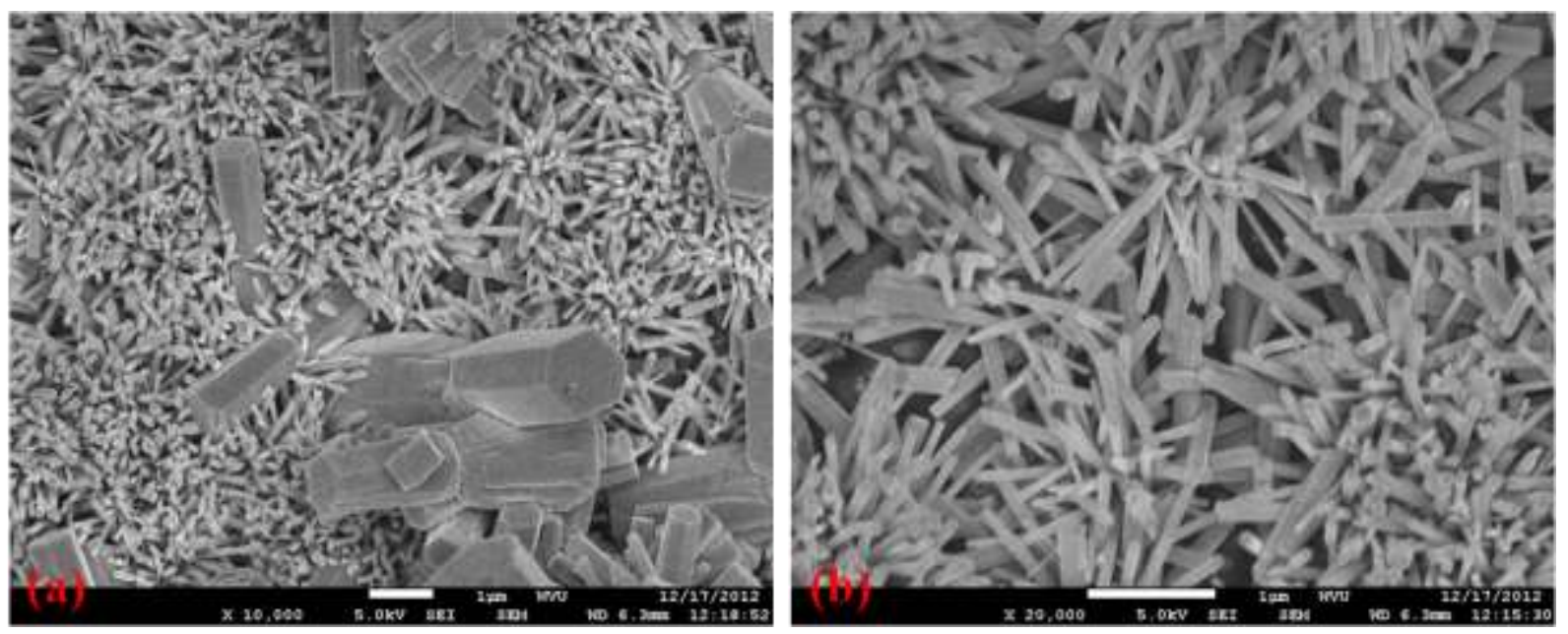

Figure 28: ZnO structures grown on PEN substrate. 
$\mathrm{ZnO}$ structures for the preliminary devices where grown in a $25 \mathrm{mmol} \mathrm{L}^{-1}$ solution at $70^{\circ} \mathrm{C}$, as it was shown to have high quality vertically aligned rods. A photo of a preliminary device based on PEN is presented in Figure 29. By pressing with an index finger, the peak open circuit voltage was measured to be $120 \mathrm{mV}$, shown in Figure 30. The device was also subjected to buckling, similar to what is seen in Figure 29, an open circuit voltage of $12 \mathrm{mV}$ is measured. This is attributed to the fact that a small vertical force is applied to the nanorods when the device is subjected to buckling.

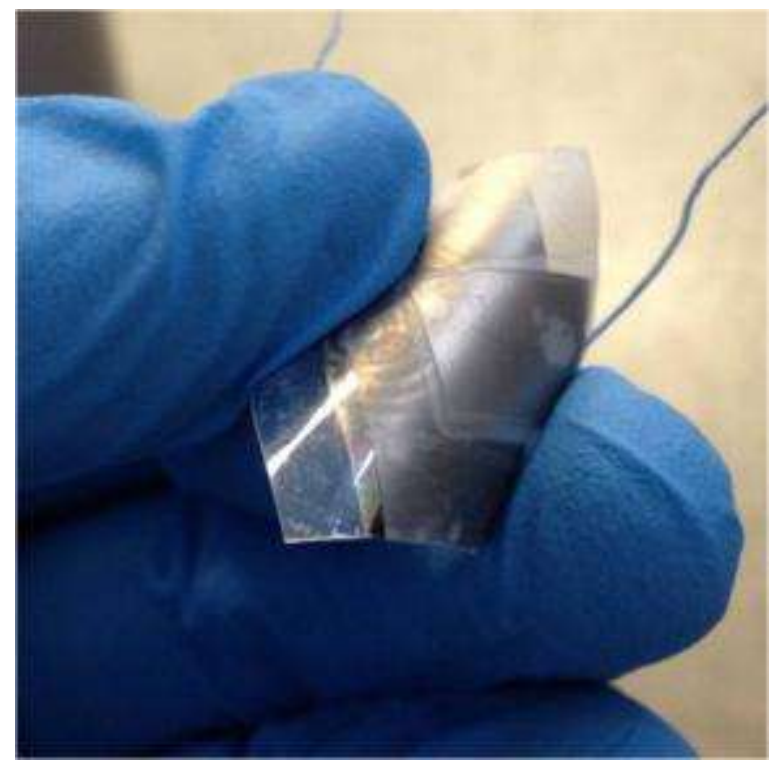

Figure 29: PEN-based ZnO nanostructure device. 


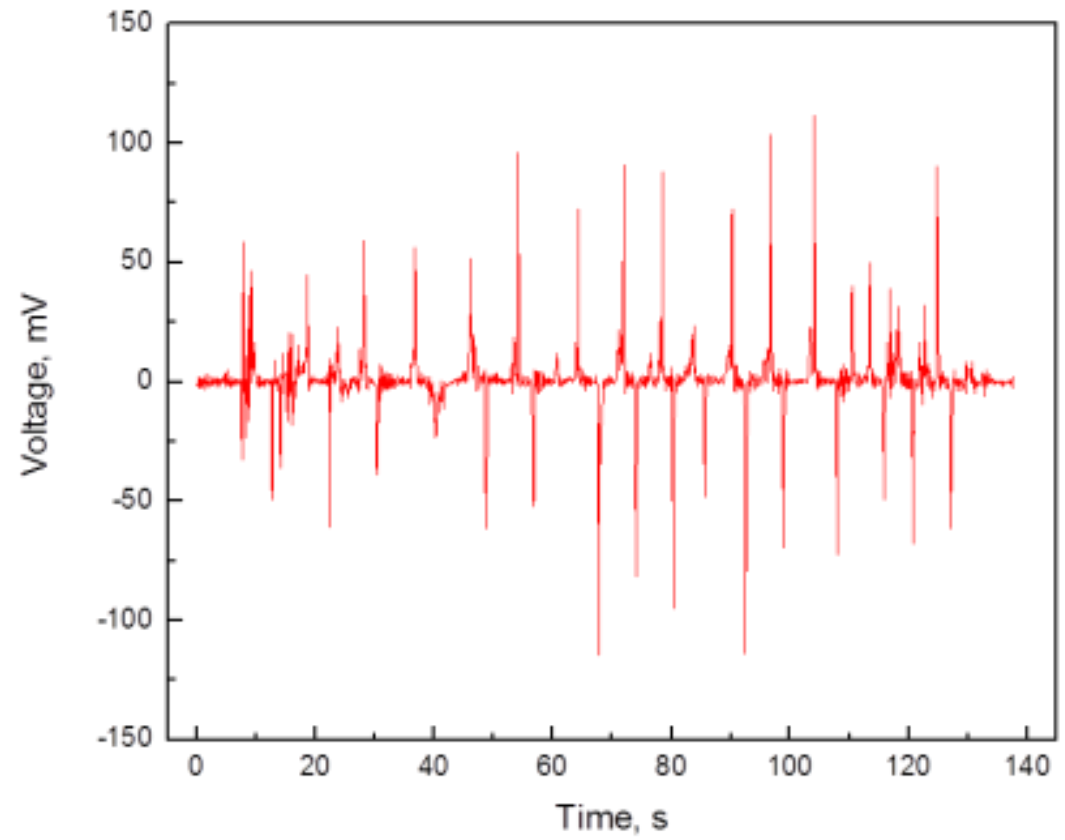

Figure 30: Piezoelectric output of PEN-based ZnO nanostructure device.

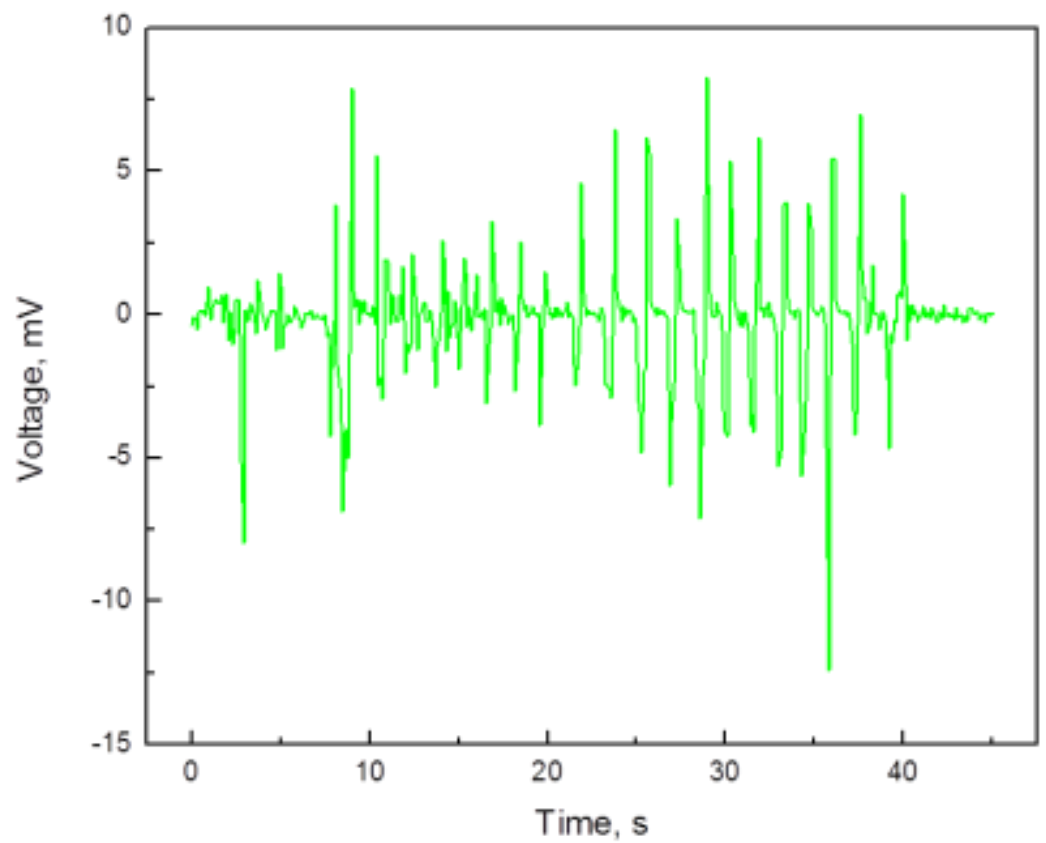

Figure 31: Open circuit voltage of $\mathrm{ZnO}$ device subjected to buckling. 
The device was allowed to age, without being touched, for 3 months before testing the open circuit voltage again. The maximum open circuit voltage measured was $80 \mathrm{mV}$, which is a reduction of $33 \%$ over the 3 month span. It has been previously reported that a $50 \%$ decrease in the open circuit voltage is recognized after 2 weeks [7].

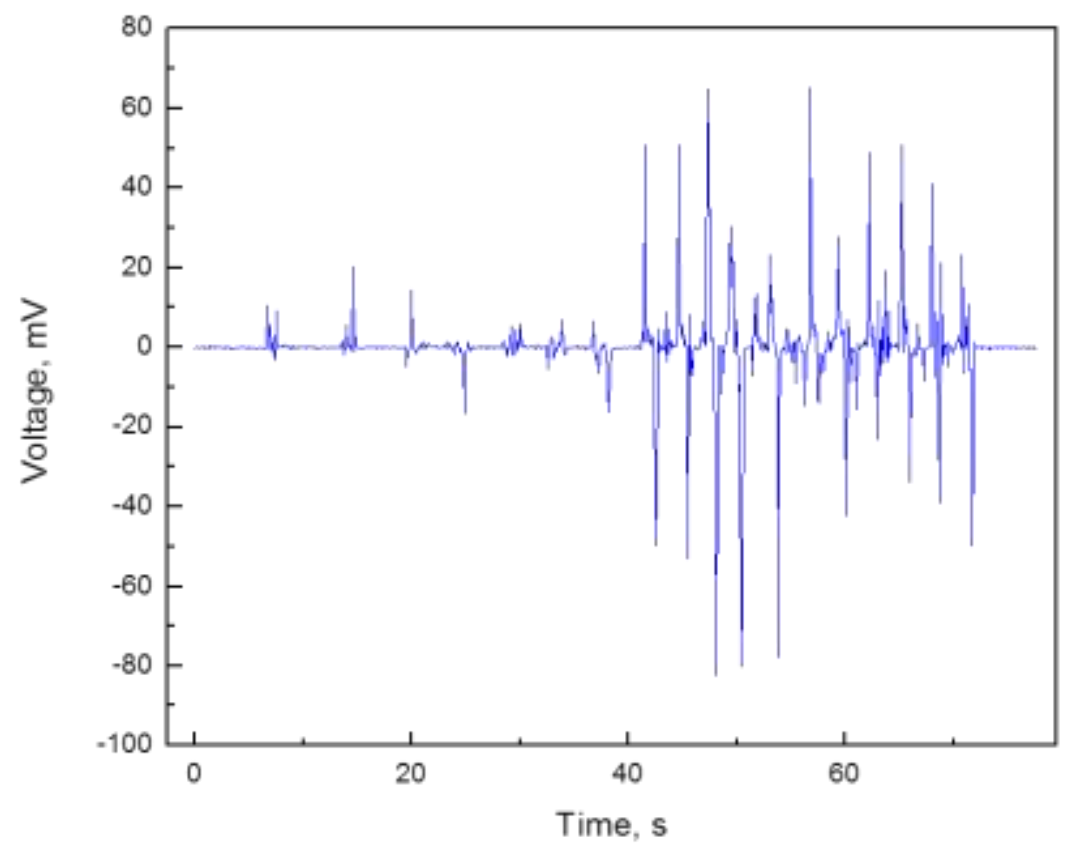

Figure 32: Open circuit voltage for PEN-based device after aging for 3 months.

A patterned $\mathrm{ZnO}$ structure was fabricated by first depositing a photoresist on a Cr-coated glass substrate which was then exposed to UV to leave a patterned photoresist. Then a seedlayer was deposited and dried at $150^{\circ} \mathrm{C}$. The multilayer was then placed in a $0.025 \mathrm{~mol} \mathrm{~L}^{-1}$ solution at $70^{\circ} \mathrm{C}$ for $24 \mathrm{hrs}$. Once the growth process was over the photoresist was remove by placing the sample in acetone. Images of the patterned $\mathrm{ZnO}$ are displayed in Figure 33. It can be seen that some rods have grown in the photoresist area. After images where gathered of the rods PMMA was deposited and then plasma etched. Finally, a Cr-coated PEN substrate was placed on top, to complete the multi-stack. 

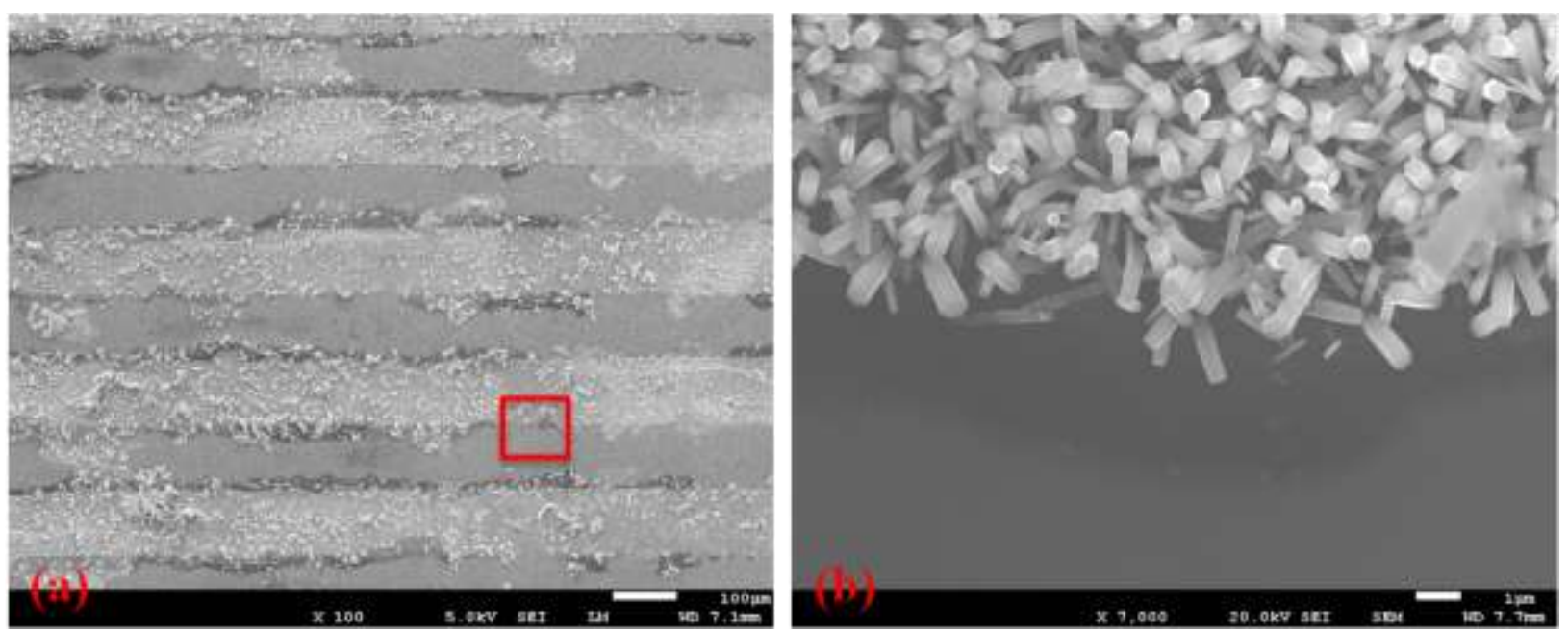

Figure 33: (a) SEM image of patterned $\mathrm{ZnO}$ nanorods, (b) magnified image of highlighted region of (a)

The device was tested using microindentation while measuring the open circuit voltage in-situ. The open circuit voltages for different pressures are presented in Figure 34. From the indentation the maximum output is $33 \mathrm{mV}$ for a pressure of $78 \mathrm{kPa}$, with higher pressures the open circuit voltages drop. The drop in voltage may be due to the destruction of the $\mathrm{ZnO}$ nanostructures. Investigation of the area subjected to indentation was accomplished utilizing SEM. Figure 35 displays images of damaged $\mathrm{ZnO}$ nanorods, showing this presumption may be correct, although more testing is needed. 


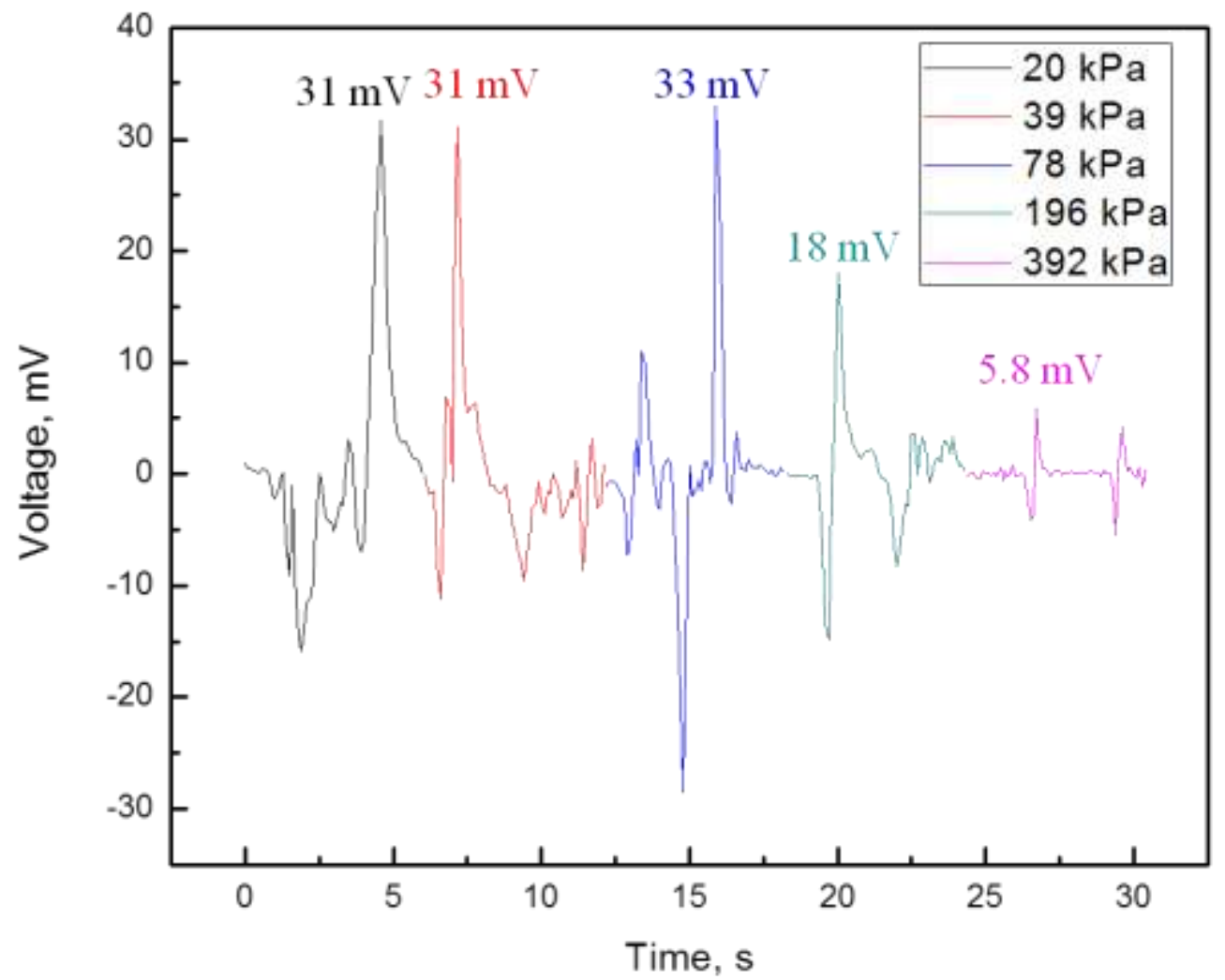

Figure 34: Open circuit voltage measured for patterned $\mathrm{ZnO}$ device during microindentation for various applied loads.
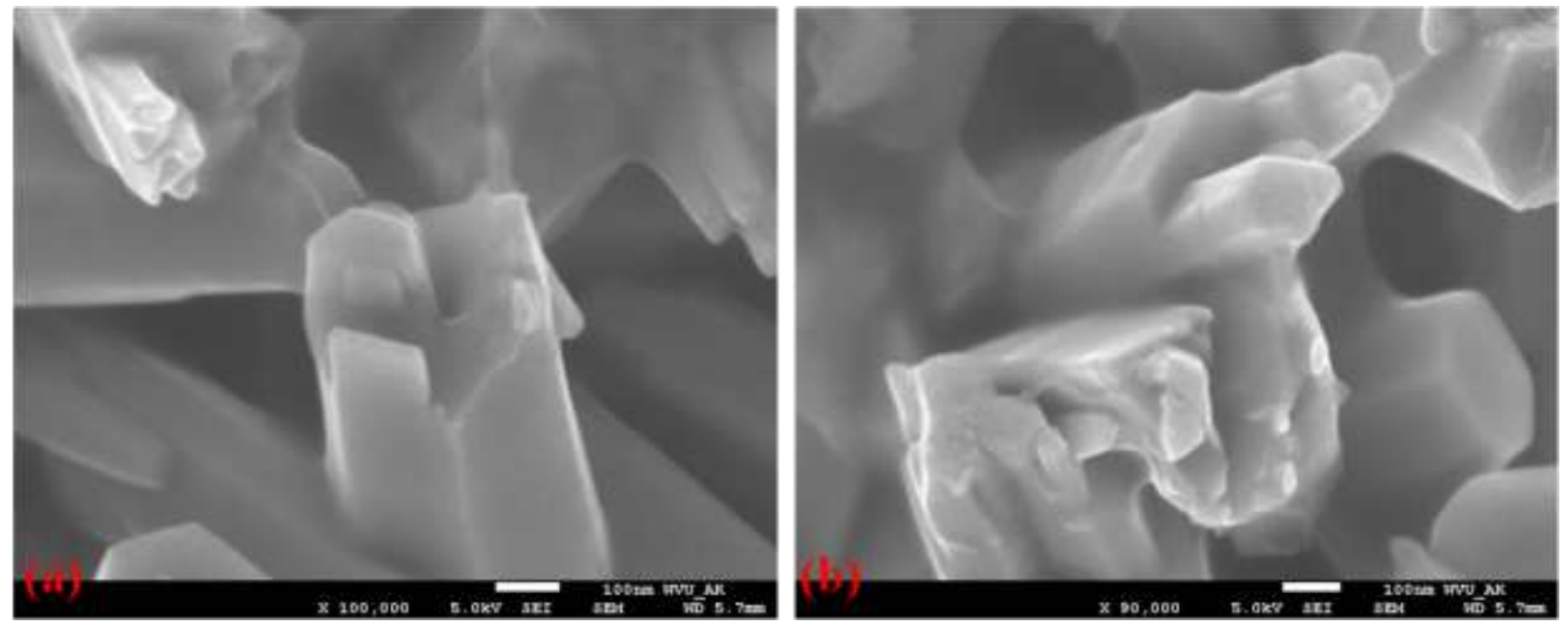

Figure 35: SEM images of $\mathrm{ZnO}$ nanorods after microindentation. 


\subsection{Dip-Pen Nanolithography of ZnO Patterns}

Microdots of $\mathrm{ZnO}$ were deposited by DPN using modified $\mathrm{ZnO}$ sols as the ink. At first, polypropylene glycol (PPG, Molecular Weight=1,000) was utilized as a thickening agent for the sols. But, as seen in Figure 36, minutes after deposition the dots have lost their shape. This can be attributed to the fact that PPG is a wetting agent, which lowers the surface tension between the ink and substrate allowing the ink to spread across the surface. It was then decided to use glycerol as a thickening agent.
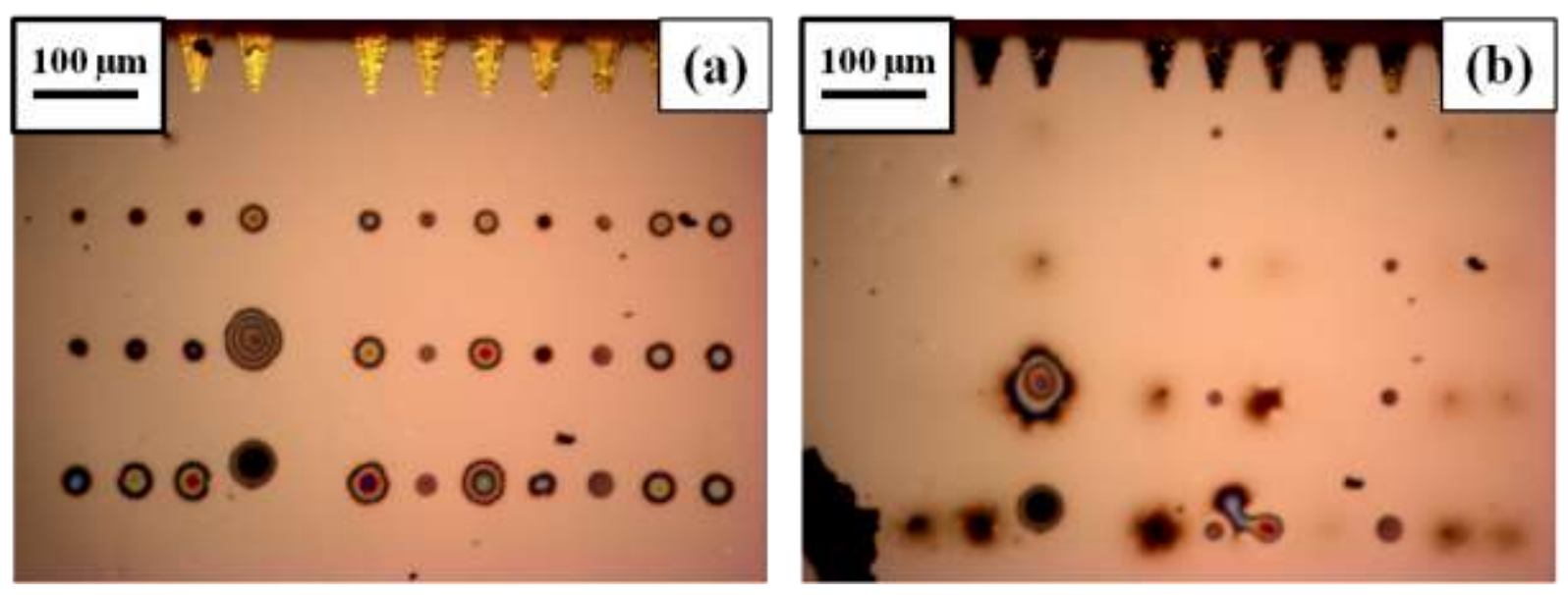

Figure 36: $10 \mathrm{~s}$ dwell time for 1:1 ZnO to PPG solution, (a) as deposited, (b) 5 minutes after deposition.

Figure 37 depicts the viscosities of the different inks used for DPN as a function of glycerol added to the $\mathrm{ZnO}$ sol. It is suggested by Nanoink that the ink have a viscosity greater than water, as the ink will be immediately discharged upon touching the substrate [108]. Moreover, the viscosity significantly affects the transfer rate, displaying a slower rate for more viscous inks [109]. Additionally, it is noted that the $1: 2 \mathrm{ZnO}$ to glycerol solution started to hydrolyze after $4 \mathrm{hrs}$ and the 1:1 solution hydrolyzed after 24 hrs. For this reason, all depositions and viscosity measurments were conducted immediately after synthesis of the solutions. Figure 38, 39, and 40 illustrates ink dots as deposited. The as deposited ink dots were 
analyzed to using ImageJ's Analyze Particles to measure the dots' area, from which the radius was calculated. A comparison of the inks as a function of the deposition row, keeping the dwell time constant, can be seen in Figure 41, 42, and 43. The less viscous solutions show larger radii due to the higher transfer rate. In addition, for all inks and dwell times, the dots' radii exhibit an exponential decay as a function of row number. Additionally, the number of rows deposited decreases with increasing dwell time, due to more ink deposited with longer dwell times depleting the tip faster. Except, it is noticed that the $1: 1 \mathrm{ZnO}$ to glycerol solution with a $10 \mathrm{~s}$ dwell only 4 rows of ink dots were deposited as compared to $15 \mathrm{~s}$ dwell depositing 5 rows. As there is the same amount of ink on the tips, this illustrates that the $15 \mathrm{~s}$ dwell time overcomes a threshold to deposit a visible fifth row. Although a fifth row is not seen for the $10 \mathrm{~s}$ dwell time, there may be one at the nanoscale.

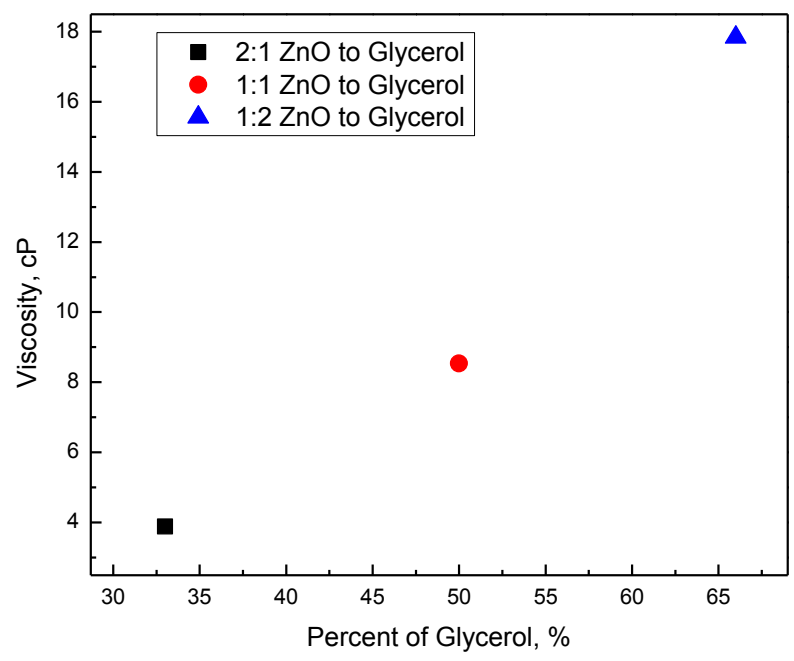

Figure 37: Viscosity of inks used for DPN as a percentage of glycerol. 


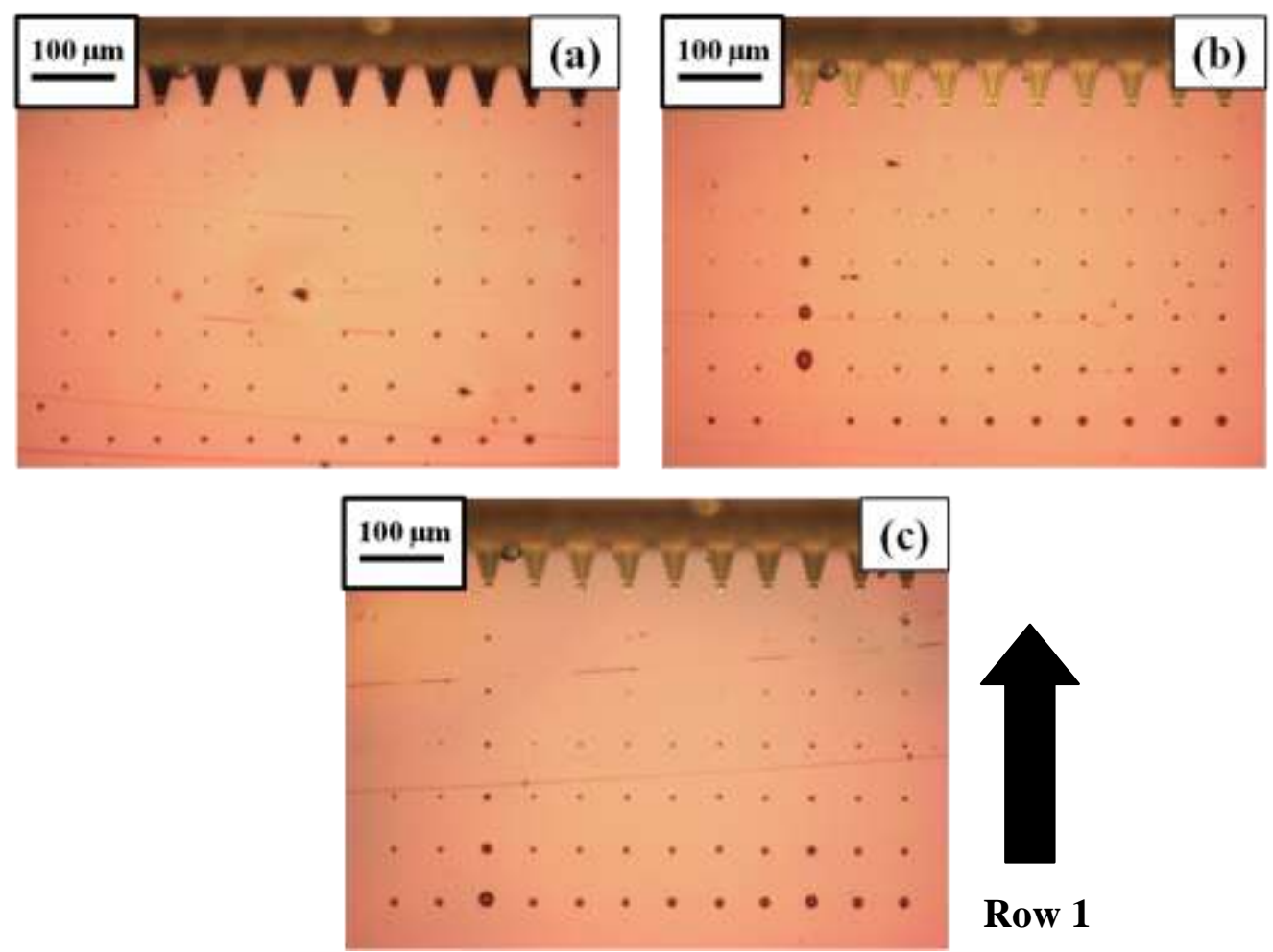

Figure 38: As deposited 2:1 ZnO to glycerol dots on a PVP release layer for different dwell times (a) $5 \mathrm{~s}$, (b) $10 \mathrm{~s}$, (c) $15 \mathrm{~s}$. The arrow indicates tip movement. 

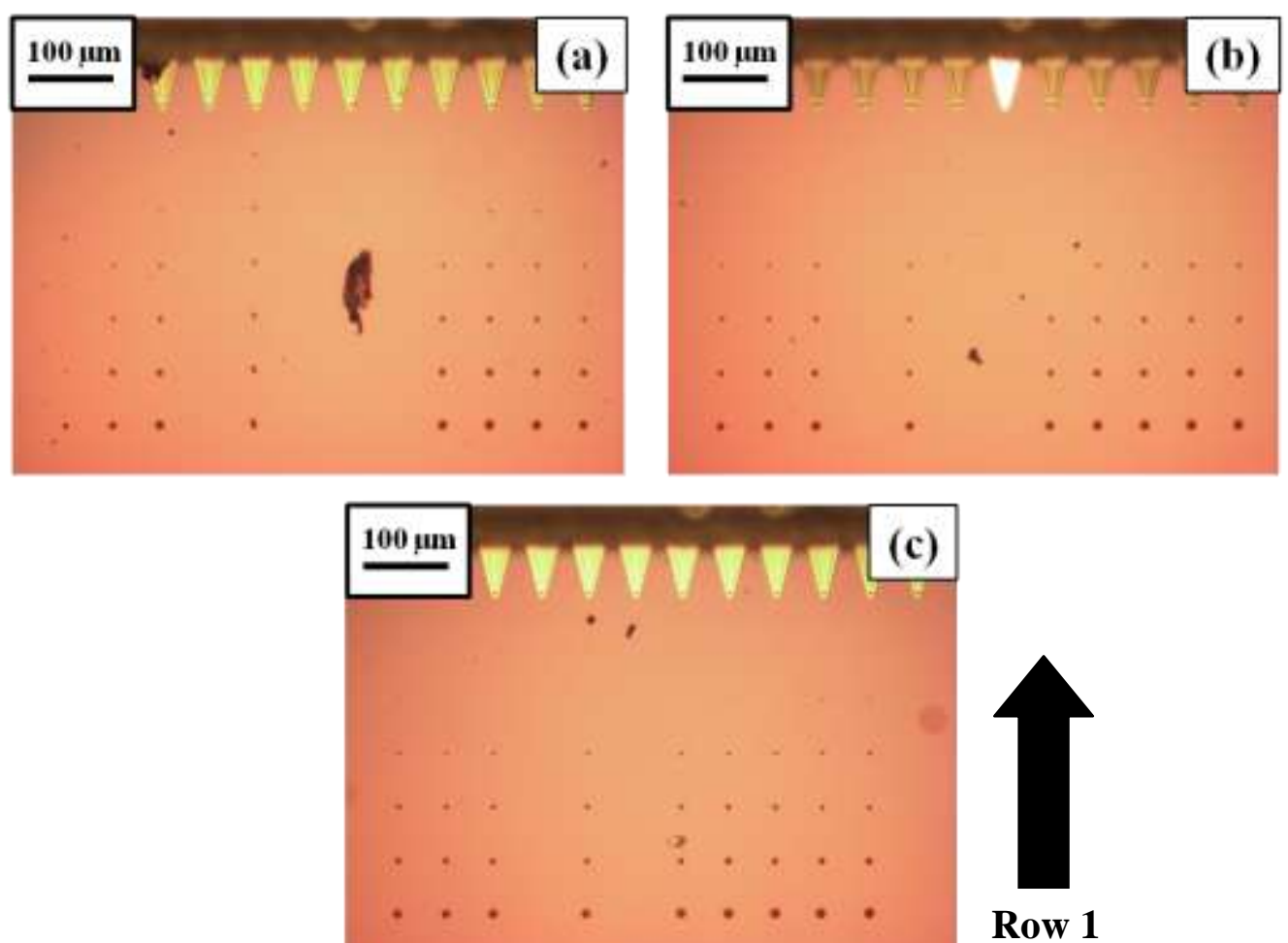

Figure 39: As deposited 1:1 ZnO to glycerol dots on a PVP release layer for different dwell times (a) $5 \mathrm{~s}$, (b) $10 \mathrm{~s}$, (c) $15 \mathrm{~s}$. The arrow indicates tip movement.

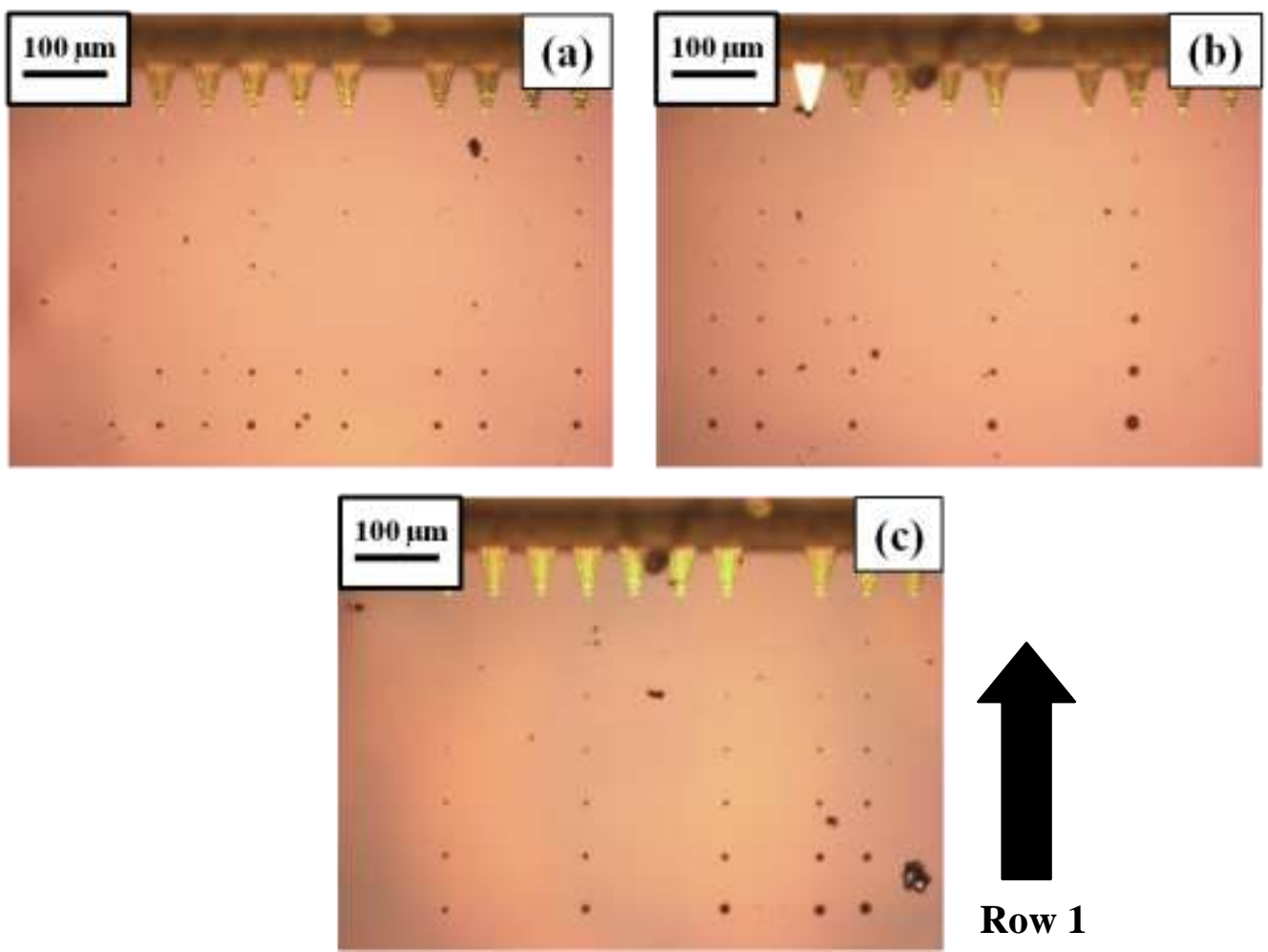

Figure 40: As deposited 1:2 ZnO to glycerol dots on a PVP release layer for different dwell times (a) $5 \mathrm{~s}$, (b) $10 \mathrm{~s}$, (c) $15 \mathrm{~s}$. The arrow indicates tip movement. 


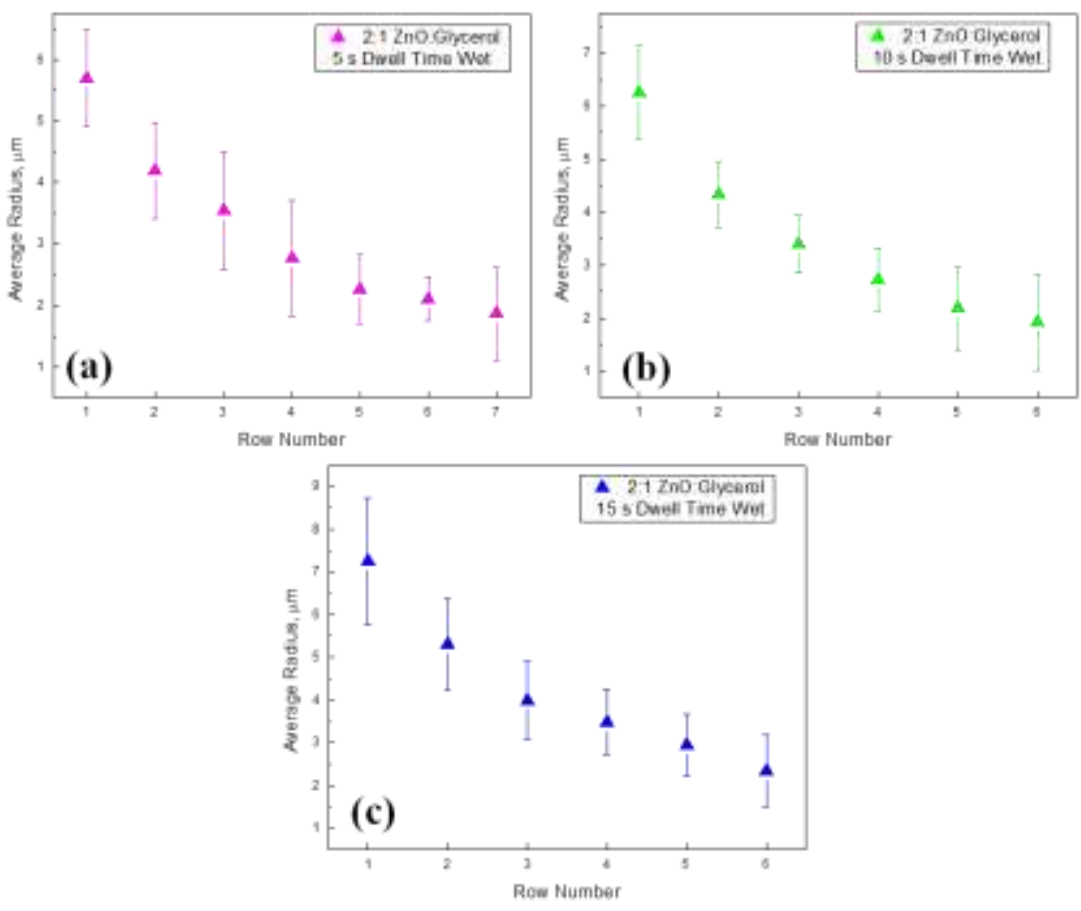

Figure 41: As deposited radius measurements as a function of row number for 2:1 ZnO to glycerol solution for different dwell times, (a) $5 \mathrm{~s}$, (b) $10 \mathrm{~s}$, (c) $15 \mathrm{~s}$.

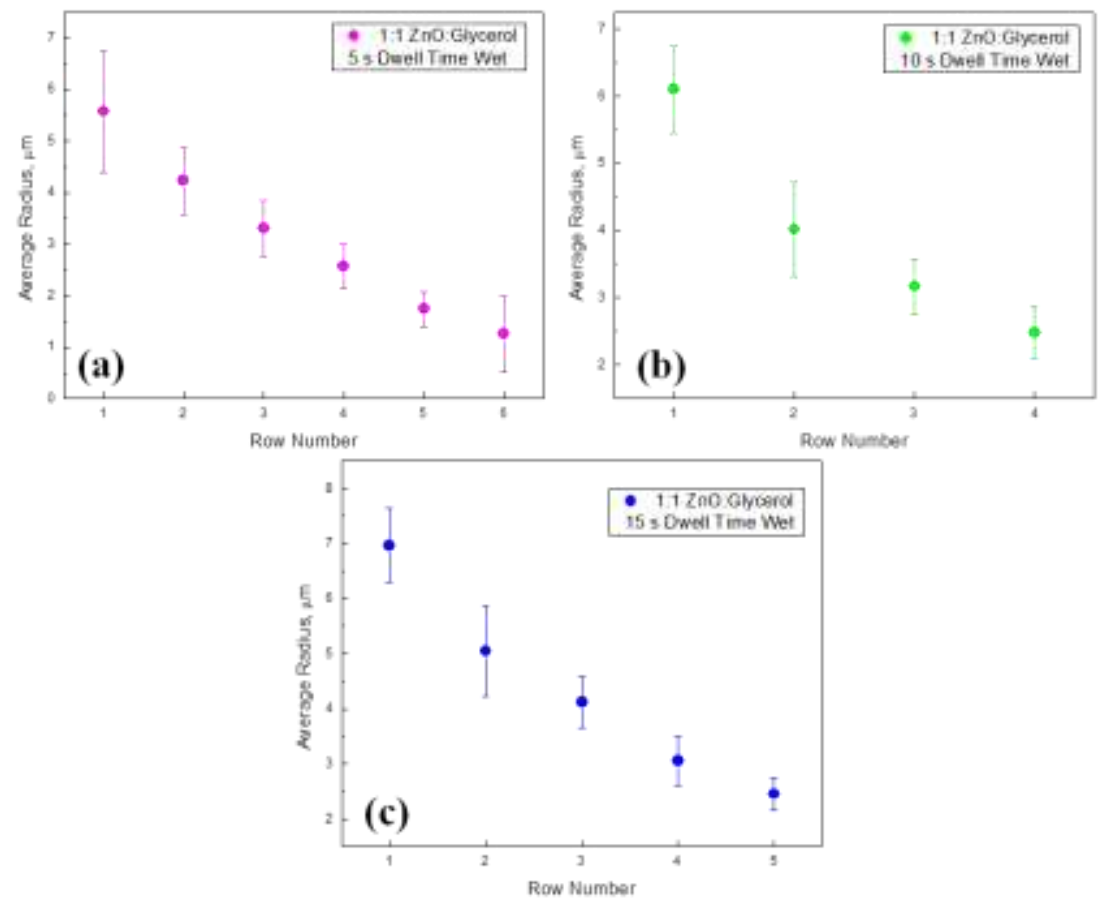

Figure 42: As deposited radius measurements as a function of row number for 1:1 $\mathrm{ZnO}$ to glycerol solution for different dwell times, (a) $5 \mathrm{~s}$, (b) $10 \mathrm{~s}$, (c) $15 \mathrm{~s}$. 


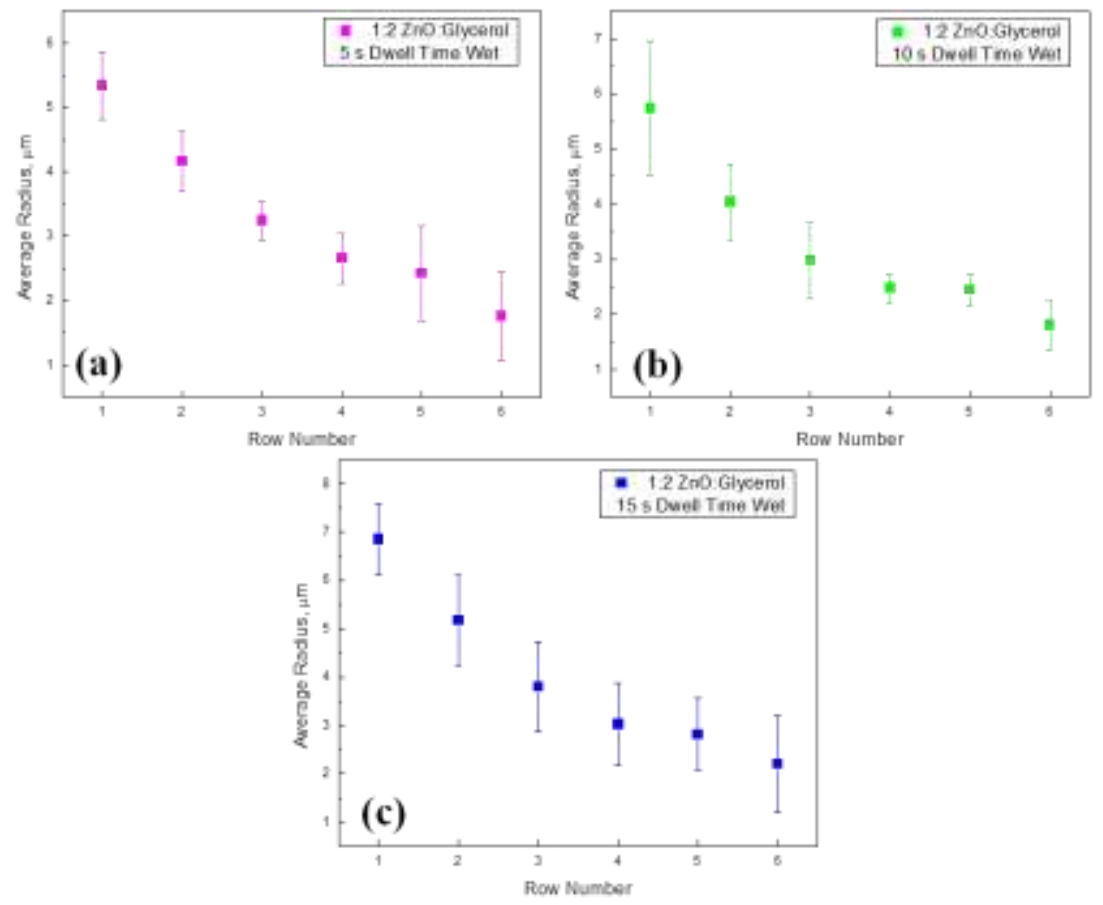

Figure 43: As deposited radius measurements as a function of row number for 1:2 ZnO to glycerol solution for different dwell times, (a) $5 \mathrm{~s}$, (b) $10 \mathrm{~s}$, (c) $15 \mathrm{~s}$.

The DPN patterns were then fired at $500^{\circ} \mathrm{C}$ to cure the $\mathrm{ZnO}$ dots and fully decompose the PVP release layer. After the drying process photos of the patterns were taken showing shrinkage of the dots. Figure 44, 45, and 46 illustrates typical dot arrays after firing. The 1:2 $\mathrm{ZnO}$ to glycerol solution with a $15 \mathrm{~s}$ dwell time could not be found. This could indicate that dots are on the nanoscale. Furthermore, the shrinkage can be explained by the model proposed Deegan et al. [110]. As indicated by this model, evaporation of the droplet initiates at the edge of the droplet resulting in contracted features, when the contact line is not fixed. 

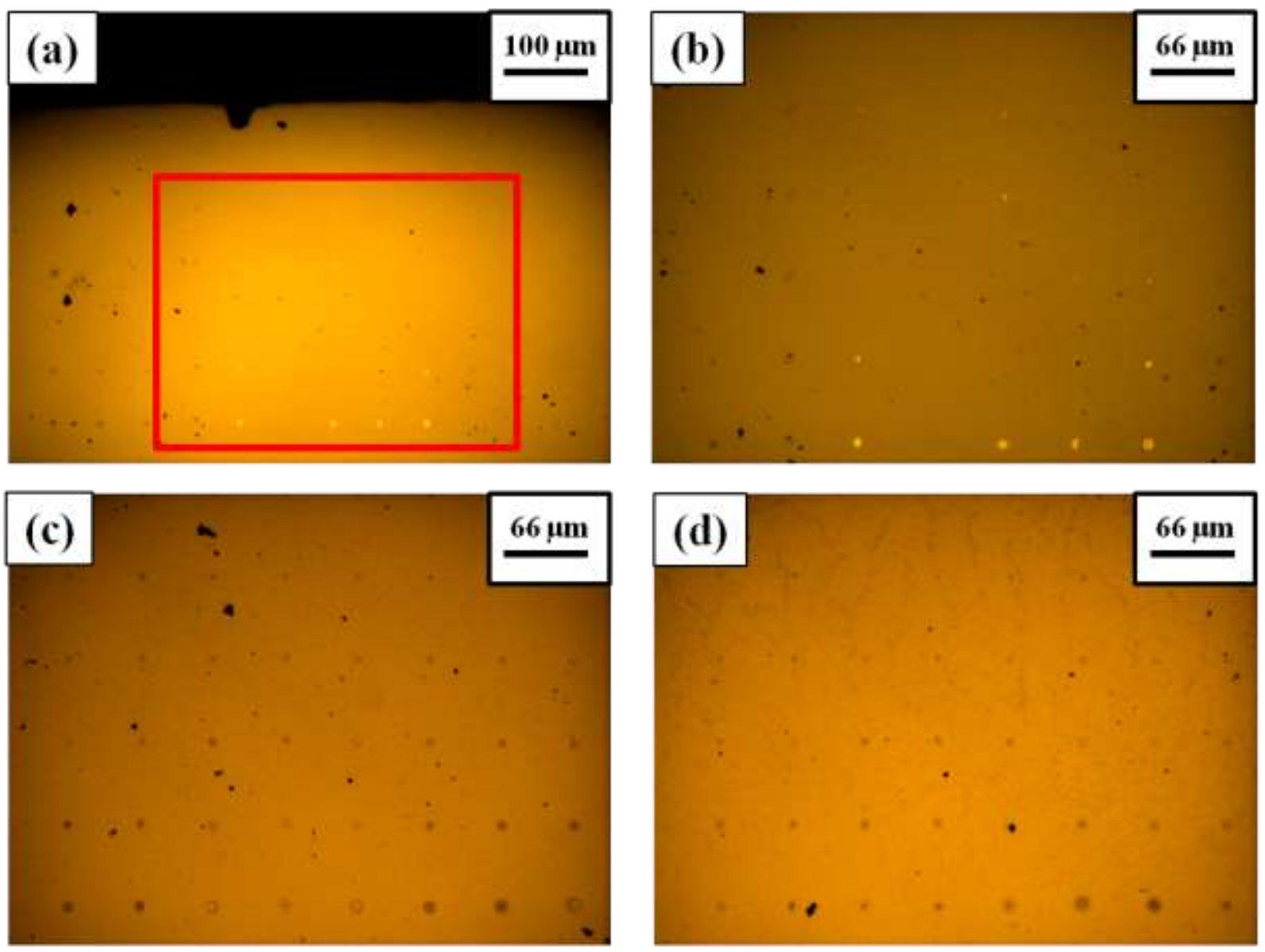

Figure 44: Fired 2:1 ZnO to glycerol on PVP release layer (a) $5 \mathrm{~s}$ dwell time, (b) magnified image of highlighted area of (a), (c) $10 \mathrm{~s}$ dwell time, (d) $15 \mathrm{~s}$ dwell time. 

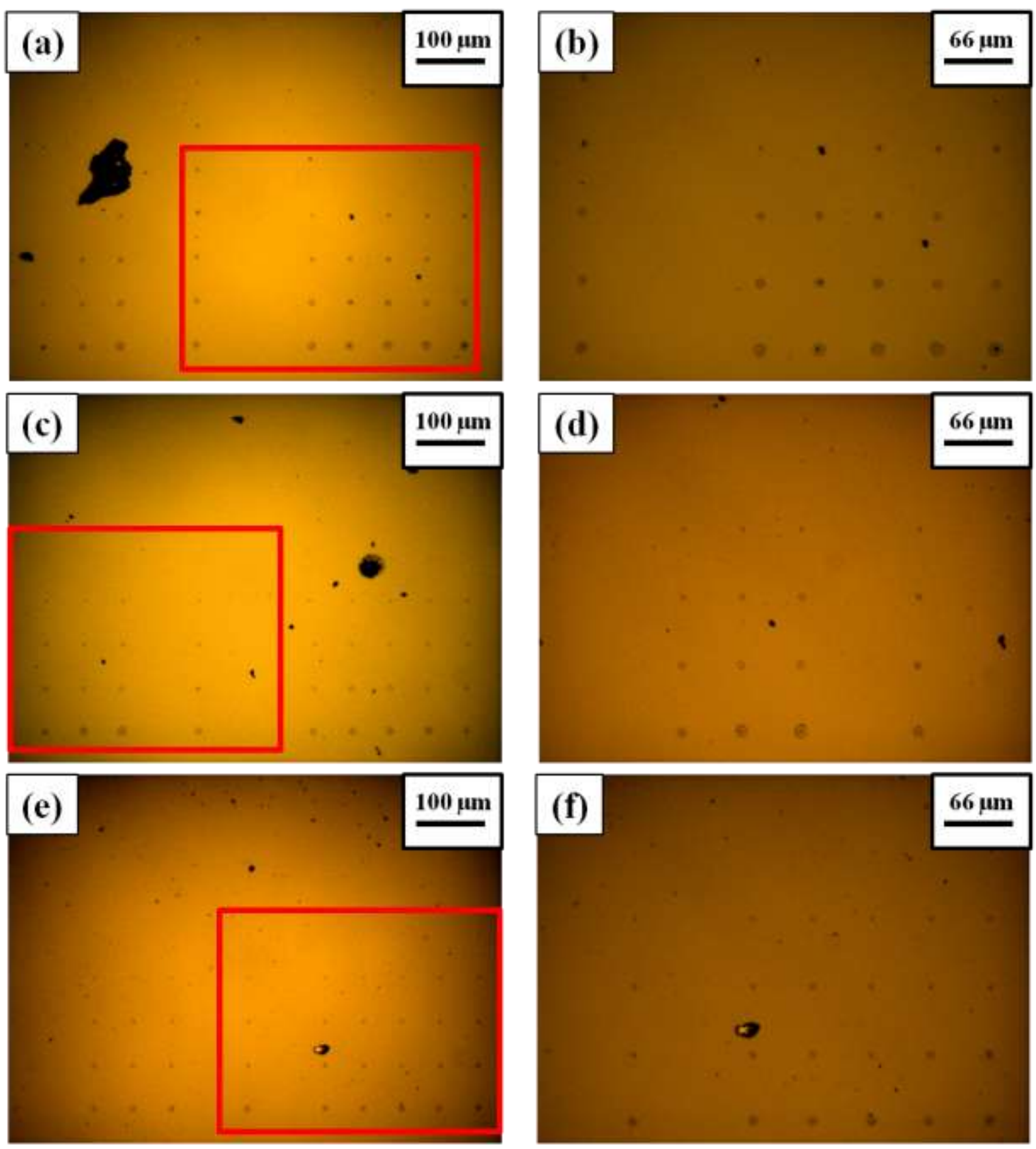

Figure 45: Fired 1:1 ZnO to glycerol on PVP release layer for different dwell times (a) $5 \mathrm{~s}$, (b) magnified image of highlighted area of (a), (c) $10 \mathrm{~s}$, (d) magnified image of highlighted area of (c), (e) $15 \mathrm{~s}$, (f) magnified image of highlighted area of (e). 

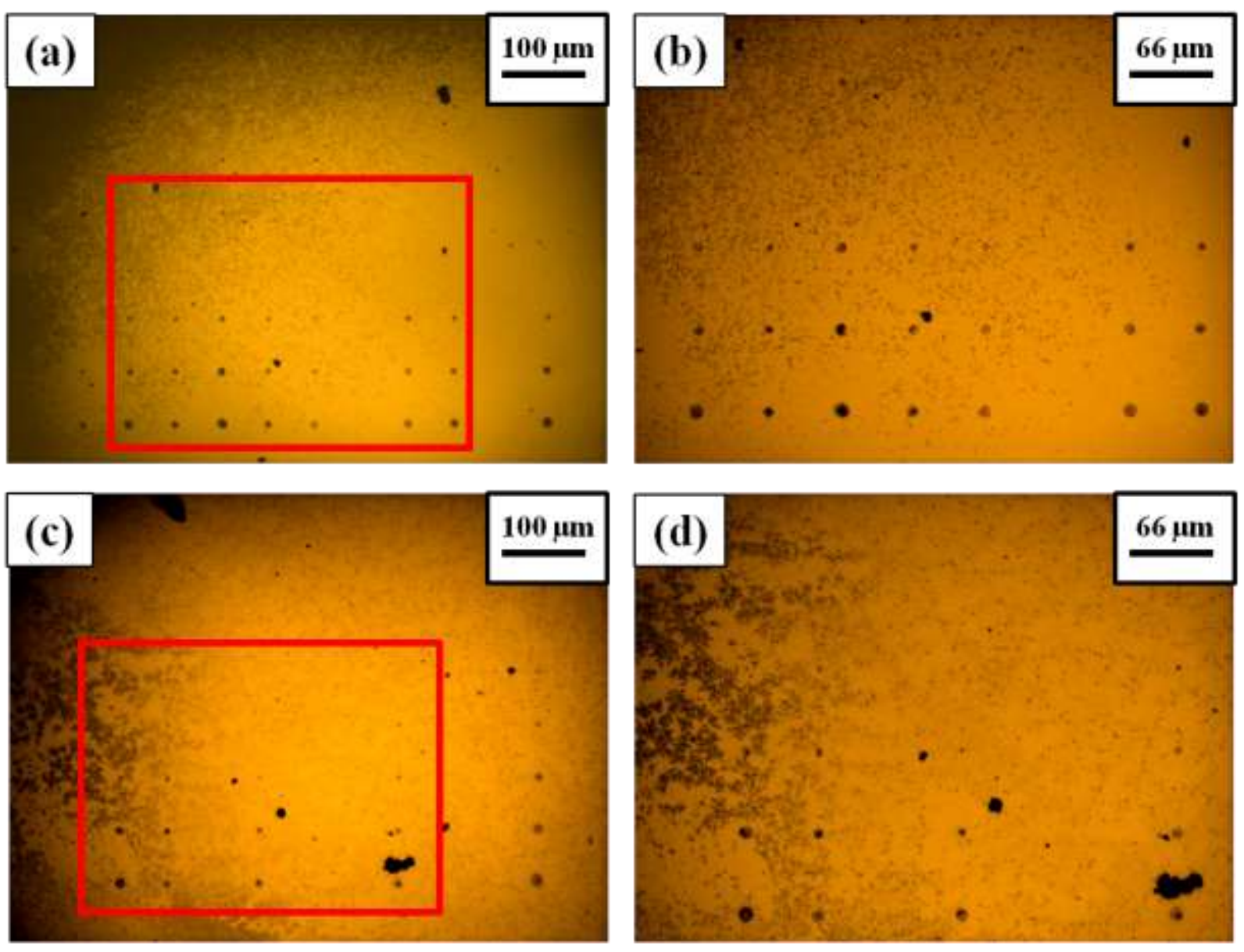

Figure 46: Fired 1:2 ZnO to glycerol on PVP release layer for different dwell times (a) $5 \mathrm{~s}$, (b) magnified image of highlighted area of (a), (c) $10 \mathrm{~s}$, (d) magnified image of highlighted area of (c).

Using ImageJ, photos of the fired drops were analyzed to quantify the amount of shrinkage. Figure 47, 48, and 49 depicts the measured average radii for the fired droplets. From observation of the data, a linear relation is detected for the fired radii decreasing as a function of row number. Demonstrating larger sized droplets evaporate at a faster rate than smaller droplets, which is supported by previous studies [110]. Explaining that the total evaporation rate is equal to $4 \pi \mathrm{R}$, where $\mathrm{R}$ is the radius of the drop at the base. To further illustrate this outcome, comparison graphs of the as deposited and fired drops radii are shown in Figure 50, 51 and 52. 

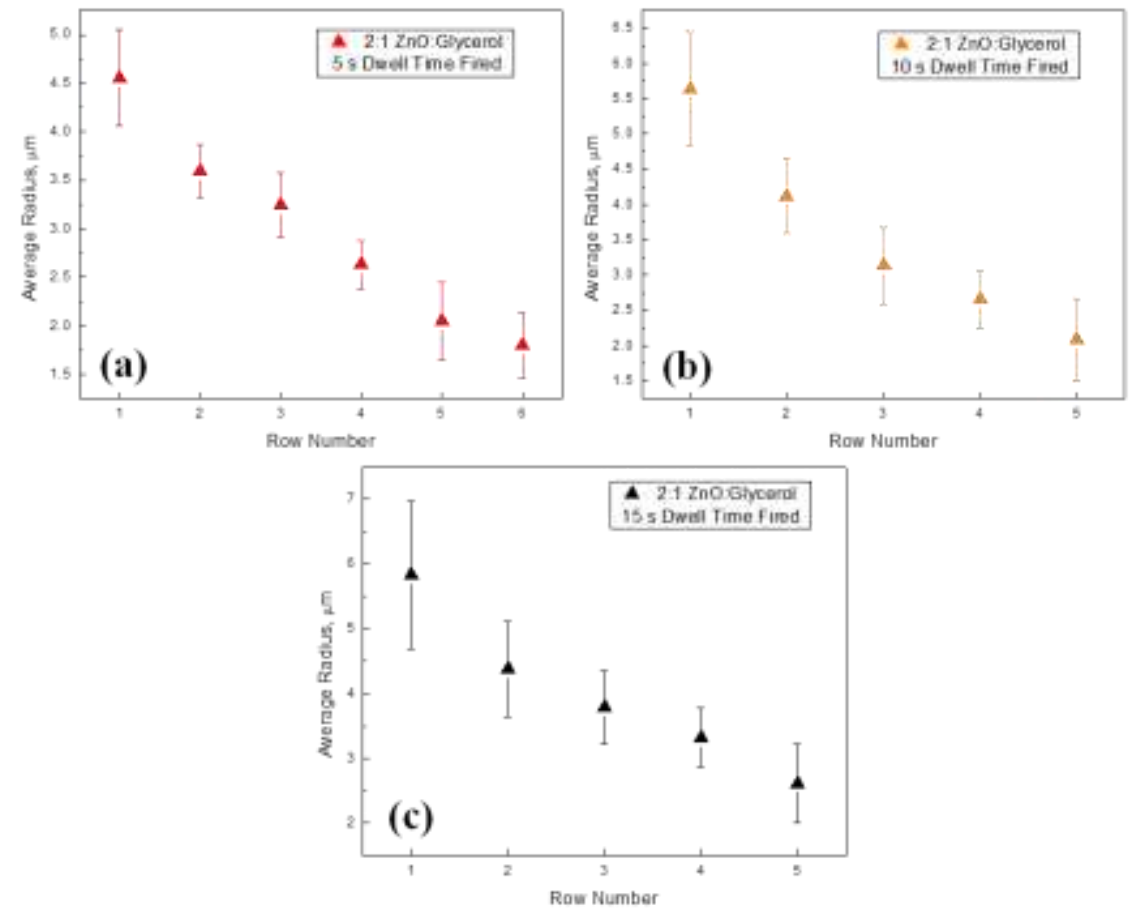

Figure 47: Fired radius measurements as a function of row number for 2:1 $\mathrm{ZnO}$ to glycerol solution, (a) $5 \mathrm{~s}$ dwell time, (b) $10 \mathrm{~s}$ dwell time, (c) $15 \mathrm{~s}$ dwell time.

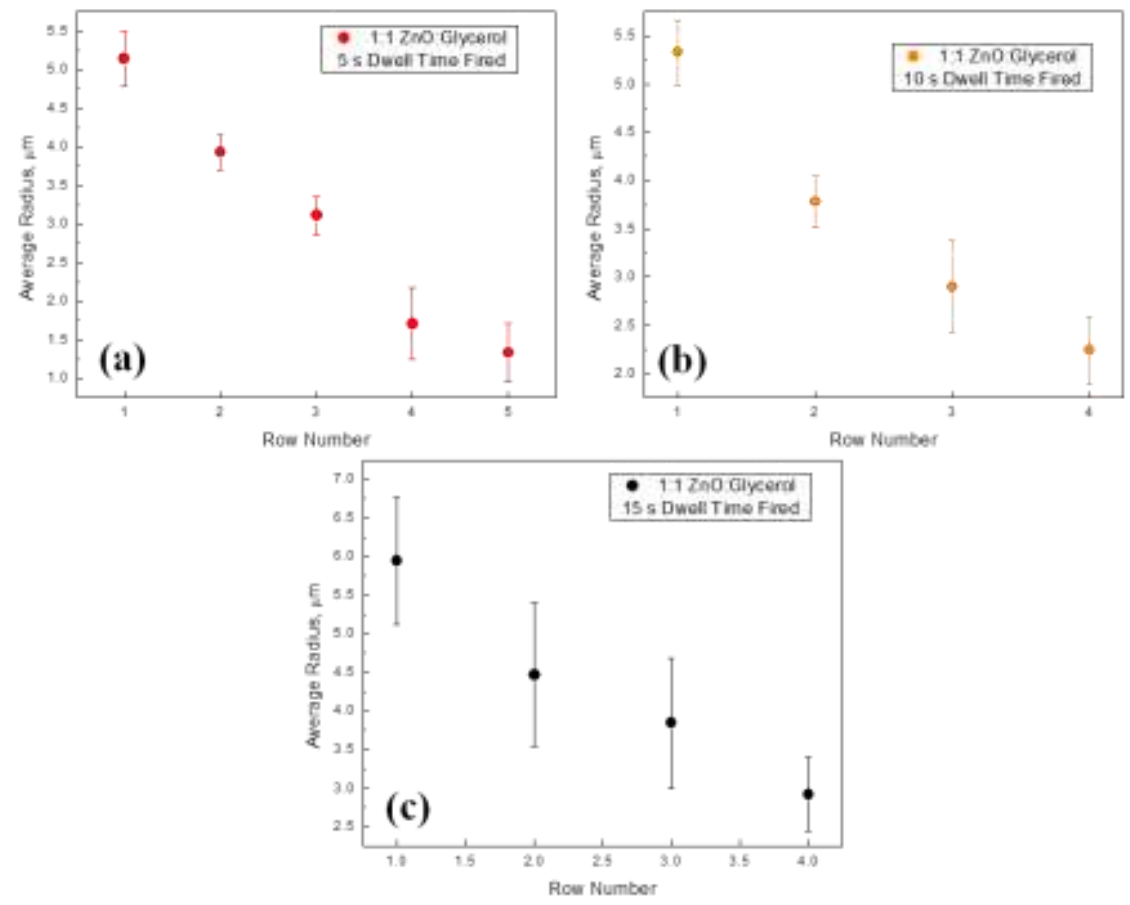

Figure 48: Fired radius measurements as a function of row number for 1:1 $\mathrm{ZnO}$ to glycerol solution, (a) $5 \mathrm{~s}$ dwell time, (b) $10 \mathrm{~s}$ dwell time, (c) $15 \mathrm{~s}$ dwell time. 

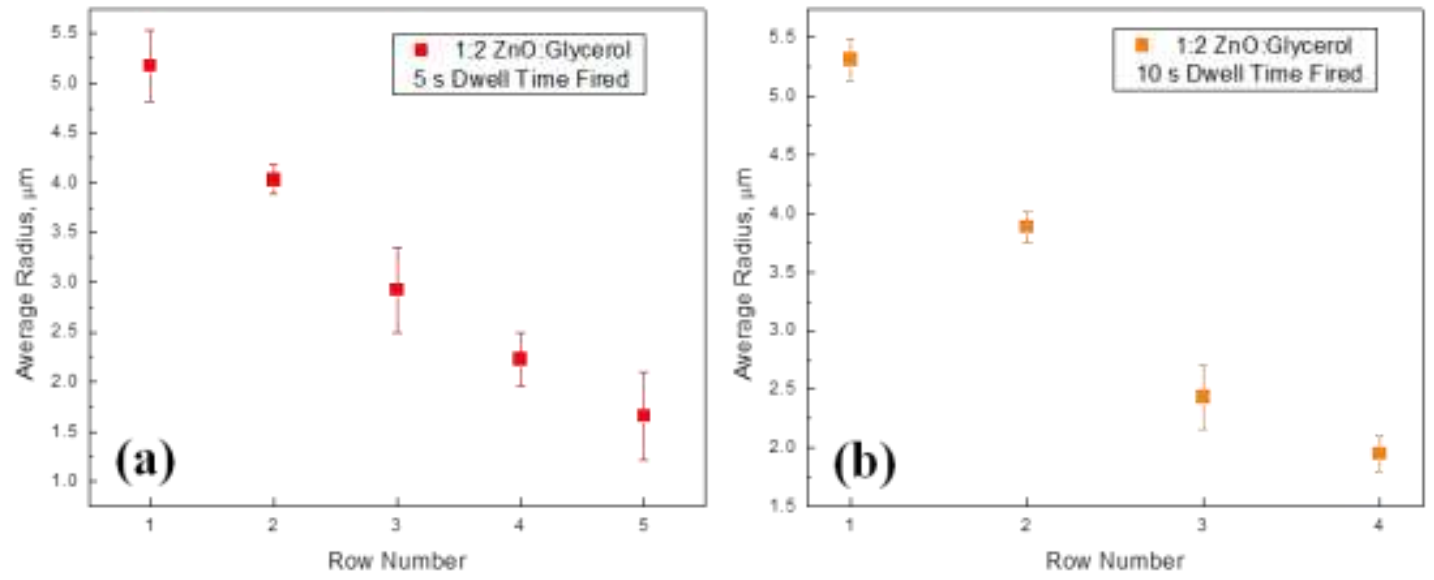

Figure 49: Fired radius measurements as a function of row number for 1:2 $\mathrm{ZnO}$ to glycerol solution, (a) $5 \mathrm{~s}$ dwell time, (b) $10 \mathrm{~s}$ dwell time, (c) $15 \mathrm{~s}$ dwell time.
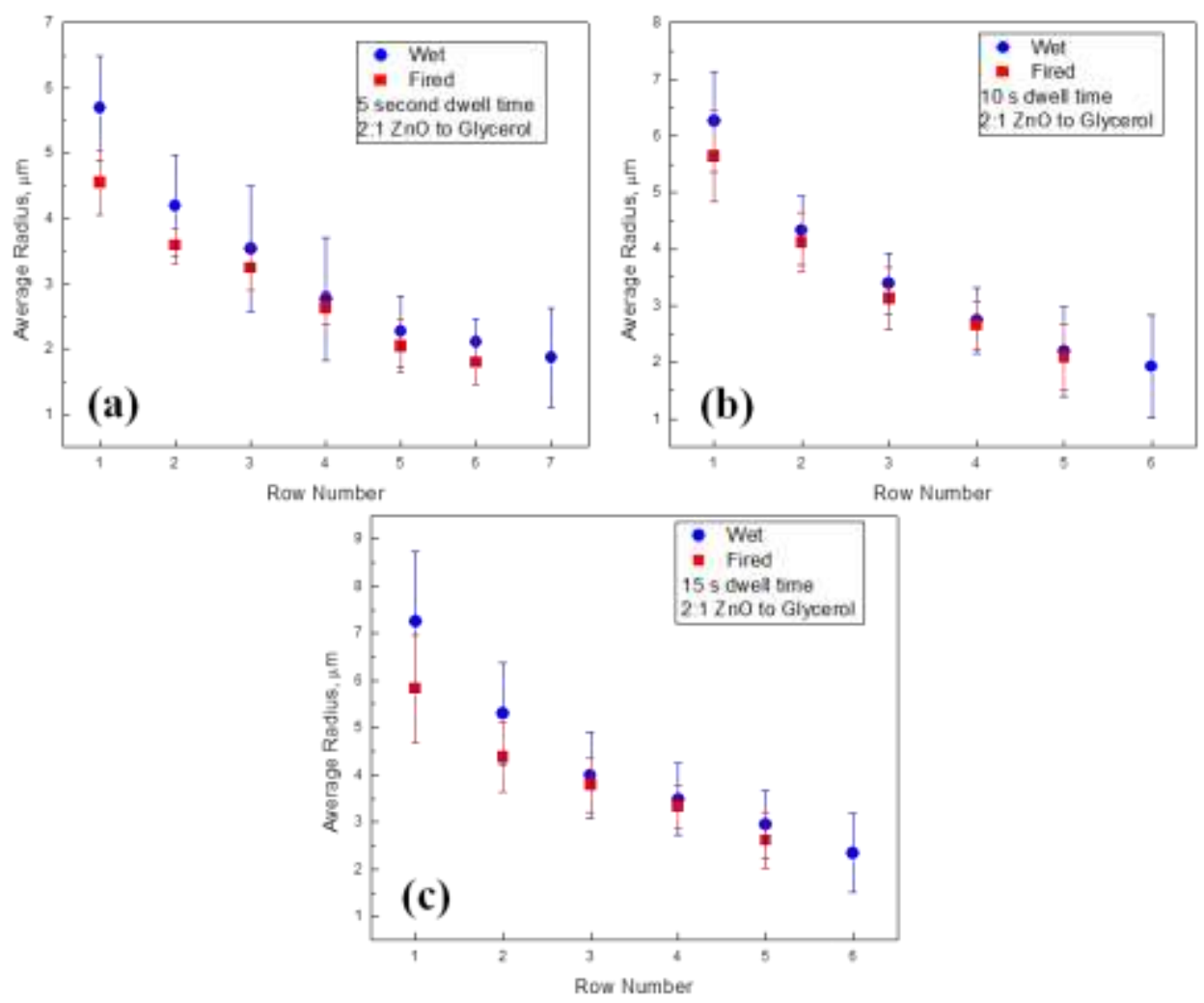

Figure 50: Comparison of wet and fired radii for 1:1 $\mathrm{ZnO}$ to glycerol, (a) $5 \mathrm{~s}$ dwell time, (b) $10 \mathrm{~s}$ dwell time, (c) $15 \mathrm{~s}$ dwell time. 

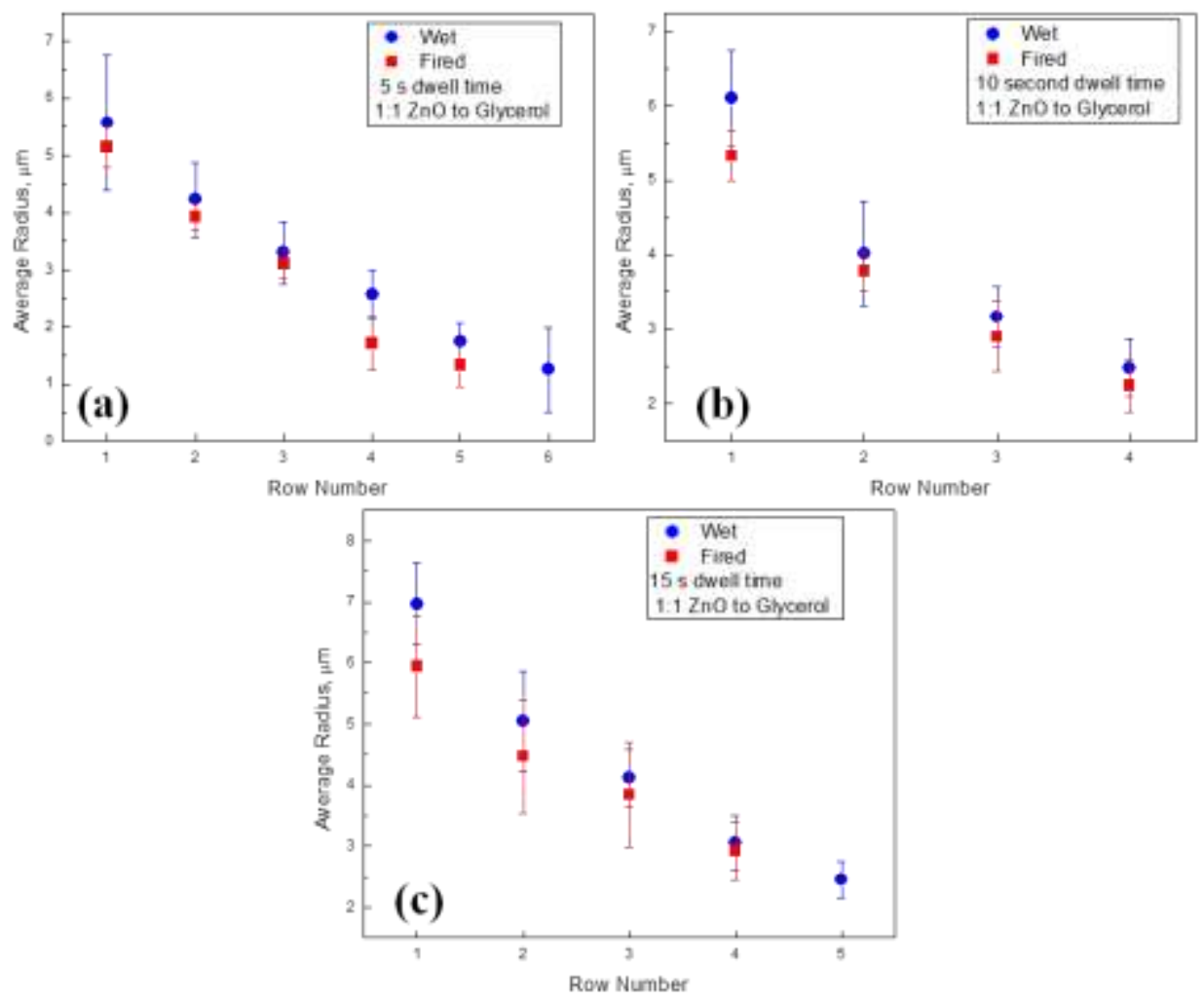

Figure 51: Comparison of wet and fired radii for 1:1 $\mathrm{ZnO}$ to glycerol, (a) $5 \mathrm{~s}$ dwell time, (b) $10 \mathrm{~s}$ dwell time, (c) $15 \mathrm{~s}$ dwell time.
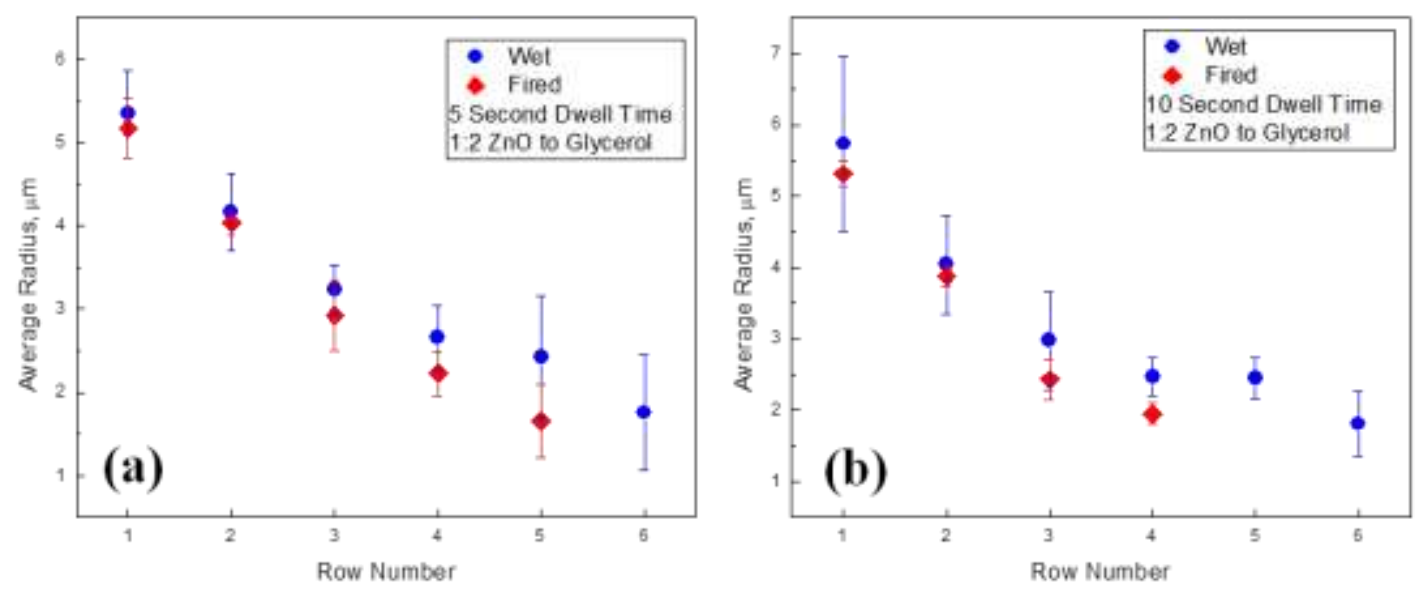

Figure 52: Comparison of wet and fired radii for 1:2 $\mathrm{ZnO}$ to glycerol, (a) $5 \mathrm{~s}$ dwell time, (b) $10 \mathrm{~s}$ dwell time.

The fired patterns were then transferred onto PEN substrates using a hot-press set to $170^{\circ} \mathrm{C}$. Figure 53 displays images of the $\mathrm{ZnO}$ dot arrays on PEN. It was seen that only the $15 \mathrm{~s}$ 
dwell times were transferred. Additionally, only the first three rows could be identified. During the transfer process about a $1 \mu \mathrm{m}$ loss in radius of the $\mathrm{ZnO}$ dots is observed. The measured average radii are displayed in Figure 54. Moreover, significant amounts of debris were recognized while trying to find transferred microdots.
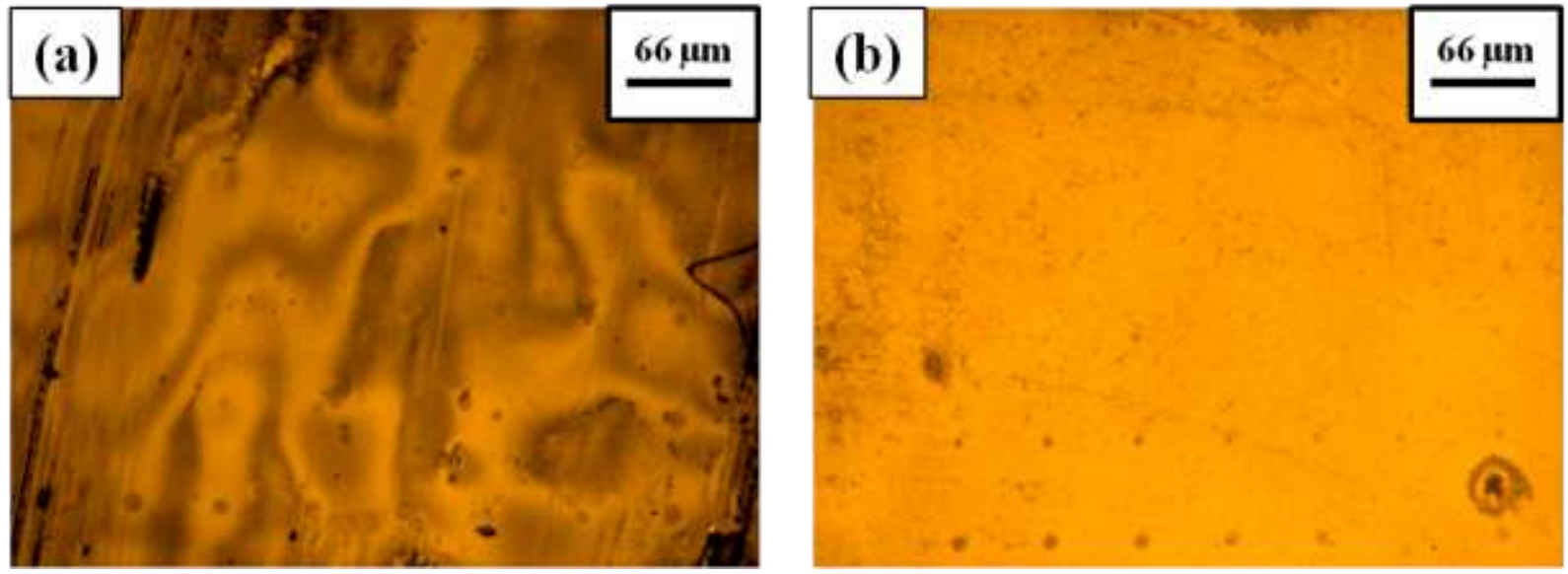

Figure 53: Transferred ZnO dot arrays on PEN. Dwell time is 15s, (a) 2:1 ZnO to Glycerol, (b) 1:1 ZnO to Glycerol.
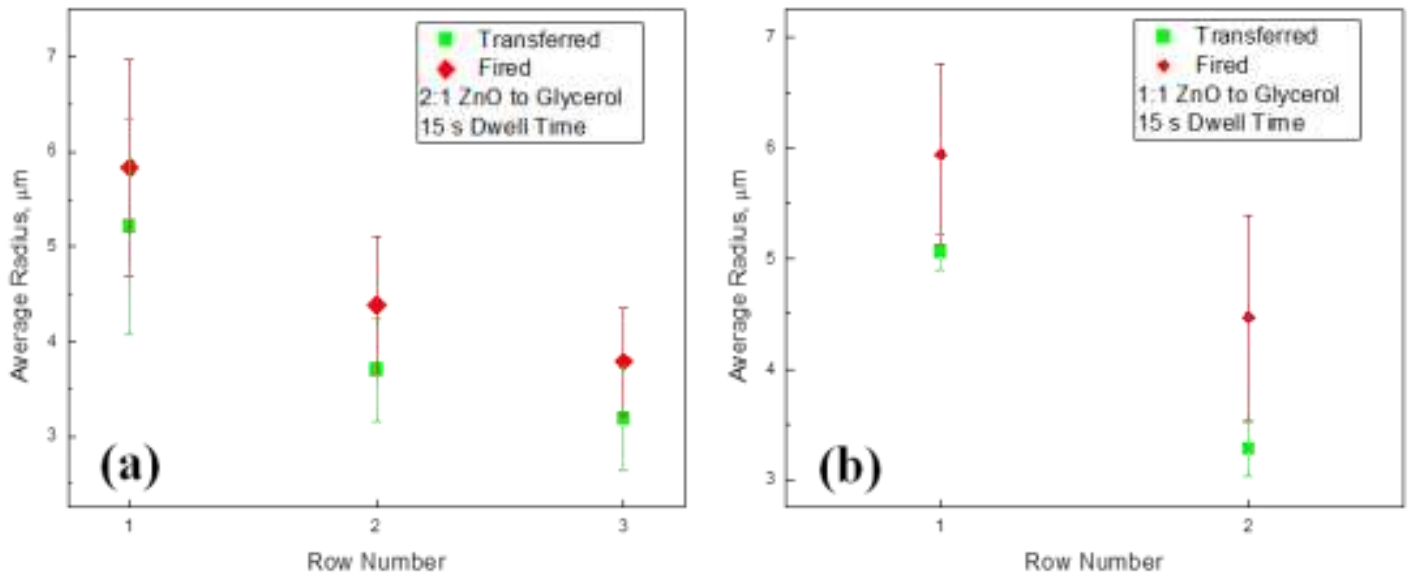

Figure 54: Comparison of fired and transferred radii for $15 \mathrm{~s}$ dwell time, (a) 2:1 ZnO to Glycerol (b) 1:1 ZnO to Glycerol.

Transfer of a $\mathrm{ZnO}$ film was attempted to study the transfer process further. The $\mathrm{ZnO}$ film was deposited on to a PVP-coated glass substrate via spin coating, the resulting film is shown in Figure 55. It is observed the most of the PEN surface is coated. Although, there are some voids 
in the film. This can be attributed to a number of reasons including uneven surface features causing no contact between the polymer and film, debris on the film, void in release layer allowing the film to adhere to the rigid substrate, shearing between the film and substrate, and/or edge effects.

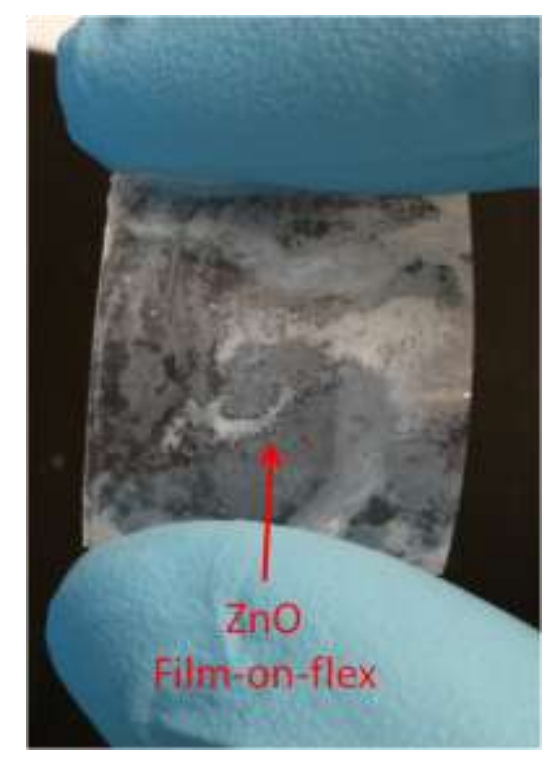

Figure 55: Image of transferred ZnO film on a flexible PEN substrate.

To understand if a crystallized $\mathrm{ZnO}$ film was transferred to the PEN substrate, XRD was performed on the sample. The XRD spectrum of the transferred film is shown in Figure 56. No peaks corresponding to crystallized $\mathrm{ZnO}$ film were observed. This could be attributed to a few different issues. The film may not be thick enough, not full transfer, and/or the film is still amorphous. In addition, there is an unusual peak around $56^{\circ}$. Further tests are needed but promising results of transfer have been reported in the past [102,103]. 


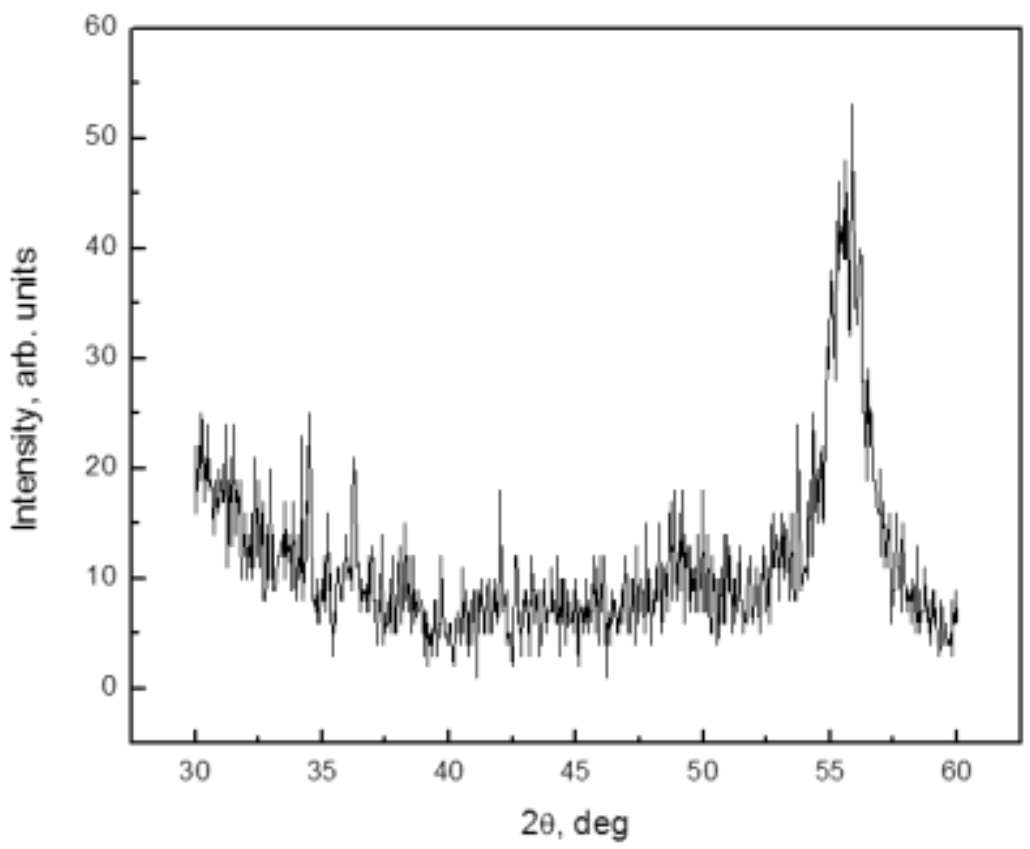

Figure 56: X-ray diffraction pattern of a $2 \theta$ scan for the transferred $\mathrm{ZnO}$ film

\subsection{Dip-Pen Nanolithography of YAG:Ce Patterns}

Furthermore, YAG:Ce was attempted to prove more complex chemistries could also be used in this fabrication process. The viscosities of the inks used for the patterning of YAG:Ce are shown below in Figure 57. Initially, deposition of dots was attempted under ambient conditions of $23^{\circ} \mathrm{C}$ and $30 \%$ humidity, but these conditions proved to be unsuccessful. Then the humidity was increased to $70 \%$ in the environmental chamber, exhibiting some promise but a limited amount of YAG:Ce was deposited. The humidity was then increased to $90 \%$, which proved to have successful patterning. Increasing the humidity promotes an enlarged meniscus that is formed between the tip and substrate surface, allowing for an increase in ink transportation to the surface [109]. Additionally, writing could not be completed with the 2:3 and 1:1 YAG to PVA solutions. This signifies a viscosity threshold of $10 \mathrm{cP}$, above which direct writing is challenging. 


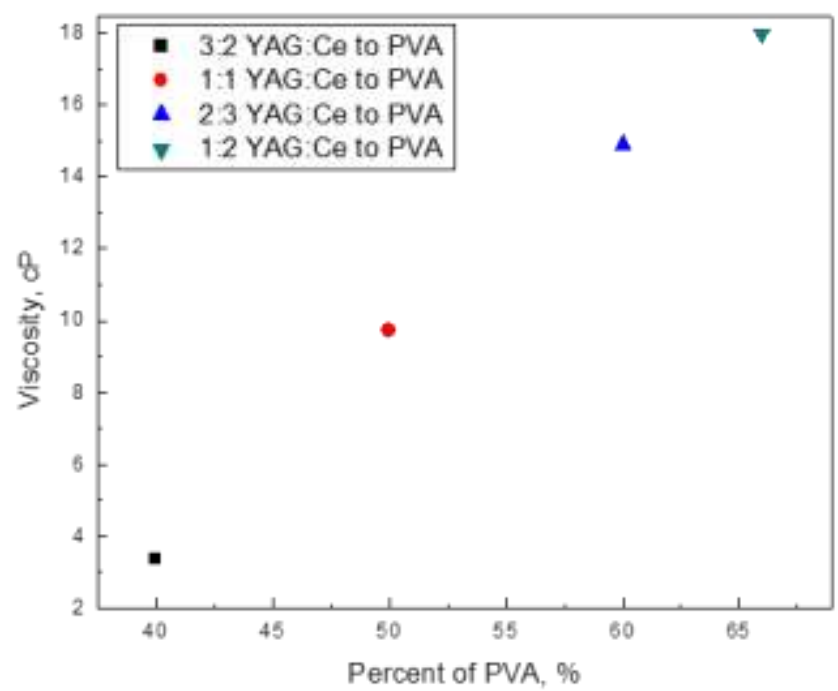

Figure 57: Viscosity of inks used for DPN as a percentage of PVA.

Images of the as deposited YAG dots are shown in Figure 58 and 59. As with the $\mathrm{ZnO}$, the average radius as a function of row number was measured using ImageJ. The data is shown in Figure 60. Although, unlike $\mathrm{ZnO}$, both YAG solutions showed a decreasing linear relation with row number. Moreover, the 3:2 YAG to PVA solution displays average larger radii as compared to the 1:1 solution, attributed to the higher transfer rate for lower viscosities. 

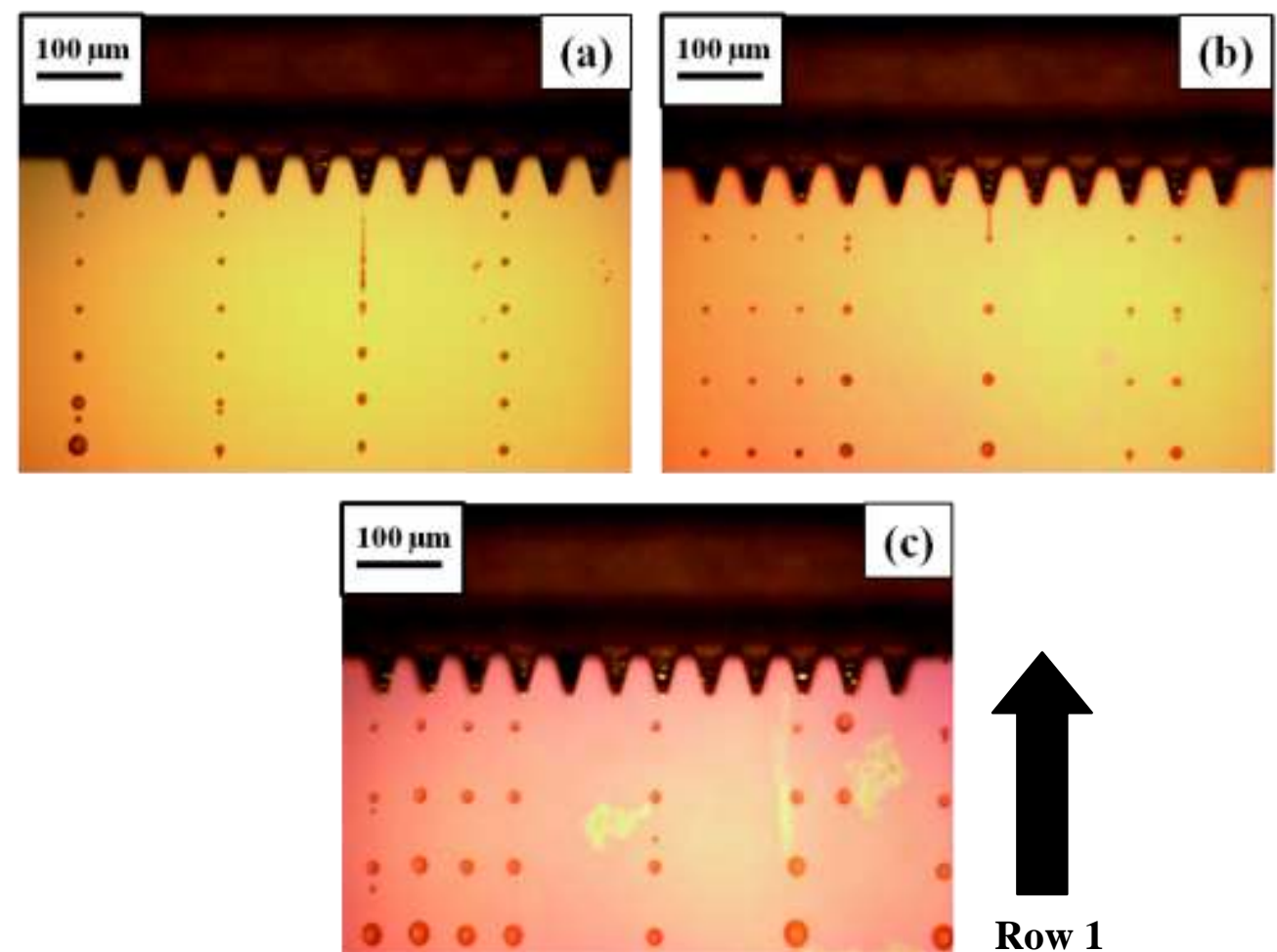

Figure 58: As deposited 3:2YAG:Ce to PVA dots on a PVP release layer for different dwell times (a) $5 \mathrm{~s}$, (b) $10 \mathrm{~s}$, (c) $15 \mathrm{~s}$. The arrow indicates tip movement.
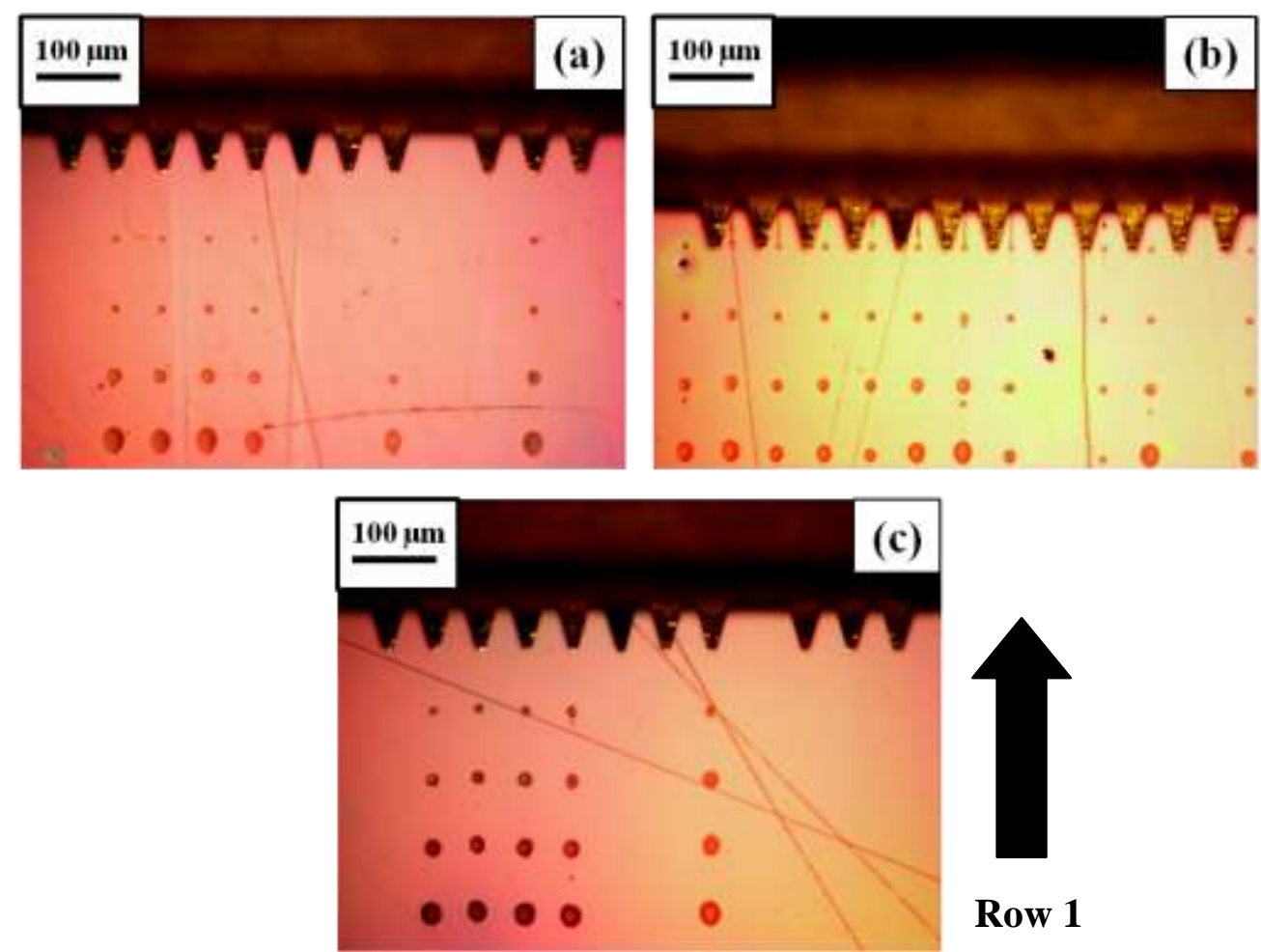

Row 1

Figure 59: As deposited 1:1 YAG:Ce to PVA dots on a PVP release layer for different dwell times (a) $5 \mathrm{~s}$, (b) $10 \mathrm{~s}$, (c) $15 \mathrm{~s}$. The arrow indicates tip movement. 


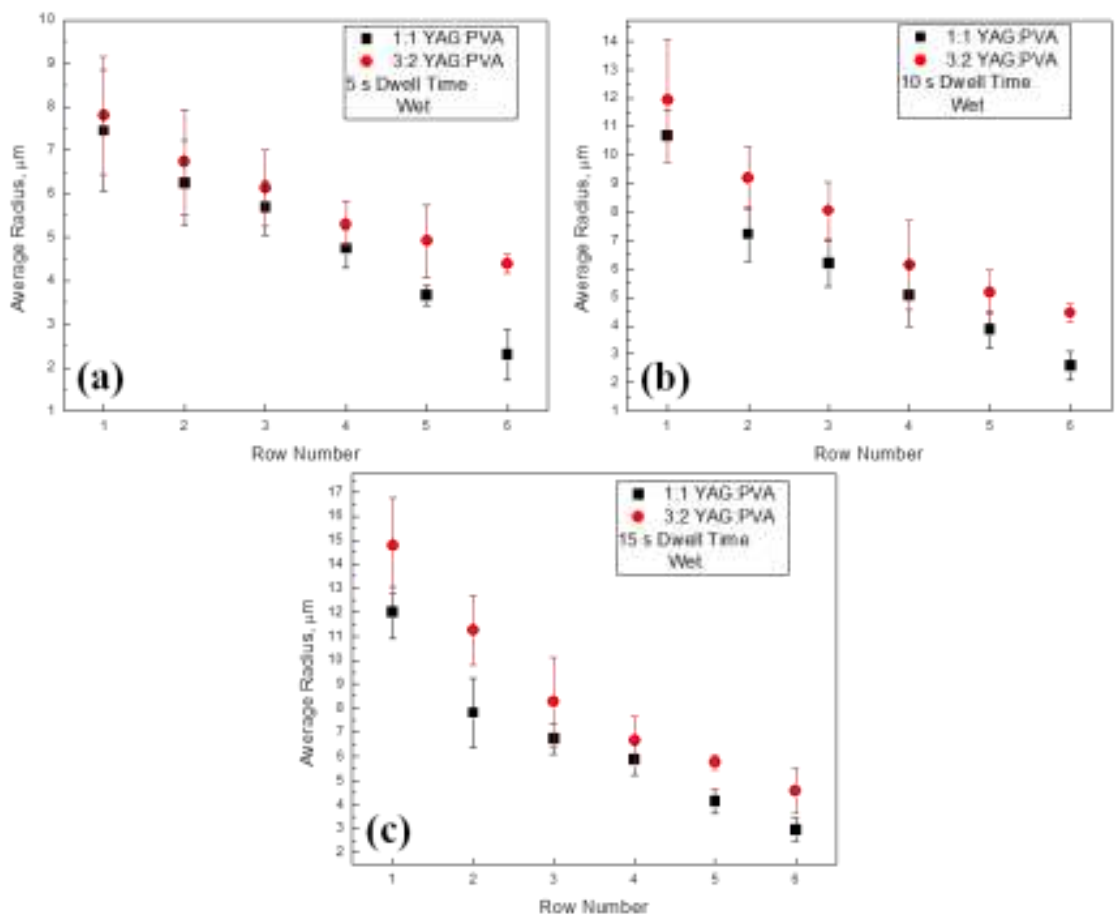

Figure 60: As deposited radius measurements as a function of row number for 3:2 and 1:1 YAG:Ce to PVA solution for different dwell times (a) $5 \mathrm{~s}$, (b) $10 \mathrm{~s}$, (c) $15 \mathrm{~s}$.

The arrays of YAG:Ce droplets were then fired at $500^{\circ} \mathrm{C}$ to decompose the PVP release layer. Typical images of the fired dots are shown in Figure 61 and 62. Additionally, Figure 63 displays typical SEM image of a 1:1 YAG:Ce to PVA dot with a $15 \mathrm{~s}$ dwell time. It is observed that the drying process is initiated at the edges. Coarsening and sintering mechanisms are also noticed along with minor micro-cracking at the center of the dot. The average fired radii per row were found to have a linear digression from the first row. The measured results are illustrated in Figure 64. 

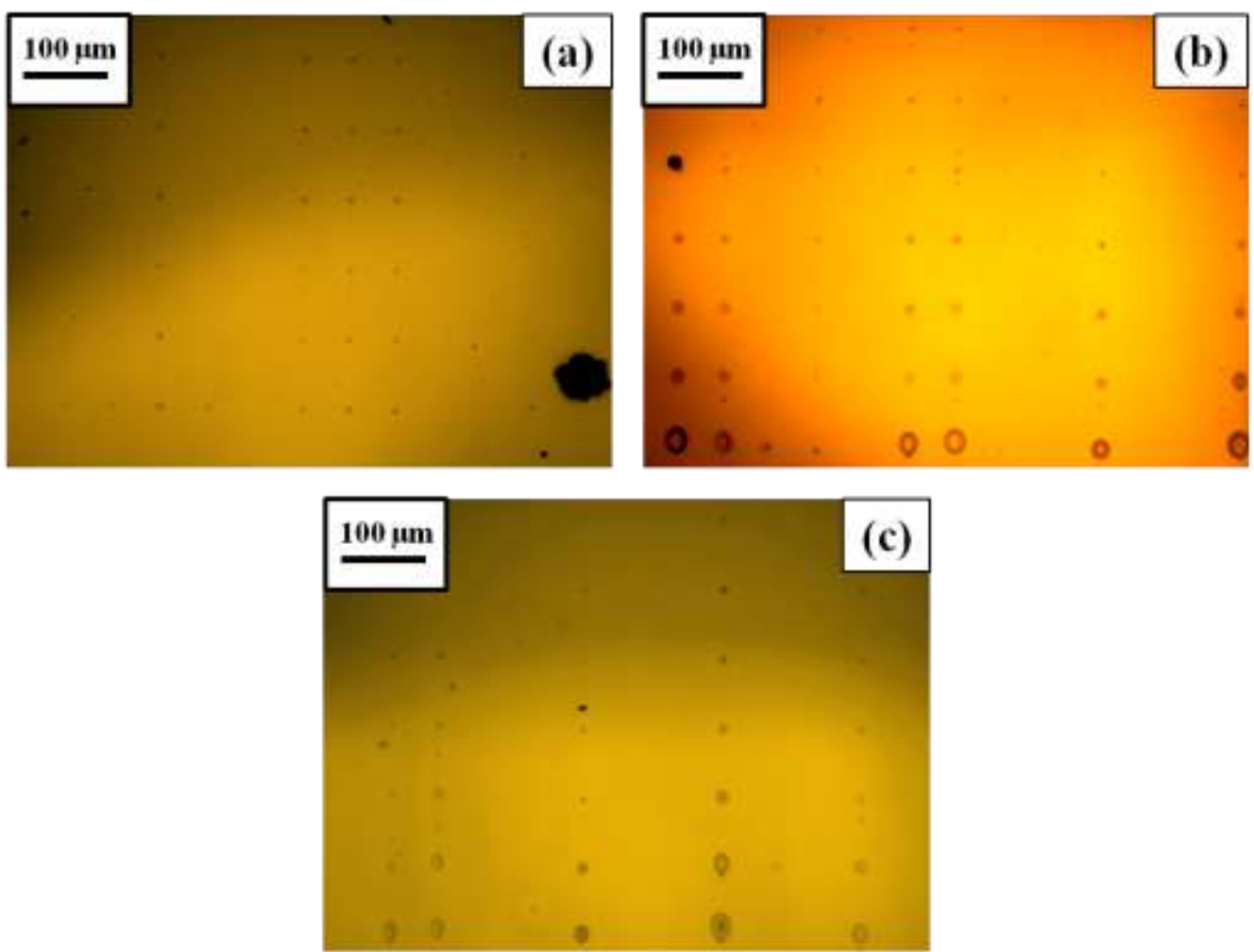

Figure 61: Fired 3:2 YAG:Ce to PVA on PVP release layer for different dwell times (a) $5 \mathrm{~s}$, (b) $10 \mathrm{~s}$, (c) $15 \mathrm{~s}$.
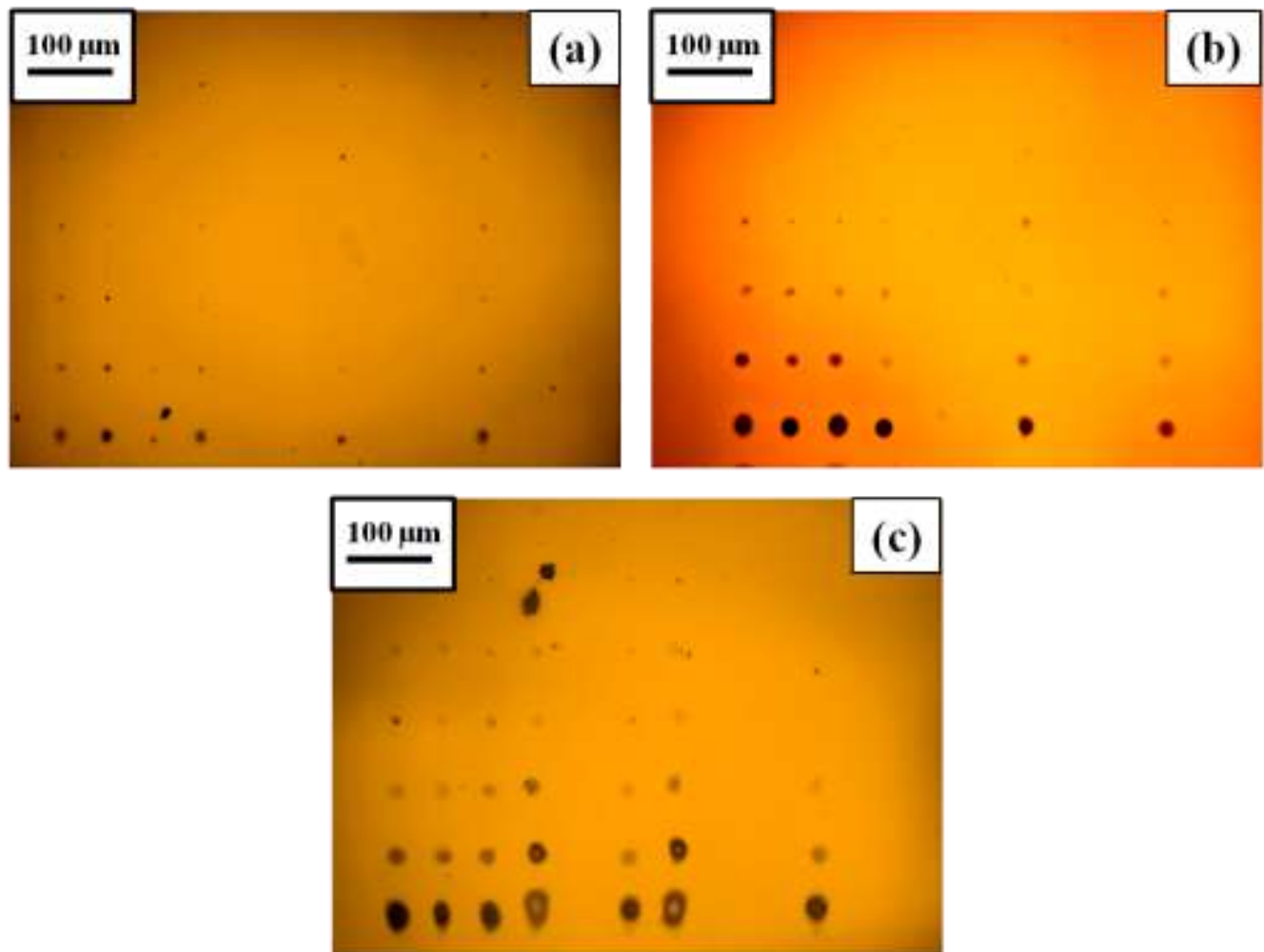

Figure 62: Fired 3:2 YAG:Ce to PVA on PVP release layer for different dwell times (a) $5 \mathrm{~s}$, (b) $10 \mathrm{~s}$, (c) $15 \mathrm{~s}$. 


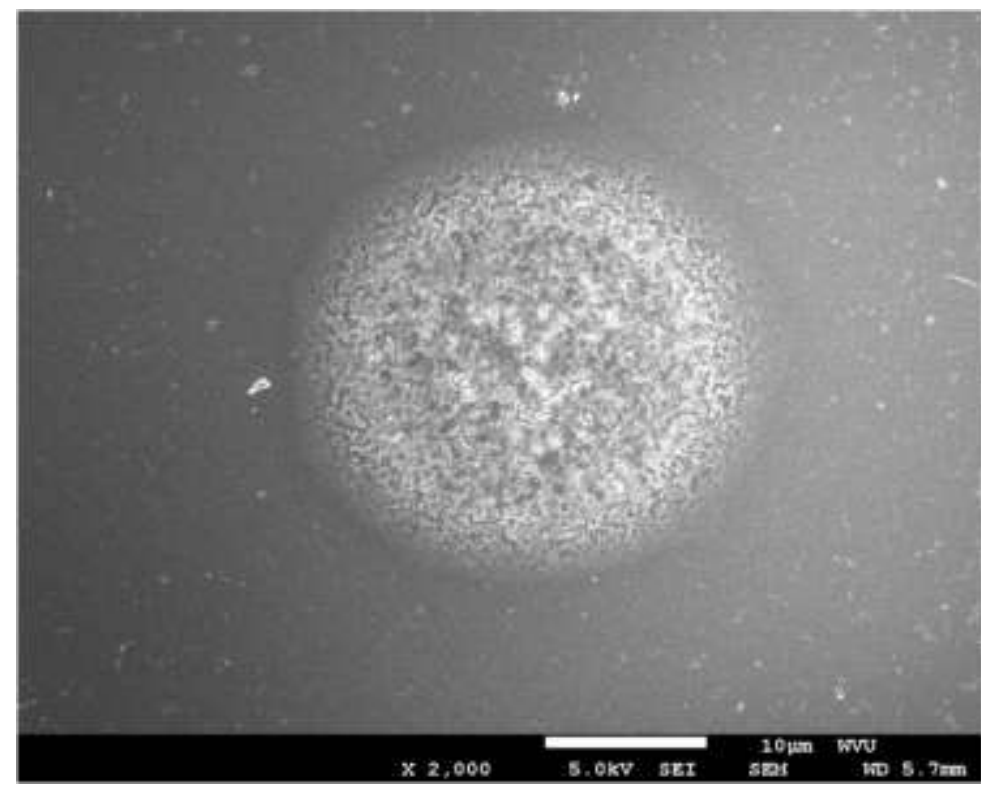

Figure 63: Typical SEM image of a YAG:Ce fired dot on a PVP release layer. Dwell time is $15 \mathrm{~s}$ and 1:1 YAG to PVA solution.
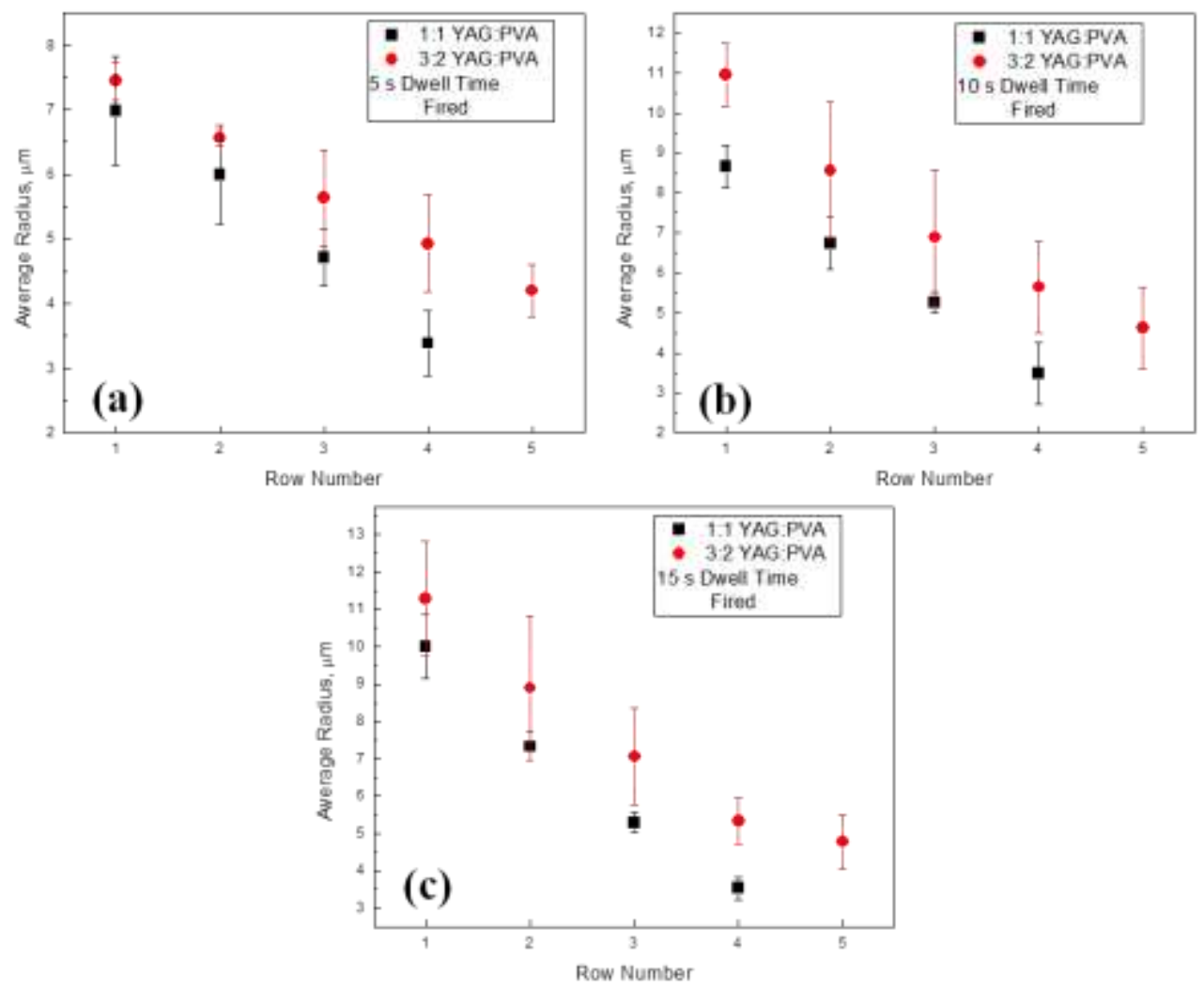

Figure 64: Fired radius measurements as a function of row number for 3:2 and 1:1 YAG:Ce to PVA solution for different dwell times, (a) $5 \mathrm{~s}$, (b) $10 \mathrm{~s}$, (c) $15 \mathrm{~s}$. 
Comparison graphs of the wet and fired measured radii are shown in Figure 65 and 66. It is observed that the longer dwell times have larger contraction for the fired radii. Also, the fired radii maintain the decreasing linear relation with row number.

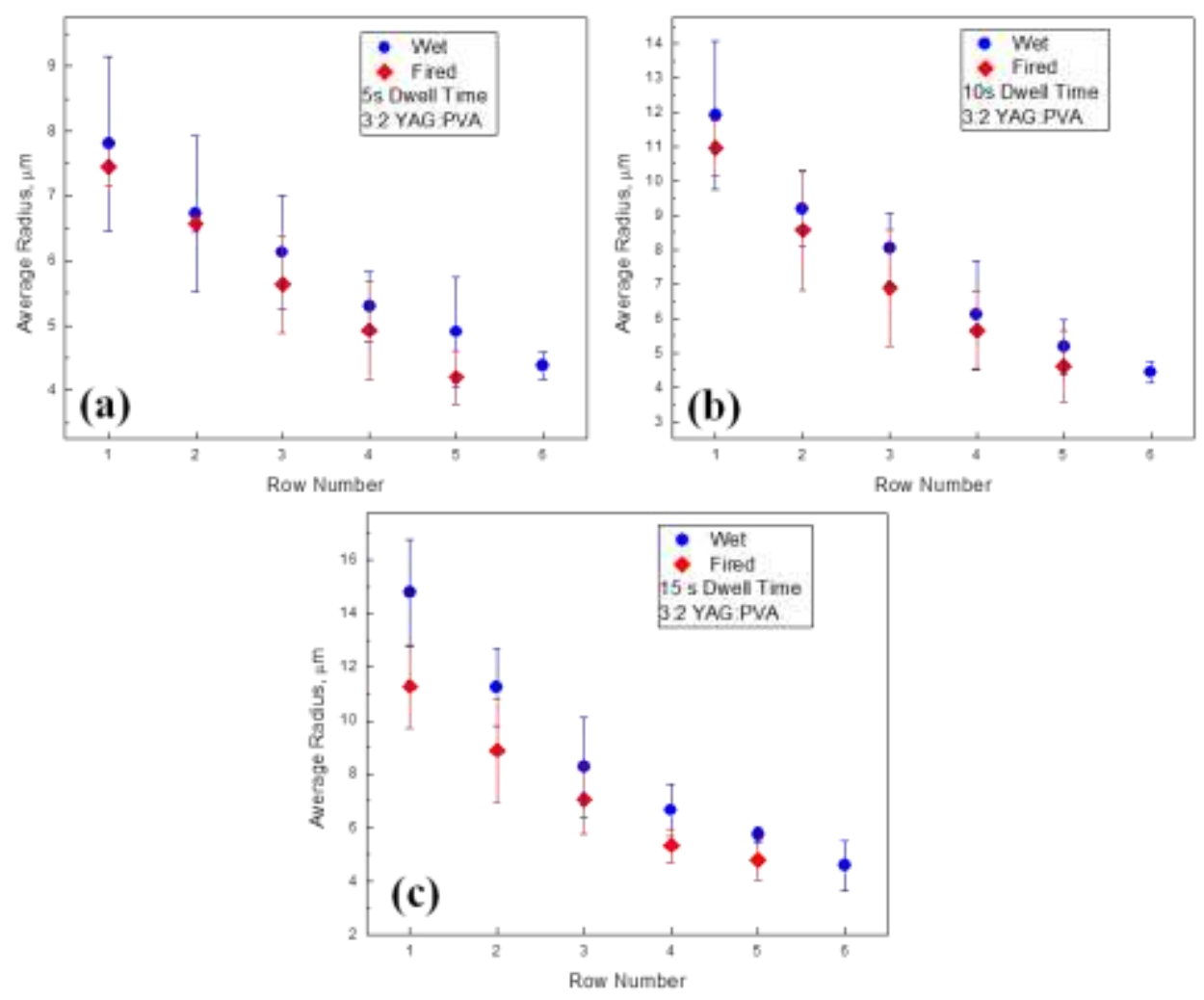

Figure 65: Comparison of wet and fired radii for 3:2 YAG:Ce to PVA for different dwell times, (a) $5 \mathrm{~s}$, (b) $10 \mathrm{~s}$, (c) $15 \mathrm{~s}$. 

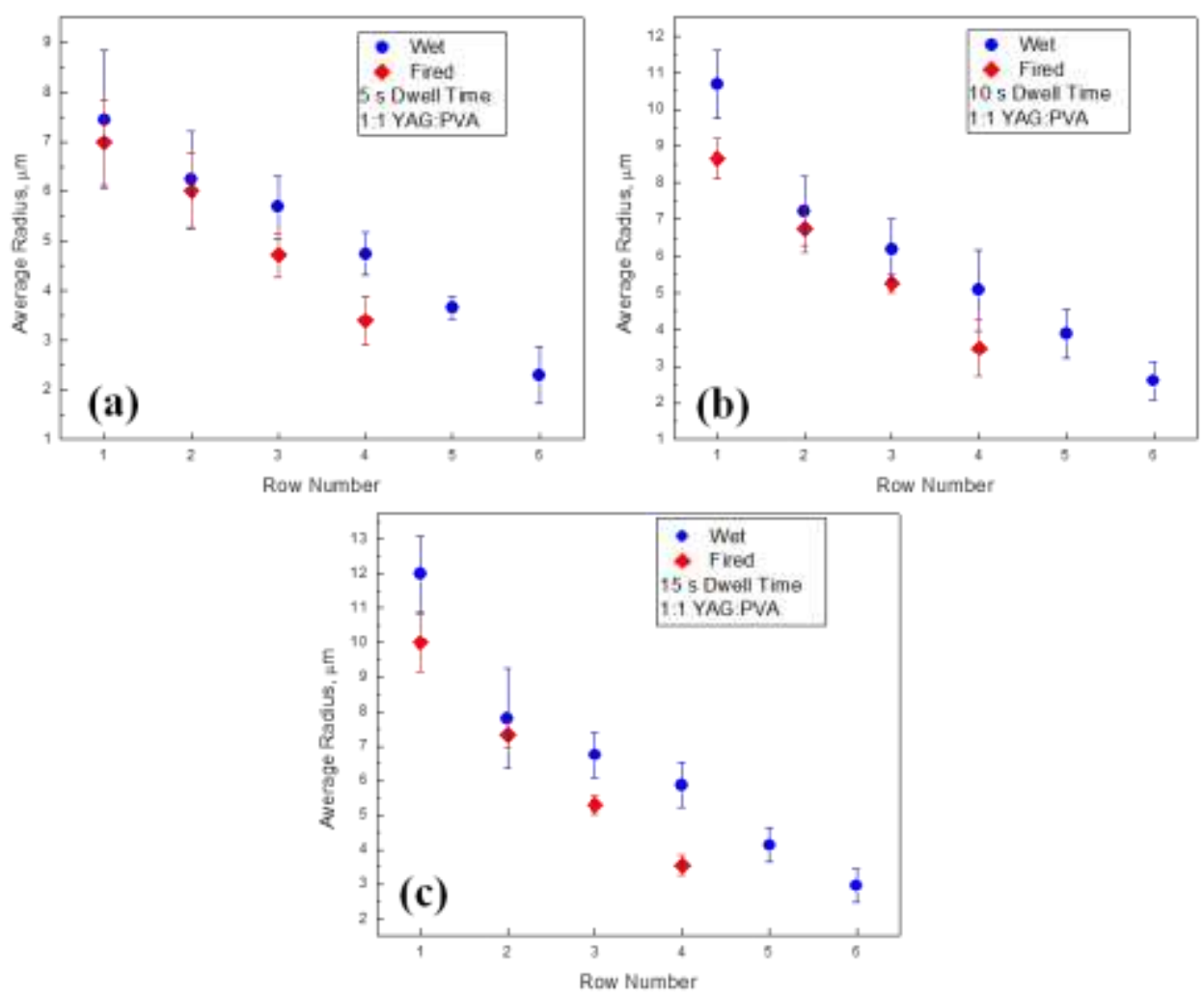

Figure 66: Comparison of wet and fired radii for 1:1 YAG:Ce to PVA for different dwell times, (a) $5 \mathrm{~s}$, (b) $10 \mathrm{~s}$, (c) $15 \mathrm{~s}$.

Successful transfer was recognized for all YAG:Ce arrays. Although, it is noticed there were significant losses during the transfer process. A typical image of the transferred dots can be seen in Figure 67 (a), showing rings of YAG:Ce. The incomplete transfer of the dots may be due to similar reasons stated earlier in the Dip-Pen Nanolithography of $\mathrm{ZnO}$ Patterns section. Although, complete transfer of an array of dots is shown in Figure 67 (b), showing promise for future efforts. 

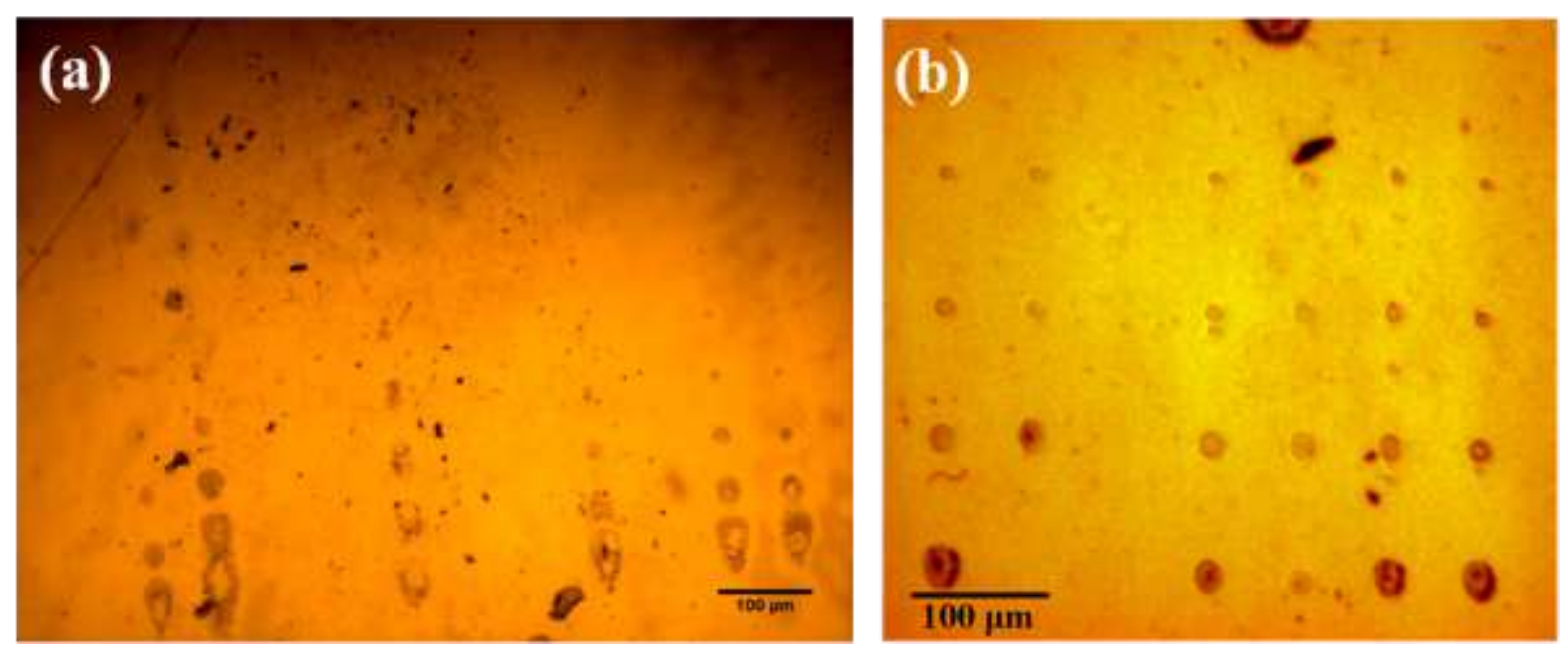

Figure 67: Transferred YAG:Ce dot arrays on PEN for different solutions (a) 3:2 YAG:Ce to PVA, (b) 1:1 YAG:Ce to PVA. Dwell time is $5 \mathrm{~s}$.

The YAG:Ce sol utilized in this study is typically fired in the range of $800^{\circ} \mathrm{C}$ to $1200^{\circ} \mathrm{C}$ for crystallization. The dots cannot be fired at such a high temperature as the release layer fully decomposes at $500^{\circ} \mathrm{C}$. XRD was performed to known if calcined YAG:Ce was obtained when fired at $500^{\circ} \mathrm{C}$, which was executed on YAG:Ce powders. The YAG:Ce powders were formed by firing the YAG:Ce precursor sol at temperatures of $500^{\circ} \mathrm{C}, 700^{\circ} \mathrm{C}$, and $900^{\circ} \mathrm{C} . \mathrm{XRD}$ spectrums of the powders are shown in Figure 68. It is observed that YAG:Ce has not crystallized for temperatures of $500^{\circ} \mathrm{C}$ and $700^{\circ} \mathrm{C}$. Previous studies have shown that YAG starts to crystallize at $750^{\circ} \mathrm{C}[111]$. In order for YAG patterns to be manufactured through this transfer process, a higher temperature must be utilized and/or an additive to lower the crystallization temperature of YAG. 


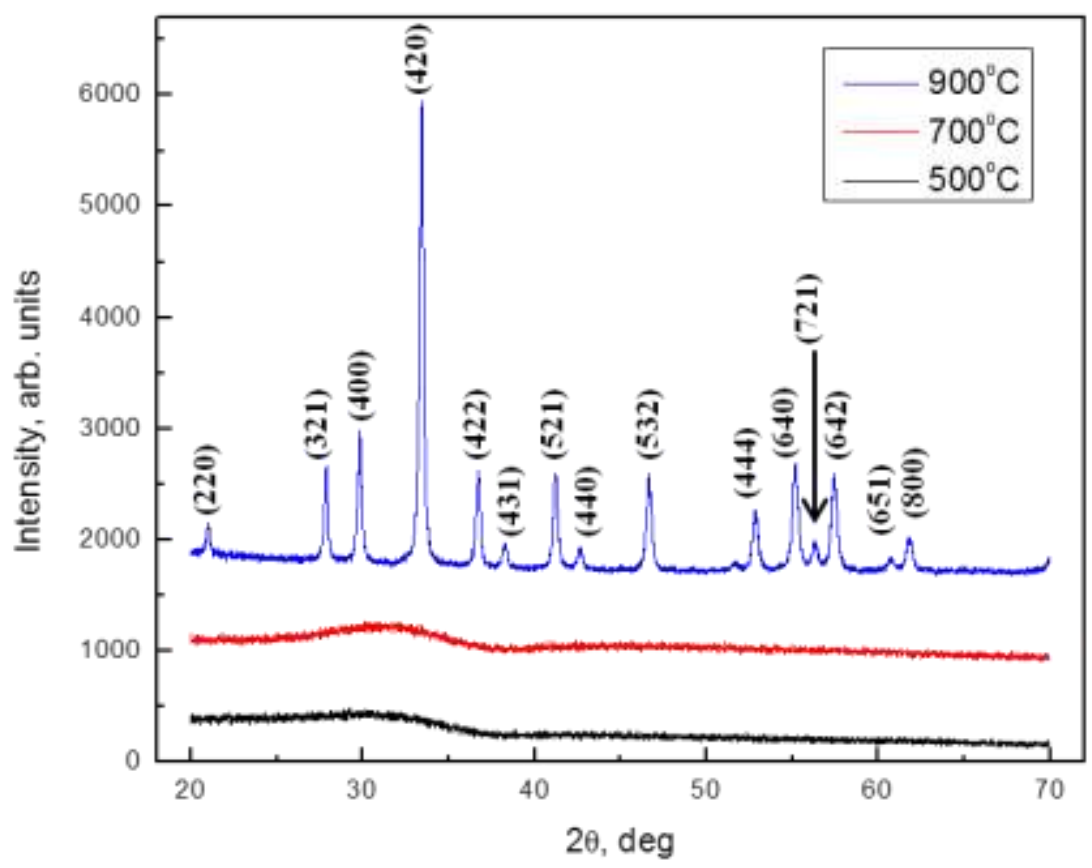

Figure 68: X-ray diffraction patterns for YAG:Ce powders fired at different temperatures.

\section{Summary and Conclusions}

In this work low cost, large-area deposition techniques were explored for the fabrication of $\mathrm{ZnO}$ films and patterns on to flexible substrates. Developing low cost, large-area piezoelectric systems were first investigated using dip-coated $\mathrm{ZnO}$ sol-gel films. Fabrication of a flexible device was then performed utilizing hydrothermal growth of $\mathrm{ZnO}$ nanorods. Finally, patterned $\mathrm{ZnO}$ microdots were transferred from rigid glass substrates to flexible PEN substrates.

$\mathrm{ZnO}$ films fabricate using sol-gel processing were deposited via dip-coating, utilizing preheating and post-heating temperatures of $275^{\circ} \mathrm{C}$ and $500^{\circ} \mathrm{C}$ respectively. It was observed that the optical transmission of the films was dependent on thickness. Additionally, the $\mathrm{Zn}$ concentration played a role in the crystal structure, showing a solution concentration of $0.75 \mathrm{~mol}$ 
$\mathrm{L}^{-1}$ to be optimum. But, the $\mathrm{Zn}$ concentration had no effect on the mechanical properties of the films.

A preliminary tribological based device was fabricated using the previous sol-gel films. It is observed that the adhesion of the $\mathrm{ZnO}$ film increases with increased $\mathrm{UV}$ exposure time, which can be used to control the $\mathrm{ZnO}$ surface friction. Weight measurements indicate limited $\mathrm{ZnO}$ transfer to rolling counterface and relatively limited $\mathrm{ZnO}$ wear below 7500 cycles. Also, the UV exposed $\mathrm{ZnO}$ sample showed significant wear above 7500 cycles compared to the nonUV exposed $\mathrm{ZnO}$ sample. Mixed rolling-sliding wear mechanisms are observed using optical microscopy. Abrasion mechanisms are also noted. Preliminary device design exhibits response to external mixed rolling-sliding stimulus and remains functional for up to 7500 cycles.

Furthermore, $\mathrm{ZnO}$ structures were grown through a facile wet chemical routine. Agreeing with previous studies, the optimum temperature for vertically aligned structures is $70^{\circ} \mathrm{C}$. Also, a seed-layer dried at $150^{\circ} \mathrm{C}$ showed improved vertical alignment over a $100^{\circ} \mathrm{C}$ dried seed-layer. The open circuit voltage of a truly flexible PEN-based $\mathrm{ZnO}$ nanostructure was measured to be $120 \mathrm{mV}$. After being allowed to age for 3 months a 33\% decrease in the open circuit voltage was observed, showing improved stability over previously reported results [7].

Direct writing of $\mathrm{ZnO}$ microdot arrays on a PVP release layer was achieved with DPN. Modifying previously fabricated $\mathrm{ZnO}$ sols were utilized as inks. It is observed that thickening agent plays a significant role in the transfer rate of the ink and adhesion to the substrate. In addition, higher viscosity inks allow for more controlled depositions and lower contractions after firing. Transferring of the dot arrays shows promise for fabricating patterned flexible-based systems. 
The versatility of DPN was demonstrated by employing a complex chemistry solution of cerium-doped yttrium aluminum garnet. Increased humidity presented successful patterning of dots, whereas lower humidity proved to be challenging. It was observed that the lower viscous inks exhibited more shrinkage when fired as opposed to more viscous inks. Overall the key to developing the next-generation of large-area flexible patterned devices is DPN. Additionally, there is further work to be completed; this is explained in detail in the next section.

\section{Further Work}

There is still work to be completed. Developing standardized mechanical testing of $\mathrm{ZnO}$ nanostructure devices is an area that still requires work. One possibility is to perform indentation on a macro-scale while measuring the voltage in-situ to correlate the output. After indentation is performed optical investigation should be performed to recognize mechanical damage. Also, tensile testing and buckling testing should be executed with in-situ voltage measurements. Additionally, optical microscopy can be conducted in-situ to notice possible failure mechanisms.

Much of what has been completed with DPN was on the microscale, the next step is to move towards fabricating nanoscale features. Additionally, only arrays of dots were deposited, other designs and patterns, such as lines, should be fabricated. Furthermore, AFM measurements are required to obtain height profiles of the dots, allowing for full characterization of the drying mechanisms and to confirm edge-to-center evaporation. Finally, a patterned $\mathrm{ZnO}$ device should be fabricated on a rigid substrate.

Another area to study further is the transfer process. Optimizing the transfer process is necessary to ensure all patterns are transferred to the polymer substrate without voids and debris. There are a few possibilities for utilizing the transferred $\mathrm{ZnO}$ patterns. One is to develop a 
device from the patterned $\mathrm{ZnO}$ features, similar to the rigid device mentioned earlier, by transferring the dots onto a Au- or Cr-coated polymer substrate. Another is to utilize the transferred patterns as a seed-layer for patterned hydrothermal growth of $\mathrm{ZnO}$ structures. 


\section{References}

1. iquid-Pressure and Heartbeat-Driven Flexible Fiber Nanogenerators as a Micro/Nano-Power Source or Diagnostic Sensor" Advanced Materials 23 (2011) 84-89

2. S.-J. Chang, T.-J. Hsueh, C.-L. Hsu, Y.-R. Lin, I-C. Chen, B.-R. Huang, "A ZnO nanowire vacuum pressure sensor" Nanotechnology 19 (2008) 095505

3. B.Y. Oh, M.C. Jeong, T.H. Moon, W. Lee, J.M. Myoung, J.Y. Hwang, D.S. Seo, "Transparent conductive Al-doped $\mathrm{ZnO}$ films for liquid crystal displays" Journal of Applied Physics 99 (2006) 124505

4. H. Kobayashi, H. Mori, T. Ishida, Y. Nakato, "Zinc oxide/n-Si junction solar cells produced by spray-pyrolysis method" Journal of Applied Physics 77 (1995) 1301-1307

5. D.G. Baik, S.M. Cho, "Application of sol-gel derived films for $\mathrm{ZnO} / n$-Si junction solar cells" Thin Solid Films 354 (1999) 227-231

6. A. Yu, Y. Zhao, P. Jiang, Z.L. Wang, “A nanognerator as self-powered sensor for measuring the vibration spectrum of a drum membrane" Nanotechnology 24 (2012) 055501

7. Y. Hu, L. Lin, Y. Zhang, Z.L. Wang, "Replacing a Battery by a Nanogenerator with $20 \mathrm{~V}$ Output” Advanced Materials 24 (2012) 110-114

8. J.Y. Lee, Y.S. Choi, W.H. Choi, H.W. Yeom, Y.K. Yoon, J.H. Kim, S. Im, "Characterization of films and interfaces in n-ZnO/p-Si photodiodes" Thin Solid Films 420 (2002) 112-116

9. T. Yamamoto, T. Shiosaki, A. Kawabata, "Characterization of $\mathrm{ZnO}$ piezoelectric films prepared by rf planar-magnetron sputtering” Journal of Applied Physics 51 (1980) 31133121

10. D. Bao, H. Gu, A. Kuang, "Sol-gel-derived c-axis oriented $\mathrm{ZnO}$ thin films" Thin Solid Films 312 (1998) 37-39

11. K. Govender, D.S. Boyle, P.B. Kenway, P. O’Brian, "Understand the factors that govern the deposition and morphology of thin films of $\mathrm{ZnO}$ from aqueous solution" Journal of Materials Chemistry 14 (2004) 2575-2591

12. C. Ye, T. Tamagawa, D.L. Polla, "Experimental studies on primary and secondary pyroelectric effects in $\mathrm{Pb}\left(\mathrm{Zr}_{\mathrm{x}} \mathrm{Ti}_{1-\mathrm{x}}\right) \mathrm{O}_{3}, \mathrm{PbTiO}_{3}$, and $\mathrm{ZnO}$ thin films" Journal of Applied Physics 70 (1991) 5538-5544

13. S.V. Prasad, S.D. Walck, J.S. Zabinski, "Microstructural evolution in lubricious ZnO films grown by pulsed laser deposition" Thin Solid Films 360 (2000) 107-117

14. U. Ozgur, Ya.I. Alivov, C. Liu, A. Teke, M.A. Reshchikov, S. Dogan, V. Avrutin, S.-J. Cho, H. Morkoc, "A comprehensive review of $\mathrm{ZnO}$ materials and devices" Journal of Applied Physics 98 (2005) 041301

15. S.J. Pearton, D.P. Norton, K. Ip, Y.W. Heo, T. Steiner, "Recent progress in processing and properties of ZnO” Progress in Materials Science 50 (2005) 293-340

16. P.X. Gao, J. Song, J. Liu, Z.L. Wang, "Nanowire Piezoelectric Nanogenerators on Plastic Substrates as Flexible Power Sources for Nanodevices" Advanced Materials 19 (2007) 67-72

17. S. Xu, Y. Qin, C. Xu, Y. Wei, R. Yang, Z.L. Wang, "Self-powered nanowire devices" Nature Technology 5 (2010) 366-373 
18. X. Wang, K. Kim, Y. Wang, M. Stadermann, A. Noy, A.V. Hamza, J. Yang, D.J. Sirbuly, "Matrix-Assisted Energy Conversion in Nanostructured Piezoelectric Arrays" Nano Letters 10 (2010) 4901-4907

19. R. Yang, Y. Qin, C. Li, G. Zhu, Z.L. Wang, “Converting Biomechanical Energy into Electricity by a Muscle-Movement-Driven Nanogenerator" Nano Letters 9 (2009) 1201-1205

20. M. Lee, C.-Y. Chen, S. Wang, S.N. Cha, Y.J. Park, J.M. Kim, L.-J. Chou, Z.L. Wang, “A Hybrid Piezoelectric Structure for Wearable Nanogenerators" Advanced Materials 24 (2012) 1759-1764

21. D. Choi, K.Y. Lee, M.-J. Jin, S.-G. Ihn, S. Yun, X. Bulliard, W. Choi, S.Y. Lee, S.-W. Kim, J.-Y. Choi, J.M. Kim, Z.L. Wang, "Control of naturally coupled piezoelectric and photovoltaic properties for multi-type scavengers" Energy \& Environmental Science 4 (2011) 4607-4613

22. J.-Q. Liu, H.-B. Fang, Z.-Y. Xu, X.-H. Mao, X.-C. Shen, D. Chen, H. Liao, B.-C. Cai, “A MEMS-based piezoelectric power generator array for vibration energy harvesting" Microelectronics Journal 39 (2008) 802-806

23. T. Kobayashi, R. Maeda, $\mathrm{T}$. Itoh, "A fatigue test method for $\mathrm{Pb}(\mathrm{Zr}, \mathrm{Ti}) \mathrm{O}_{3}$ thin films by using MEMS-based self-sensitive piezoelectric mirocantilevers" Journal of Micromechanics and Microengineering 18 (2008) 115007

24. A. Kuoni, R. Holzherr, M. Boillat, N.F. de Rooij, "Polyimide membrane with ZnO piezoelectric thin film pressure transducers as a differential pressure liquid flow sensor" Journal of Micromechanics and Microengineering 13 (2003) S103-S107

25. J.H. Lee, K.H. Ko, B.O. Park, "Electrical and optical properties of $\mathrm{ZnO}$ transparent conduction films by the sol-gel method" Journal of Crystal Growth 247 (2003) 119-125

26. L. Znaidi, G.J.A.A. Soler Illia, S. Benyahia, C. Sanchez, A.V. Kanaev, "Oriented ZnO thin films synthesis by sol-gel process for laser application" Thin Solid Films 428 (2003) 257-262

27. Z. Chai, X. Lu, D. He, "Atomic layer deposition of zinc oxide films: Effects of nanocrystalline characteristics on tribological performance" Surface \& Coatings Technology 207 (2012) 361-366

28. L. Vayssieres, K. Keis, S.-E. Lindquist, A. Hagfeldt, "Purpose-Built Anisotropic Metal Oxide Material: 3D Highly Oriented Microrod Array of ZnO" Journal of Physical Chemistry B 105 (2001) 3350-3352

29. L. Vayssieres, K. Keis, A. Hagfeldt, S.-E. Lindquist, "Three-Dimensional Array of Highly Oriented Crystalline ZnO Microtubes" Chemistry of Materials 13 [12] (2001) 4395-4398

30. L. Vayssieres, "Growth of Arrayed Nanorods and Nanowires of $\mathrm{ZnO}$ from Aqueous Solutions" Advanced Materials 15 [5] (2003) 464-466

31. M. Guo, P. Diao, S. Cai, "Hydrothermal growth of well-aligned $\mathrm{ZnO}$ nanorods arrays: Dependence of morphology and alignment ordering upon preparing conditions" Journal of Solid State Chemistry 178 (2005) 1864-1873 
32. S. Muhamad, N.F.A. Rahman, S.A. Bakar, M.H. Mamat, M. Rusop, "Controllable Density of Aligned Zinc Oxide Nanorod Arrays by Molarities Variation” IEEE Symposium on Humanities (2012) 1295-1297

33. S. Xu, C. Lao, B. Weintraub, Z.L. Wang, "Density-controlled growth of aligned ZnO nanowire arrays by seedless chemical approach on smooth surfaces" Journal of Material Research 23[8] (2008) 2072- 2077

34. S. Yamabi, H. Imai, "Growth condition for wurtzite zinc oxide films in aqueous solutions" Journal of Materials Chemistry 12 (2002) 3773-3778

35. Q. Li, V. Kumar, Y. Li, H. Zhang, T.J. Marks, R.P.H. Chang, "Fabrication of ZnO Nanorods and Nanotubes in Aqueous Solutions" Chemistry of Materials 17 (2005) 1001-1006

36. Y. Tak, K. Yong, "Controlled Growth of Well-Aligned ZnO Nanorod Array Using a Novel Solution Method" Journal of Physical Chemistry B 109 (2005) 19263-19269

37. Q. Ahsanulhaq, A. Umar, Y.B. Hahn, "Growth of aligned $\mathrm{ZnO}$ nanorods and nanopencils on $\mathrm{ZnO} / \mathrm{Si}$ in aqueous solution: growth mechanism and structural and optical properties" Nanotechnology 18 (2007) 115603

38. J. Song, S. Lim, "Effect of Seed Layer on the Growth of ZnO Nanorods" Journal of Physical Chemistry C 111 (2007) 596-600

39. Z. Chen, L. Gao, "A facile route to $\mathrm{ZnO}$ nanorods arrays using wet chemical method" Journal of Crystal Growth 293 (2009) 522-527

40. G.-W. She, X.-H. Zhang, W.-S. Shi, X. Fan, J.C. Chang, C.-S. Lee, S.-T. Lee, C.-H. Liu, "Controlled synthesis of oriented single-crystal $\mathrm{ZnO}$ nanotube arrays on transparent conductive substrates" Applied Physics Letters 92 (2008) 053111

41. P.M. Martin, M.S. Good, J.W. Johnston, G.J. Posakony, L.J. Bond, S.L. Crawford, "Piezoeletric films for 100-MHz ultrasonic transducers" Thin Solid Films 379 (2000) 253258

42. M.N. Kamalasanan, S.Chandra, "Sol-gel synthesis of ZnO thin films" Thin Solid Films 288 (1996) 112-115

43. M. Ohyama, H. Kozuka, T. Yoko, "Sol-gel preparation of $\mathrm{ZnO}$ films with extremely preferred orientation along (002) plane from zinc acetate solution” Thin Solid Films 306 (1997) 78-85

44. Y. Natsume, H. Sakata, "Zinc oxide films prepared by sol-gel spin-coating" Thin Solid Films 372 (2000) 30-36

45. T. Schuler, M.A. Aegerter, "Optical, electrical and structural properties of sol gel ZnO:Al coatings" Thin Solid Films 351 (1999) 125-131

46. H. Li, J. Wang, H. Liu, H. Zhang, X. Li, "Zinc oxide films prepared by sol-gel method" Journal of Crystal Growth 275 (2005) e943-e946

47. Y.S. Kim, W.P. Tai, S.J. Shu, "Effect of preheating temperature on structural and optical properties of $\mathrm{ZnO}$ thin films by sol-gel process" Thin Solid Films 491 (2005) 153-160 
48. M. Wang, J. Wang, W. Chen, Y. Cui, L. Wang, "Effect of preheating and annealing temperatures on quality characteristics of $\mathrm{ZnO}$ thin film prepared by sol-gel method" Materials Chemistry and Physics 97 (2006) 219-225

49. M.W. Zhu, J.H. Xia, R.J. Hong, H. Abu-Samra, H. Huang, T. Staedler, J. Gong, C. Sun, X. Jian, "Heat-activated structural evolution of sol-gel-derived $\mathrm{ZnO}$ thin films" Journal of Crystal Growth 310 (2008) 816-823

50. Z. Liu, Z. Jin, W. Li, J. Qiu, "Preparation of $\mathrm{ZnO}$ porous thin films by sol-gel method using PEG template" Materials Letters 59 (2005) 3620-3625

51. S. O'Brien, L.H.K. Koh, G.M. Crean, "ZnO thin films prepared by a single step sol-gel process" Thin Solid Films 516 (2008) 1391-1395

52. L. Znaidi, "Sol-gel-deposited $\mathrm{ZnO}$ thin films: A review" Materials Science and Engineering B: Solid-State Materials for Advanced Technology 174 (2010) 18-30

53. L.-Y. Lin, D.-E. Kim, "Effect of annealing temperature on the tribological behavior of $\mathrm{ZnO}$ films prepared by sol-gel method" Thin Solid Films 517 (2009) 1690-1700

54. X. Feng, L. Feng, M. Jin, J. Zhai, L. Jiang, D. Zhu, "Reversible Super-hydrophobicity to Super-hydrophilicity Transition of Aligned ZnO Nanorod Films" Journal of American Chemical Society 126 (2004) 62-63

55. H. Liu, L. Feng, J. Zhai, L. Jiang, D. Zhu, "Reversible Wettability of a Chemical Vapor Deposition Prepared ZnO Film between Superhydrophobicity and Superhydrophilicity" Langmuir 20 (2004) 5659-5661

56. R.-D. Sun, A. Nakajima, A. Fujishima, T. Watanabe, K. Hashimoto, "Photoinduced Surface Wettability Conversion of $\mathrm{ZnO}$ and $\mathrm{TiO}_{2}$ Thin Films" Journal of Physical Chemistry B 105 (2001) 1984-1990

57. P. Horváth, G. Kiriakidis, P.M. Nagy, S. Christoulakis, "Mechanical Properties and Deformation Behavior of ZnO Thin Films under Illumination" In: Anonymous Proceedings of the 2nd IEEE International Conference on Nano/Micro Engineered and Molecular Systems, IEEE NEMS 2007, (2007) 421-425

58. M.-Y. Choi, D. Choi, M.-J. Jin, I. Kim, S.-H. Kim, J.-Y. Choi, S. Y. Lee, J.M. Kim, S.-W. Kim, "Mechanically Powered Transparent Flexible Charge-Generating Nanodevices with Piezoelectric ZnO Nanorods" Advanced Materials 21 (2009) 2185-2189

59. B. D. Gates, Q. Xu, M. Stewart, D. Ryan, C. G. Wilson, G. M. Whitesides "New approaches to nanofabrication: Molding, printing, and other techniques" Chemical Reviews 105 (2005) 1171-1196

60. S.A. Morin, F.F. Amos, S. Jin, "Biomimetic Assembly of Zinc Oxide Nanorods onto Flexible Polymers" Journal of American Chemical Society 129 (2007) 13776-13777

61. S.-H. Yi, S.-K Choi, J.-M. Jang, S.-H Ko, J.-A. Kim, W.-G. Jung, "Patterned growth of ZnO nanorods by solution chemical method", Proceedings of SPIE-The International Society for Optical Engineering 6474 (2007) 64741L

62. D. Wang, P. Yang, Z. Cheng, W. Wan, P. Ma, X. Zhai, J. Lin "Facile pattenring of luminescent $\mathrm{GdVO}_{4}: \mathrm{Ln}\left(\mathrm{Ln}=\mathrm{Eu}^{3+}, \mathrm{Dy}^{3+}, \mathrm{Sm}^{3+}\right)$ thin films by microcontact printing process" Journal of Nanoparticle Research 14 (2012) 707 
63. J.A.M. Sondag-Huethorst, H.R.J. van Helleputte, L.G.J. Fokkink, “Generation of electrochemically deposited metal patterns by means of electron beam (nano)lithography of self-assembled monolayer resists" Applied Physics Letters 64 (1994) 285-287

64. Q. Tang, S.-Q. Shi, "Preparation of gas sensors via dip-pen nanolithography" Sensors and Actuators B 131 (2008) 379-383

65. Y.-J. Kim, C.-H Lee, Y.J. Hong, G.-C. Yi, S.S. Kim, H. Cheong "Controlled selective growth of $\mathrm{ZnO}$ nanorods and microrod arrays on Si substrate by a wet chemical method" Applied Physics Letters 89 (2006) 163128

66. S. Xu, Y. Wei, M. Kirkham, J. Liu, W. Mai, D. Davidovic, R.L. Snyder, Z.L. Wang, "Patterned Growth of Vertically Aligned ZnO Nanowire Arrays on Inorganic Substrates at Low Temperature without Catalyst" Journal of American Chemical Society 130 (2008) 14958-14959

67. M. Singh, H.M. Haverinen, P. Dhagat, G.E. Jabbour, "Inkjet Printing - Process and Its Applications" Advanced Materials 22 (2010) 673-685

68. R.G. Sweet, Fluid droplet recorder, U.S. Patent 3596275 (1971)

69. H.L. Le, "Progress and Trends in Ink-jet Printing Technology" Journal of Imaging Science and Technology 42 (1998) 49-62

70. J.E. Fromm, "Numerical-calculation of the fluid-dynamics of drop-on-demand jets" IBM Journal of Research and Development 28 (1984) 322-333

71. N. Reis, B. Derby, "Ink jet deposition of ceramic suspensions: modeling and experiments of droplet formation" Materials Research Society Symposium - Proceedings 624 (2000) 65-70

72. D. Roy, M. Munz, P. Colombi, S. Bhattacharyya, J.-P. Salvetat, P.J. Cumpson, M.-L. Saboungi, "Directly writing with Nanoparticles at the nanoscale using dip-den nanolithography” Applied Surface Science 254 (2007) 1394-1398

73. S. Hong, J. Zhu, C.A. Mirkin, "New tool for studying the in situ growth processes for selfassembled monolayers under ambient conditions" Langmuir 15 (1999) 7897-7900

74. R.D. Piner, J. Zhu, F. Xu, S. Hong, C.A. Mirkin, ““"Dip-Pen” Nanolithography” Science 283 (1999) 661-663

75. S. Hong, J. Zhu, C. A. Mirkin, "Multiple ink nanolithography: Toward a multiple-pen nanoplotter" Science 286 (1999) 523-525

76. K. Salaita, Y. Wang, C.A. Mirkin, “Applications of dip-pen nanolithography” Nature Nanotechnology 2 (2007) 145-155

77. Y. Wang, L.R. Giam, M. Park, S. Lenhert, H. Fuchs, C.A. Mirkin, "A Self-Correcting Inking Strategy for Cantilever Arrays Addressed by an Inkjet Printer and Used for Dip-Pen Nanolithography" small 4 (2008) 1666-1670

78. K. Salaita, Y. Wang, J. Fragala, R.A. Vega, C. Liu, C.A. Mirkin "Massively parallel dip-pen nanolithography with 55 000-pen two-dimensional arrays" Angewandte Chemie International Edition 25 (2006) 7220-7223

79. M. Su, X. Liu, S.-Y. Li, V.P. Dravid, C.A. Mirkin, "Moving beyond Molecules: Patterning Solid-State Features via Dip-Pen Nanolithography with Sol-Based Inks" Journal of American Chemical Society 124 (2002) 1560-1561

80. L. Fu, X. Liu, Y. Zhang, V.P. Dravid, C.A.Mirkin, "Nanopattering of "Hard" Magnetic Nanostructures via Dip-Pen Nanolithography and a Sol-Based Ink" Nano Letters 3 (2003) 757-760 
81. G. Gundiah, N.S. John, P.J. Thomas, G.U. Kulkarni, C.N.R. Rao, S. Heun, "Dip-pen nanolithography with magnetic $\mathrm{Fe}_{2} \mathrm{O}_{3}$ nanocrystals" Applied Physics Letters 84 (2004) 53415343

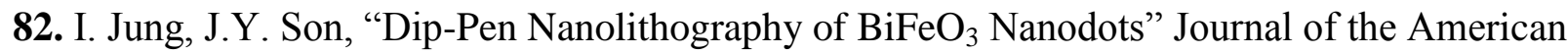
Ceramic Society 96 (2012) 3716-3718

83. I. Jung, J.Y. Son, "Dip-Pen Nanolithography of ferroelectric $\mathrm{PbTiO}_{3}$ Nanodots" Journal of American Chemical Society 131 (2009) 14676-14678

84. J.Y. Son, Y.-S. Shin, Y.-H. Shin, "Formation of Semiconducting ZnO nanowires Using DipPend Nanolithography and Step Edge Decoration Approach" Electrochemical and SolidState Letters 14 (2011) H397-H399

85. Z.L. Wang, "Towars Self-Powered Nanosystems: From Nanogenerators to Nanopiezotronics" Advanced Functional Materials 18 (2008) 3553-3567

86. S.R. Anton, H.A. Sodano, A review of power harvesting using piezoelectric materials (20032006)" Smart Materials and Structures 15 (2007) R1-R21

87. P. Muralt, R.G, Polcawich, S. Trolier-Mckinstry, "Piezoelectric Thin Films for Sensors. Actuators, and Energy Harvesting” MRS Bulletin 34 (2009) 658-664

88. S. Roundy, P.K. Wright, J. Rabaey, "A study of low level vibrations as a power source for wireless sensor nodes" Computer Communications 26 (2003) 1131-1144

89. K.-I, Park, S. Xu, Y. Liu, G.-T. Hwang, S.-J.L. Kang, Z.L. Wang, K.J. Lee, "Piezoelectric $\mathrm{BaTiO}_{3}$ Thin Film Nanogenerator on Plastic Substrates" Nano Letters 10 (2010) 4939-4943

90. L. Lin, C.-H. Lai, Y. Hu, Y. Zhang, X. Wang, C. Xu, R.L. Snyder, L.-J. Chen, Z.L. Wang, "High output nanogenerators based on assembly of GaN nanowires" Nanotechnology 22 (2011) 475401-475405

91. X. Chen, S. Xu, N. Yao, Y. Shi, "1.6 V Nanogenerator for Mechanical Energy Harvesting Using PZT nanofibers" Nano Letters 10 (2010) 2133-2137

92. L. Gu, N. Cui, L. Cheng, Q. Xu, S. Bai, M. Yuan, W. Wu, J. Liu, Y. Zhao, F. Ma, Y. Qin, Z.L. Wang, "Flexible Fiber Nanogenerator with 209 V Output Voltage Directly Powers a Light-Emitting Diode" Nano Letters 13 (2013) 91-94

93. C. Chang, V.H. Tran, J. Wang, Y.-K. Fuh, L. Lin, "Direct-Write Piezoelctric Polymeric Nanogenerator with High Energy Conversion Efficiency" Nano Letters 10 (2010) 726-731

94. B. Kumar, S.-W. Kim, "Energy harvesting based on semiconducting piezoelectric ZnO nanostructures" Nano Energy 1 (2012) 342-355

95. B. Kumar, S.-W. Kim, "Recent advances in power generation through piezoelectric nanogenerators" Journal of Materials Chemistry 21 (2011) 18946-18958

96. A. Erol, S. Okur, B. Comba, O. Mermer, M.C. Arikan, "Humidity sensing properties of ZnO nanoparticles synthesized by sol-gel process" Sensors and Actuators B 145 (2010) 174-180

97. X. Wang, J. Zhou, J. Song, J. Liu, N. Xu, Z.L. Wang, "Piezoelectric Field Effect Transistor and Nanoforce Sensor Based on a Single ZnO Nanowire" Nano Letters 6 (2006) 2768-2772

98. K.K.-H. Tseng, A.S.K Naidu, "Non-parametric damage detection and characterization using smart piezoceramic material" Smart Materials and Structures 11 (2002) 317-329

99. M.H. Lee, H.R. Nicholls, "Tactile sensing for mechatronics - a state of the art survey" Mechatronics 9 (1999) 1-31 
100. I. Murat Koc, E. Akca, "Design of a piezoelectric based tactile sensor with bio-inspired micro/nano-pillars" Tribology International 59 (2013) 321-331

101. G.M. Krishna, K. Rajann, "Tactile Sensor Based on Piezoelectric Resonance” IEEE Sensors Journal 4 (2004) 691-697

102. H. Kozuka, A. Yamano, T. Fukui, H. Uchiyama, M. Takahashi, M. Yoki, T. Akase, "Large area ceramic thin films on plastics: A versatile route via solution processing" Journal of Applied Physics 111 (2012) 016106

103. H. Kozuka, T. Fukui, M. Takahashi, H. Uchiyama, S. Tsuboi, "Cermic Thin Films on Plastics: A Versatile Transfer Process for Large Area as Well as Patterned Coating” ACS Applied Materials Interfaces 4 (2012) 6415-6420

104. E. Garskaite, M. Lindgren, M.-A. Einarsrud, T. Grande, "Luminescent properties of rare earth $(\mathrm{Er}, \mathrm{Yb})$ doped yttrium aluminium garnet thin films and bulk samples synthesized by an aqueous sol-gel technique” Journal of European Ceramic Society 30 (2010) 1707-1715

105. A.J. Kessman, S.N. Kukureka, D.R. Cairns, "Tribology of non-wetting fluorinated mesoporous silica films" Wear 271 (2011) 2144-2149

106. A.J. Kessman, D.K.P. Huckaby, C.R. Snyder, S.N. Kukureka, D.R. Cairns, "Tribology of water and oil repellent sol-gel coatings for optical applications" Wear 267 (2009) 614-618

107. S.-Y. Liu, T. Chen, J. Wan, G.-P. Ru,B.-Z. Li, X.-P. Qu, "The effect of pre-annealing of sputtered $\mathrm{ZnO}$ seed layers on growth of $\mathrm{ZnO}$ nanorods through a hydrothermal method" Applied Physics A 94 (2009) 775-780

108. Internal Communication with Nanoink Inc.

109. G. Liu, Y. Zhou, R.S. Banga, R. Boya, K.A. Brown, A.J. Chipre, S.T. Nguyen, C.A. Mirkin, "The role of viscosity of polymer ink transport in dip-pen nanolithography" Chemical Science 4 (2013) 2093-2099

110. R. D. Deegan, O. Bakajin, T. F. Dupont, G. Huber, S. R. Nagel, T. A. Witten "Contact line deposits in an evaporating drop" Physical Review E 62 (2000) 756-765

111. L. Yang, T. Lu, H. Xu, N. Wei, "Synthesis of YAG powder by the modified sol-gel combustion method" Journal of Alloys and Compounds 484 (2009) 449-451 